\title{
Expectations Evoked On Hearing A Piece Of Music For The First Time: Evidence From A Musical Savant
}

\author{
RUTH GRUNDY [1] \\ ADAM OCKELFORD \\ University of Roehampton
}

\begin{abstract}
The purpose of this study is to investigate a hitherto unresearched feature of the "zygonic" model of implication and expectation in music: in particular, the projections that stem from recently appearing groups of notes (Ockelford, 2006). Using an innovative approach, data were gathered from a prodigious musical savant (Derek Paravicini), who attempted to reproduce a novel composition on the piano at the same time as hearing it. The piece was designed to minimise the impact of expectations that may arise from patterns within groups of notes and those that may be perceived as a consequence of tonality, whereby different pitch transitions are felt to occur with different probabilities according to their level of past exposure. The design of the study was informed by zygonic theory (Ockelford, 2009, 2012b), which holds that expectation in music is attributable to the capacity of structural regularities to suggest future continuations, whose perceived likelihood of occurrence, it is believed, is proportional to the number of ways in which their existence is implied in what has gone before. Using this principle, a "strength of implication" factor was calculated for each note of the stimulus piece (following the first). It was hypothesised that the higher the implication factor, the more likely Derek would predict its occurrence (and therefore play it correctly at the appropriate point in time). Data gathered from Derek's performance support the underlying principles of the zygonic model, although they also suggest certain refinements.
\end{abstract}

Submitted 2013 August 7; accepted 2014 October 16

KEYWORDS: musical expectation, first time hearing, savant syndrome, zygonic theory

\section{INTRODUCTION}

THE purpose of the study described here is to investigate a hitherto unresearched feature of the "zygonic" model of implication and expectation in music (Ockelford, 2006) - in particular the assertion that implications arising from the projection of zygonic relationships between veridically encoded groups of musical events offer a more or less specific indication of what is to come, based on previously heard material that is the same or similar (Ockelford, p.127); see Figure 1. The question is this: is it possible to model and therefore predict the specificity and strength of an implication arising from a group of notes through musicological (and, in particular, zygonic) analysis? The research outlined here takes a wholly innovative approach to tackling this issue, by having a prodigious musical savant, highly skilled in playing by ear, attempt to play along with a novel piece on a MIDI keyboard as he hears it for the first time. The piece is designed so that differing numbers of structural relationships exist between clearly identifiable groups of notes, enabling varying strengths of implication to be modeled. These predictions are compared with the savant's efforts at replication. The assumption is that the more strongly a group of notes is implied, the greater the likelihood that the savant will be able to play that group in time with the stimulus. Possibly confounding effects of within-group and tonal implication (also predicted in the zygonic model - see Figure 1) are avoided in the design of the piece. 


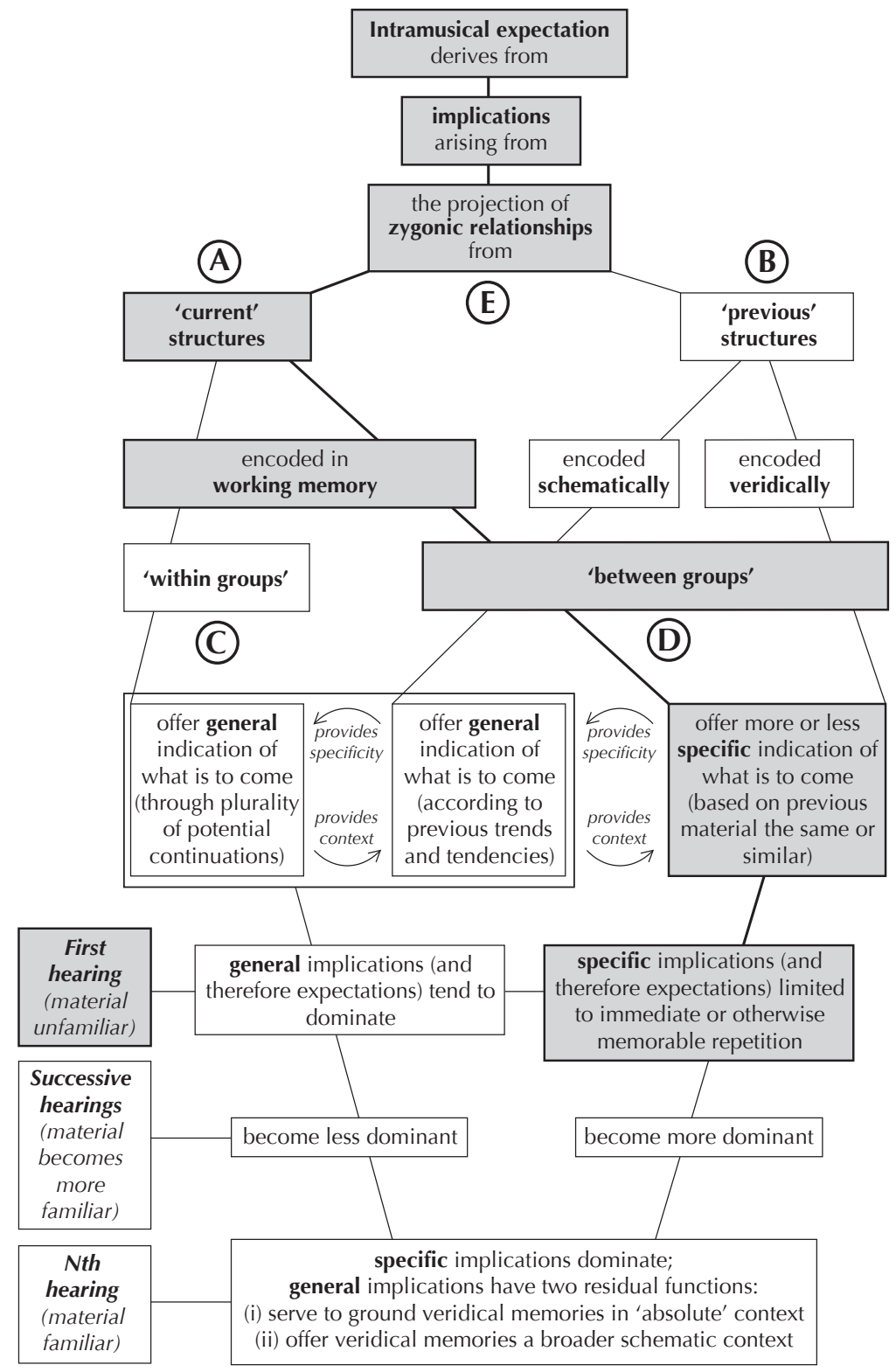

Fig. 1. Zygonic model of implication and expectation in music.

\section{Zygonic Theory - An Introduction}

Zygonic theory was first posited by the second author in the early 1990s (Ockelford, 1991), and has since informed a growing corpus of interdisciplinary work in the fields of music theory, music psychology and music education (see, for example, Ockelford, 2005; Vogiatzoglou, Ockelford, Welch and Himonides, 2011; Shibazaki, Ockelford \& Marshall, 2013; Ockelford \& Sergeant, 2013; Thorpe, Ockelford \& Aksentijevic, 2011; Ockelford, 2012b). Zygonic theory advances a musicological hypothesis that is underpinned by psychological principles: an epistemological hybrid, in which the idiographic intuitions characteristic of music theory and analysis are informed by the nomothetic findings proper to cognitive psychology (Cross, 1998; Gjerdingen, 1999; Ockelford, 2009). Thus it can most appropriately be described as "psychomusicological" in nature.

Certain ideas from mathematics are employed to explicate and illustrate the conceptual framework on which zygonic theory rests, and to manipulate the quantitative data it can generate as an analytical tool. The theory aims to explain how musical structure is modelled in cognition, and its starting point is the substance of music itself - sound 
- acknowledging that what is apprehended is likely to vary from one listener to another, according to their experience and expertise, and even between the same listener on different occasions, according to his or her prevailing mood and knowledge of the material in question (Ockelford, 2005, p. 32). However, the theory also holds that, in most circumstances, there will be sufficient commonality in the way that listeners intuitively process music in styles with which they are familiar for meaningful analytical discourse to occur.

A key area of music-psychological thinking in which zygonic theory has proved to be of particular value is the perception of implication and expectation in music (Ockelford, 2006; Ockelford, 2008b; Thorpe, Ockelford, \& Aksentijevic, 2011; Trower, 2011) - see Figure 1. The theory suggests that anticipation of what is going to occur next can stem from structures that lie broadly within the current frame of experience ("A") or that have been heard in the past ("B"), and that exist within groups of notes ("C") or between them ("D").

A "zygonic relationship" (see "E" in Figure 1) is a putative mental connection - in Lakoff"s terms, a form of "link schema" (Lakoff, 1987, p. 283) - that inhabits the mental space pertaining to music processing (Fauconnier, 1985/1994), through which one musical event or feature is felt to generate another through imitation. It is held that zygonic relationships underpin (albeit typically nonconsciously) all music-structural cognition, usually occurring simultaneously in different forms in every auditory domain: pitch, perceived time, timbre and loudness. Zygonic relationships can function directly between percepts, such as pitches or durations ("primary" zygons); or between the relationships between these, such as melodic or inter-onset intervals ("secondary" zygons); or even between the intervals between these, as in regular increases or decreases in tempo ("tertiary" zygons). Zygonic relationships can involve elements of music that are currently being experienced, or those that are remembered or even imagined. They can work reactively to compare aspects of music that have already been heard, or proactively, to anticipate what may occur next (it is these through which, it is hypothesised, expectation occurs). Zygonic relationships can be represented graphically with an arrow upon which a " $Z$ " is superimposed, bearing two suffixes: the upper indicating the feature of music that is imitated, and the lower, the "level" of the relationship (primary, secondary or tertiary). Non-zygonic relationships adopt a similar protocol, using the letter "I" (see Figures 2, 3 and 4).

To understand the role that zygonic relationships are imagined to play in musical expectation, let us take the opening motif of the theme from Eye Level by Jack Trombey. Imagine that a listener, new to the piece, has heard the second appearance of the opening melodic motif as far as the third note, defined in music-theoretical terms as equally spaced quavers G4, A4, and B4, which function as the scale degrees $5^{\wedge}, 6^{\wedge}$ and $7^{\wedge}$ in $\mathrm{C}$ major (see Figures 1 , 2 and 3). What is he or she likely to anticipate at this point? Zygonic theory proposes three things. First, that the ascent of one scale degree and the inter-onset interval of around a quarter of a second, first heard between notes 1 and 2, and imitated between notes 2 and 3 through secondary zygonic relationships, will spawn further, similar imitation ("A" and "C" in Figure 1; see Figure 2). Second, that hearing the opening of the motif will evoke a memory of the same thing heard moments earlier, leading to an expectation that the pattern will continue in the same way as before ("A" and " $D$ " in Figure 1; see Figure 3 ). Third, that hearing the leading note $\left(7^{\wedge}\right)$, will evoke memories of previous leading notes, that generally rise to the tonic $\left(1^{\wedge}\right)$, fuelling the anticipation that this transition will occur once again ("B" and "D" in Figure 1; see Figure 4) through statistical learning (cf. Saffran, 2003; Aslin \& Newport, 2012).

It is in showing that these three forms of expectation ultimately have a common music-structural source (as captured in the notion of zygonic relationships) and indicating how they function together that the zygonic model makes a significant contribution to the field. The origin of this thinking, like so many theories in contemporary cognitive musicology, lies in the pioneering work of Leonard Meyer (Meyer, 1956, 1967). Meyer's ideas sprang from two main sources: Gestalt perception and information theory, the former relating to what is termed in the zygonic model "within-group" implication, and the latter to implications heard between groups of events, schematically encoded (Bharucha, 1987, p. 4) - that is, at a probabilistic level. Eugene Narmour incorporated both of these strands in his implication-realization model (Narmour, 1977, 1990, 1992, 1996). This subsequently found some support in empirical studies (Schellenberg, 1996, 1997; Thompson \& Stainton, 1996), which showed that simplification leads to little diminution of its predictive power. Moreover, von Hippel and Huron's (2000) crosscultural analysis of melodies indicated that Narmour's key principle of registral return (a form of within-group structure in the present terminology) could be explained as an artefact of constraints on range. Much of this work is consolidated and developed in David Huron's book Sweet Anticipation (Huron, 2006), which summarizes his own thinking in this area and that of Bret Aarden (2003) and Elizabeth Margulis (2003, 2005). Here, there is an emphasis on the statistical modelling of expectation (broadly speaking, anticipating what will occur next on the basis of how frequently and in what contexts it has occurred in the past). In all this work, it is the expectations potentially generated between groups of musical events that are schematically encoded in memory that are downplayed (if not overlooked), and it is this lacuna in particular that the zygonic model seeks to fill. 


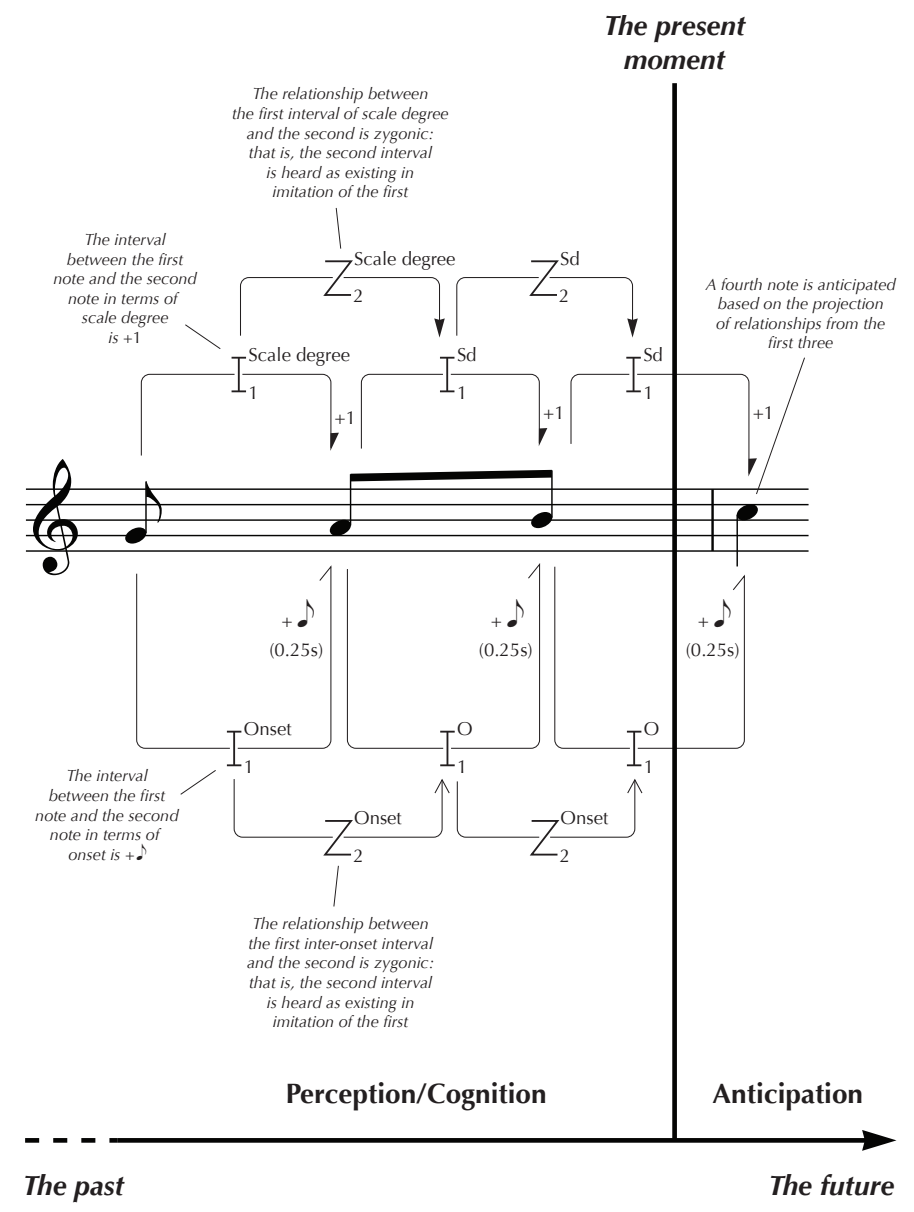

Fig. 2. The projection of the fourth note of the second appearance of the opening motif of Eye Level by Jack Trombey, based on the patterning of pitch and perceived time set up by the first three notes.

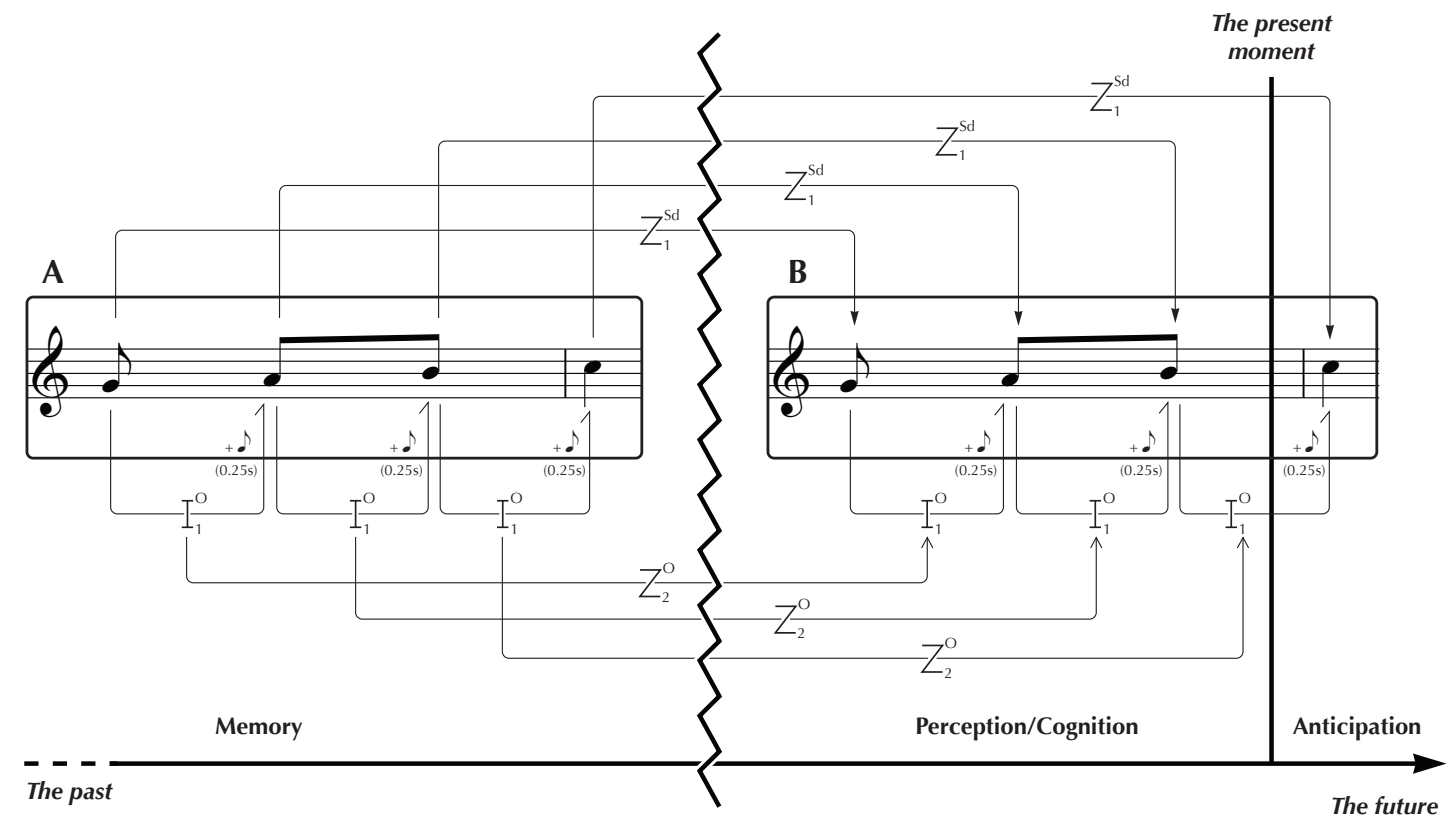


Fig. 3. The projection of the fourth note of the second appearance of the opening motif ("B") of Eye Level based on the patterning of pitch and perceived time set up by the first appearance of the motif (" $\mathrm{A}$ ").

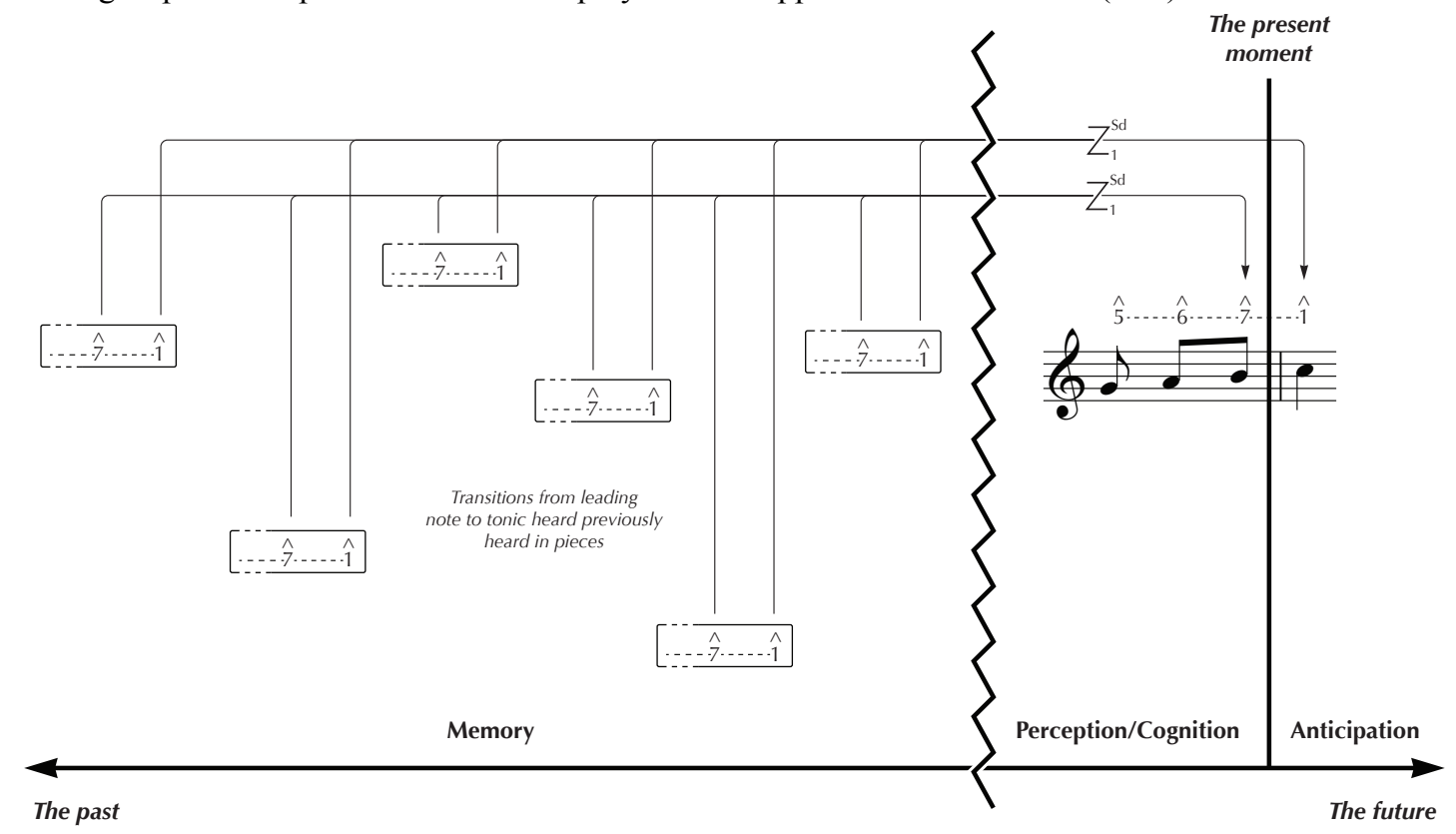

Fig. 4. The projection of the fourth note of the second appearance of the opening motif ("B") of Eye Level based on previously heard transitions from the leading note to the tonic.

While zygonic theory starts from the premise that musical logic works in a certain way (whereby one musical feature or event is deemed to derive from another through imitation), and that such connections exist only in the mind, it does not hold that the principle of perceived generation through imitation stems from a single neurological source - through one form of mental processing. To reiterate: as the model illustrated in Figure 1 and the examples presented in Figures 2, 3 and 4 suggest, there appear to be several types of cognitive activity that emerge from the same abstract auditory proposition. Sometimes, as the Eye Level analysis shows, expectations arising in different ways yield the same result, in this case all three scenarios marching the ear irresistibly up to C5. However, this need not be the case, and, in Western music, at least, it seems that some of the richest moments of the listening experience arise when expectations stemming from different sources conflict with one another. The classic example is the interrupted cadence, in which a melodic move to the tonic (such as that depicted in the Eye Level excerpt) is harmonised not with the usual chord I (here, C major) but chord vi (a minor); see Huron, 2006, p. 226. How is it, even in a piece that is familiar to the listener, that transitions such as this still sound surprising (Dowling and Harwood, 1986, p. 220) and, according to Meyer and the researchers who followed, evoke an emotional response (Meyer, 1956, 1973, 2001; Narmour, 1990, 1992; Aarden, 2003; Margulis, 2005; Huron, 2006)?[2] The answer, it seems, lies in the fact that different forms of expectation - in this instance, those induced by veridical (equivalent, in conventional psychological terms, to episodic) and schematic (or "semantic") memories (Bharucha, 1987, p. 4) - can operate independently (Jackendoff, 1991, p. 224); indeed, elsewhere, Ockelford suggests that being able to anticipate what is, in general terms, unexpected, enables us to savour it all the more (Ockelford, 2012b, p. $323)$.

It is in complex interactions such as this that the zygonic model has been shown to have particular explanatory and predictive power. For instance, Thorpe, Ockelford and Aksentijevic (2012) investigated how, in the course of an original 26-note melody, within group and between group implications work together to form an evolving continuum of expectation as the tune unfolds on a first hearing, which was accurately predicted by the zygonic model (accounting for $95 \%$ of the total variance; Ockelford, 2012b, p. 394). Trower (2011) examined how the schematic expectations that arise on hearing a novel motif for the first and second times vary, and discovered systematic differences between them, in line with the predictions of zygonic theory (Ockelford, 2012b, p. 400). In contrast, Ockelford and Sergeant (2013) explored the melodic expectations that may be at work in atonal (specifically, serial) music, using only the within group feature of the model (in inverted form). Here, the model predicted $96 \%$ of the total variance that was found (Ockelford, p. 158). 
These experiments notwithstanding, there are still a number of areas of the model that remain to be explored, and here we will focus on those pertaining to the path between the shaded boxes in Figure 1. For example, on the first hearing of a piece, how do between-group expectations interact? Specifically, what impact do repeated appearances of the same motif have on what a listener anticipates? Are they cumulative, and, if so, in what way?

Consider, for example, a listener, broadly familiar with the works of Bach, but hearing the opening of his Brandenburg Concerto No. 3 for the first time. The movement grows organically from a three-note motif comprising, in music-analytic terms, a pitch prolonged by its lower neighbour (see Figure 5). The motif, while rhythmically invariant, is, in terms of pitch, repeated, transposed and varied throughout the movement, appearing hundreds of times. While the listener, new to the work, will be unaware of this motivic-developmental detail, we may surmise, nonetheless, that his or her stylistically attuned ear will expect a taut motivic narrative that is typical of Bach.

Hence, after hearing the first two notes of the second appearance of the motif, we may suppose that a third will be expected in accordance with the pattern that precedes (see Figure 5).

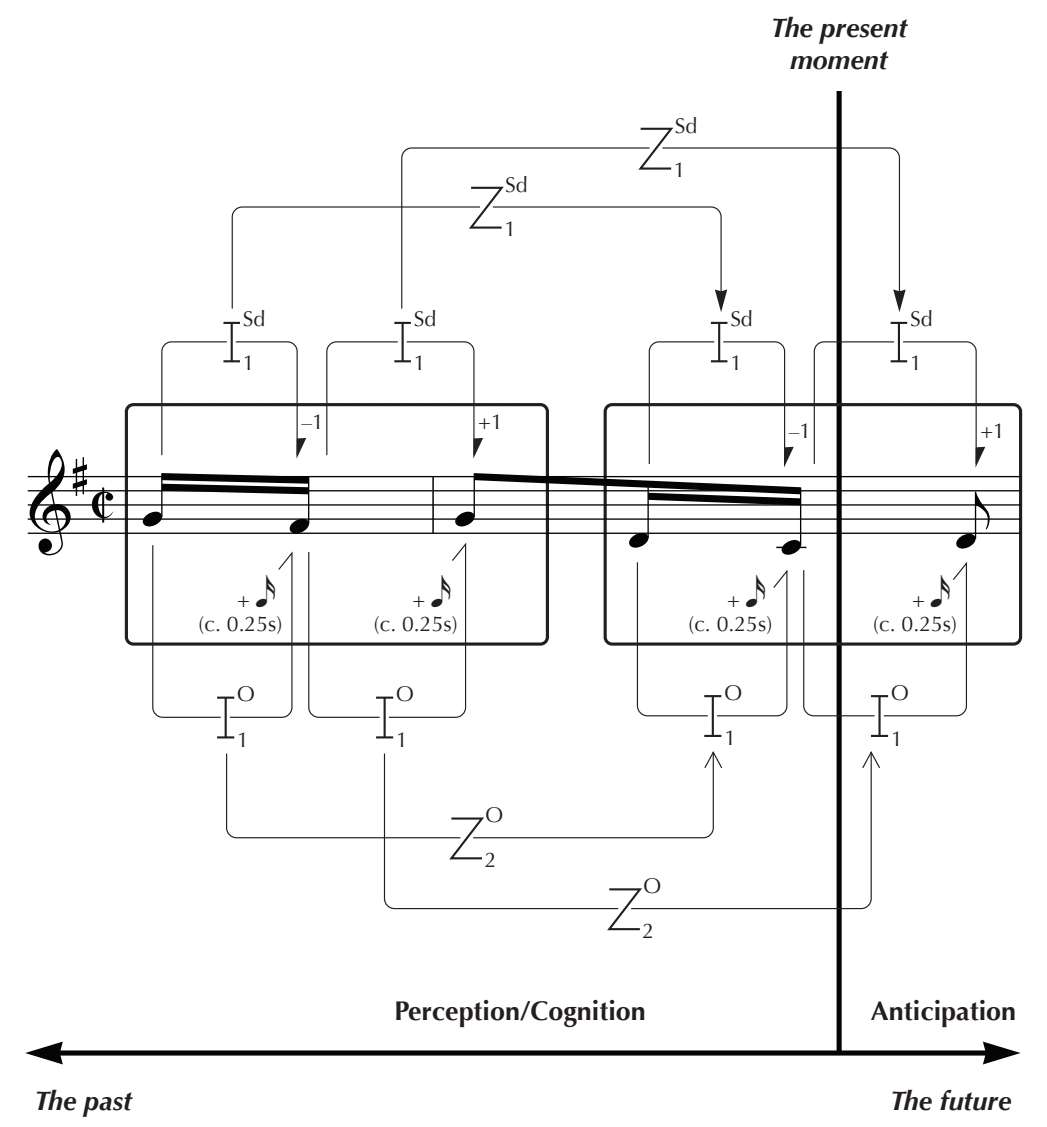

Fig. 5. The opening motifs of the violin parts of Bach's Brandenberg Concerto No. 3 showing between-group expectation that is presumed to occur.

But what of the third appearance of the motif and those that follow (Figure 6)? Reflection on the listening experience suggests, ceteris paribus, that the more often a motif has occurred in the course of a piece, the more sure a listener's expectations will be that a further, similar motif - once begun - will follow the same pattern. However, it is not clear how the expectations so evoked may interact. 


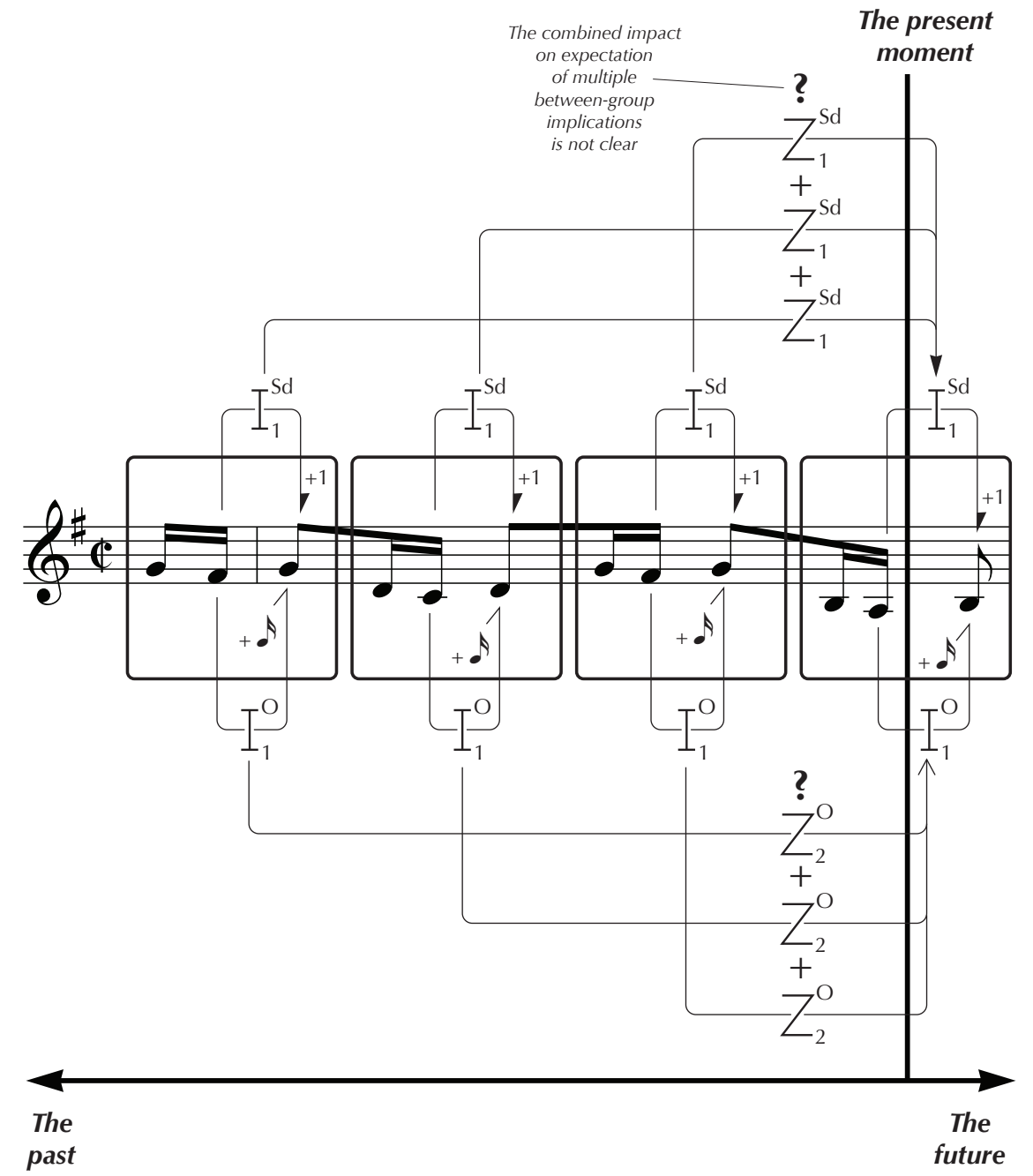

Fig. 6. Successive appearances of a motif are assumed to add weight to expectations, though the nature of the interaction between the evoked implications is not clear.

The current study represents an attempt to shed further light on this issue.

\section{FROM THEORY TO EXPERIMENTAL DESIGN: ISSUES AND SOLUTIONS}

Our initial challenge was to design empirical work that (a) would test the theory that a listener's strength of expectation increases with the number of implicative zygonic relationships that musical analysis suggests are present, and, if (a) were supported, (b) would elucidate the nature of the relationship between the two: is it linear, for example, or does it conform to some other function, and is there a saturation point beyond which the presence of more implicative relationships makes no difference to the perceived strength of expectation?

A number of different methods of detecting and measuring auditory expectation have been devised (Huron, 2006, pp. 42-52), which fall into two main categories: having subjects evaluate continuations to sequences of notes through non-musical means (using rating scales, for instance, employing the system pioneered by Krumhansl and Shepard, 1979); and asking research participants to produce continuations themselves (by singing or playing, following the work of Carlsen, Divenyi and Taylor, 1970, and Schmuckler, 1989).

In principle, it would be possible to test the "cumulative implication leads to stronger expectation" hypothesis, and to determine the relationship between the two factors involved, using rating scales. However, there are a number of practical problems that would need to be overcome: in particular, the design of suitable stimuli. 
Since the focus is on between-group expectations that may arise in the first hearing of a piece, a multiplicity of short passages would need to be constructed in order to test a listener's reaction to implications involving different numbers of motifs. To avoid possible interference, these would need to be contrasting, yet also share an underlying equivalence in terms of the cognitive processing demanded by each implicative relationship - a difficult (if not impossible) circle to square in music-compositional terms.

Similarly, at the first blush, it may be thought that continuous rating, using a device such as the "Continuous Response Measurement Apparatus" (hereafter, "CReMA") developed by Himonides (2011), which was used by Trower (2011) in her exploration of schematic expectation, could be used to gauge the impact of different aggregations of implicative relationships in the initial hearing of a piece. However, Trower's experiment used short sequences of tones that were sufficiently spaced in time (with inter-onset intervals of three seconds) to enable subjects to react unambiguously to individual events as they occurred. Because of the demands on working memory, though, and the need for events to be grouped in perception, this would be too slow a pace for expectations to arise from series of motifs: in most music, successive notes are less than a second apart. Moreover, the expectations pertaining to them (as we shall see) can vary considerably from one event to another. Hence, in the context of the current research question, subjects using the CReMA would not have time to make and externalise the necessary expectation judgements.

What of production paradigms? It would in theory be possible to ask subjects to produce continuations to discrete series of musical fragments that were designed to generate different combinations of implicative relationships. Given the (differing) responses from a group of subjects, one would have to make the assumption that the more often a particular pitch were produced, the more strongly it was expected, and (therefore) the greater the weight of the implicative relationships that had subconsciously been perceived. That is, we would use the relative frequency of particular responses as proxy indicators of the strength of musical structure (after Thorpe, Ockelford, $\&$ Aksentijevic, 2012). However, the design difficulties identified above in relation to rating scales, of devising different though structurally equivalent passages, would also apply here.

So is there any other mechanism through which it would be possible for a listener to indicate, in the course of hearing a piece for the first time, through musical production, that he or she expected particular notes to occur (based on the fact that they were structurally implied), and to show the differing strengths of expectation that were felt in anticipating such notes? Surprisingly, perhaps, the seeds of such a scenario are set in a number of everyday situations. Think of young children, for example, in a crèche, listening to an unfamiliar nursery rhyme, and perhaps joining in occasionally, as they get to know something of the tune and words; or consider a teenager, able sing along with the "hook" of a new hit after a few iterations; or imagine a recent convert attending a church service for the first time, striving to pick up the melody of a hymn by seeking to emulate those around him; or picture a youthful football fan, at her first match, keen to join in the partisan singing of more mature supporters. But how could these apparently unsystematic responses to music be adapted to the rigours of an experimental condition in which the necessary variables could be controlled?

An answer is to be found in one strand of the Fragments of Genius research project, a collaboration between the University of Roehampton, Goldsmith's College and the Institute of Education, University of London, comprising a number of investigations into the skills of musical savants - people with exceptional musical abilities in the context of learning difficulties (see, for example, Miller, 1989; Treffert, 1989; Ockelford, 2007) - in particular learning, memory, musical reproduction and creativity (Ockelford, 2011, p. 31). Building on studies including and following the seminal paper by Sloboda, Hermelin and O'Connor (1985), Fragments of Genius is based on the premise that the analysis of the music that savants produce in response to musical stimuli can offer a unique insight into the "black box" of their mental processing (Ockelford, 2012a, p. 38).

The strand of Fragments of Genius that we will be concerned with here relates to one in a series of four longitudinal studies involving Derek Paravicini, 33 years old, and internationally acknowledged for his exceptional musical abilities in the context of autism and severe learning difficulties (Derek has a verbal IQ of 58 as measured on the WAIS-R, UK version - see Pring, Woolf and Tadic, 2008)[3]. Derek's disabilities stem from being born after only 25 weeks gestation, and he is totally blind due to "retinopathy of prematurity" (Fielder and Reynolds, 2001). Derek has a highly refined sense of absolute pitch ("AP") - the capacity to recognise and reproduce pitches in isolation from others (Takeuchi and Hulse, 1993) - and can reproduce on the keyboard any musical sounds that he hears, with great rapidity and accuracy. Derek's auditory perceptual abilities were examined exhaustively in an experiment in which he attempted to replicate 20 chords each of four, five, six, seven, eight and nine notes (Ockelford, 2008a, pp. 218-225). Derek's responses were invariably swift (occurring in less than a second) and precise, with scores ranging from $100 \%$ for four-note chords to $93 \%$ for aggregations of nine notes (Ockelford, 2012b, pp. 206 and 207). (Subsequent comparative work with other savants and advanced music students with AP has shown that Derek's ability in this respect is exceptional by any standards - see Mazzeschi, et al., 2011.) 
In the longitudinal studies, Derek attempts to learn new pieces on the piano, using one of four different approaches. All these are characteristic of him in everyday life, and therefore have the ecological validity that is so particularly important in research with people with learning difficulties. The first involves hearing an entire piece of music and then trying to re-create it, a process that is re-run with increasing periods of time between sessions (see, for example, Ockelford \& Pring, 2005; Ockelford, 2008a, 2012a) - the so-called "listen and play" approach. The second procedure entails Derek endeavouring to learn a piece by hearing and attempting to replicate it in short sections, a procedure that, again, is reiterated over weeks, months and then years (Mazzeschi, 2014), and is termed "a bit at a time". The third protocol (that is of relevance here), "play along", involves Derek shadowing a new piece - attempting to reproduce it at the same time as listening to it - an approach that, once more, is re-run over a number of sessions. The fourth modus operandi, "just listen", requires Derek simply to be exposed to a piece on several occasions without playing, and then to try to reproduce it some time later.

It may seem that the third approach - asking someone repeatedly to attempt to play (or sing) along as they listen to an (initially) unfamiliar piece - is a curious thing to do, entailing a means of learning that is diametrically opposed to the approach conventionally espoused by music teachers working in the Western classical tradition, in which information is imparted through notation, and is thought to be easiest to digest and perfect one small chunk at a time. However, as observed above, this "rational" method of learning is not the way that most people actually come to know pieces of music; rather (as we saw in relation to children, teenagers, church-goers and football fans), the tendency is to approach music learning aurally and, apparently, unsystematically. Similarly, Derek, like many savants and others with learning difficulties, who approach music purely by listening, learns most naturally by attempting to sing or (in his case) play along with whatever he hears - a task of considerable cognitive complexity, involving the simultaneous processing, prediction and production of musical sounds, and the constant comparison of stimulus and response, suppressing the inevitable interference of one upon the other, identifying discrepancies, and adapting future predictions accordingly. The important thing to bear in mind, though, is that, complex though this approach may be, listening, learning and playing all at the same time constitute a form of multitasking that comes naturally to Derek - a course of action that, since he started playing the piano at the age of two, he has used successfully to get to grips with new pieces. Hence, we would argue that this strategy, unusual though it is, offers a valid way of gathering data. Observe that here we will be concerned not with how Derek learnt a new piece of music over time (that will be reported in a subsequent paper), but what happened during his initial attempt, since, as we shall see, it is the data so produced that enable us to interrogate the question of how musical implications arising between groups function in working memory to generate expectations on the first hearing of a piece.

It is worth noting that seeking to analyse the cognitive processing underlying the "play along" approach, is, as far as the authors have been able to ascertain, a novel area of research - at least, in the domain of music. The notionally comparable practice of speech shadowing - reproducing strings of words as they are heard - has featured in psychological study since the late 1950s (see, for example, Treisman, 1965; Marslen-Wilson, 1973, 1985; Lambert, 1992; Bailly, 2003), often as a means to another end: to gauge the limitations of attention in multi-modal tasks, for example (Spence \& Read, 2003); to probe the limits of working memory (for instance, Parkinson, 1972) and processing capacity (Waters, Komoda, \& Arbuckle, 1985); and, more recently, to explore the neurological correlates of spoken language (Peschke, Ziegler, Kappes. \& Baumgärtner, 2009). Moreover, speech shadowing, just like music shadowing (as the examples above suggest), occurs naturally in a number of contexts, apparently forming part of typical early language development, for instance (Kuhl and Meltzoff, 1996), as well as being a characteristic of verbal communication in many children on the autism spectrum or who are developmentally delayed or blind, where it is termed "echolalia" (Fay, 1973; Roberts, 1989; Peters, 1993; Bishop, North and Donlan, 1996). Elsewhere (Miller \& Ockelford, 2005; Ockelford, 2013), I have suggested that echolalia may result from the transfer of a key element of musical syntax (imitation) into the realm of language, which occurs when semantic understanding (and, therefore, linguistic syntax) is limited or absent. Indeed, it has always been a feature of the verbal utterances produced by Derek, for whom music was a "first language" (Ockelford, 2007).

This potential connection with music notwithstanding, speech shadowing is, however, fundamentally different in at least one respect from the "play along" scenario, whereby, in the case of language, the relationship between stimulus and response is primarily echoic rather than anticipatory, whereas in the study reported here, the opposite is true. That is, in speech shadowing, subjects continually copy what they have just heard, and there is invariably a delay between input and output (the ear-voice-span or "EVS"), although this can be as little as a quarter of second or even less (Marslen-Wilson, 1973, 1985), and may be enhanced through anticipation, since, given that language usually has a fair level of redundancy and therefore predictability, priming is possible (Treisman, 1965). Such implications are usually of the schematic type (equivalent to path B-to-D in Figure 1), though, occasionally, the repetition of distinct groups of words, as in some poetic structures, or quotations, may engender more specific expectations (set out in paths A-to-D and B-to-D respectively). These forms of prediction, and other types, generated 
through semantic understanding, may necessarily play an even greater role in simultaneous interpretation (Gile, 1995, p. 115; Setton, 1999, pp. 186-191), despite the fact that, in this context, EVSs may be around three seconds (Al-Khanji, El-Shiyab, \& Hussein, 2000, p. 603). Anticipation may be necessary because the syntactical structures of two languages may vary, giving rise to differences in the order in which concepts are presented, and so requiring inferential reasoning to complete chunks of meaning in what is said before they have been completely presented in what is heard. Again, though, such factors did not play a part in the research described here.

So, let us consider in detail what may occur as Derek listens and tries to play along with a novel stimulus, and consider what this tells us about his perception of implicative musical structures. First, we will imagine an "ideal" scenario, in which:

1. the piece was designed such that all between-group implications (as predicted by zygonic theory) that occurred were realised; and

2. Derek's performance was optimal, such that he

a. intuitively anticipated every event that was implied by the preceding structure and, conversely,

b. failed to predict any event that was not.

The results of this hypothetical situation would provide evidence as to whether the basic zygonic conjecture concerning between-group implication was reflected in one person's music-structural processing. However, it would not provide data pertaining to the notion that implications can function cumulatively, since only one implicative relationship would be sufficient to enable Derek accurately to predict what was coming next - an inbuilt ceiling effect.

The resolution to this issue lies in the fact that, due to the difficulty of the task, Derek is in reality likely to make errors. These may occur for a number of reasons, pertaining ultimately to cognitive or technical (motor) deficits or both. For example, he may:

1. fail to detect and/or remember an implicative relationship that was present;

2. fail to recall an implicative relationship, or fail to recall it at the appropriate time;

3. misrepresent a non-implicative relationship as implicative;

4. fail to position his hand and fingers quickly enough to realise on the keyboard the implied note that he heard in his head, so playing it late (that is, the right note at the wrong time);

5. make a technical error (producing the wrong note at the right time); or

6. produce a combination of both 4 and 5 (playing the wrong note at the wrong time).

Moreover, we can surmise that errors may have an exacerbatory effect: for instance, playing a wrong note may prevent a correct response being produced at the same time or shortly afterwards; and a mistake in production may interfere with the perception of the stimulus, causing further errors down the line. We should also acknowledge that, within the pitch universe available on the keyboard, Derek's responses will inevitably be constrained, and it is possible that he may play notes that accord with an implicative relationship that actually arise as a result of error, and are the same as the stimulus by chance (constituting "false positives").

So, how does the tendency to make errors assist in evaluating the proposition that two or more implicative relationships pointing to the same outcome have a cumulative effect, strengthening the expectation that such an outcome will occur? We hypothesise that the greater the number of implicative relationships that point to a given event occurring, the more likely that at least one of them will be detected, remembered, recalled and acted upon (in the sense of playing the note that is indicated), and the less likely it is that Derek will make an error. That is to say, the probability of Derek anticipating an event correctly (" $\mathrm{E}_{\mathrm{c}}$ ") is a function of the number of relationships (necessarily zygonic) through which it is implied ("\#Z"):

$$
P\left(\mathrm{E}_{\mathrm{c}}\right)=f(\# \mathrm{Z})
$$

Hence, $P\left(\mathrm{E}_{\mathrm{c}}\right)$ is held to be a proxy measure of structural implication.

The function $f(\# Z)$ can be modelled theoretically as follows. First, let $\# Z=1$. The probability of an event being anticipated correctly can be calculated thus,

$$
P\left(\mathrm{E}_{\mathrm{c}}\right)_{1}=\frac{\#\left(\mathrm{E}_{\mathrm{c}}\right)}{\#\left(\mathrm{E}_{\mathrm{c}}\right)+\#\left(\mathrm{E}_{\mathrm{i}}\right)}
$$


where $P\left(\mathrm{E}_{\mathrm{c}}\right)_{1}$ is the probability of an event being correct given $\# \mathrm{Z}=1$, and $\# \mathrm{E}_{\mathrm{i}}$ is the number of implied events that Derek realised incorrectly (or failed to play at all).

Now let us assume that $\# Z=2$, and there is no cognitive interaction between the two implicative relationships: that is, recognising, recalling and realising one (or failing to do these things) does not have an impact on the success (or otherwise) of processing the other. For Derek to anticipate an event correctly requires that either or both of the relationships are acted upon appropriately.

The probability of this occurring $-P\left(\mathrm{E}_{\mathrm{c}}\right)_{2}-$ is shown in Figure 7.

\section{RELATIONSHIP $1 \quad$ RELATIONSHIP 2}

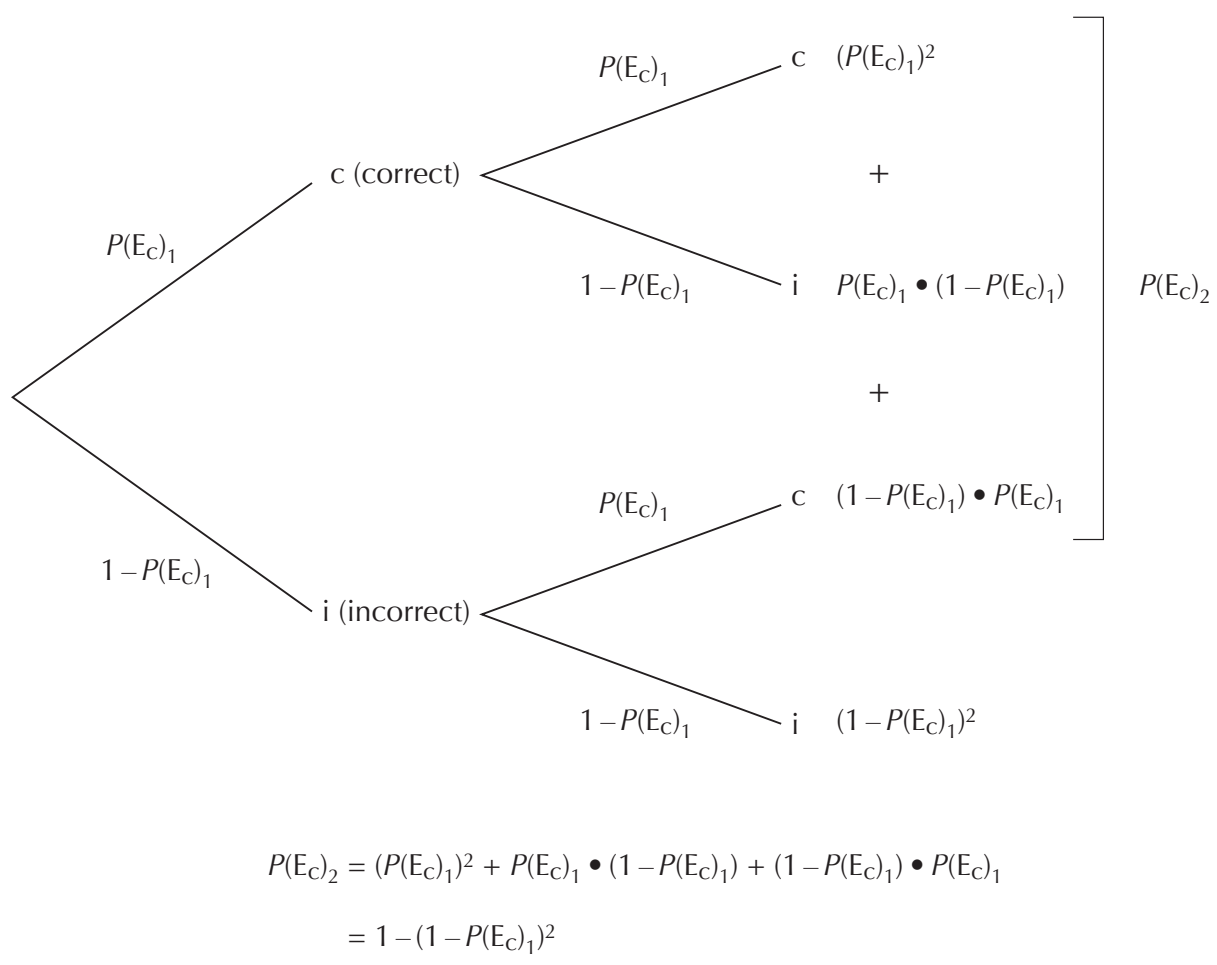

Fig. 7. Probabilities associated with two implicative relationships functioning simultaneously (assuming no interaction).

By extension, if $\# Z=3$, then

$$
P\left(\mathrm{E}_{\mathrm{c}}\right)_{3}=1-\left(1-P\left(\mathrm{E}_{\mathrm{c}}\right)_{1}\right)^{3}
$$

And in general terms, if $\# \mathrm{Z}=\mathrm{n}$, then

$$
P\left(\mathrm{E}_{\mathrm{c}}\right)_{\mathrm{n}}=1-\left(1-P\left(\mathrm{E}_{\mathrm{c}}\right)_{1}\right)^{\mathrm{n}}
$$

This yields an asymptotic trend as follows, in which the greater the number of implicative relationships (\#Z) pertaining to a given future event, the closer the probability with which it will be anticipated is to 1 (that is, complete certainty) - see Figure 8 .

$$
P\left(\mathrm{E}_{\mathrm{c}}\right)_{\mathrm{n}} \sim 1
$$

We can speculate that a number of factors may impact on this theoretical relationship between \#Z and $P\left(\mathrm{E}_{\mathrm{c}}\right)$. First, memory and recall will be affected by the nature of the musical materials, including the length and complexity of the motifs concerned, their temporal separation, and their relationships with other components of the 
piece. In general terms, since the capacity of working memory is limited, a ceiling effect is likely to be reached relatively quickly, although the tendency of motifs to form larger musical chunks (phrases) may mitigate this constraint (cf. Cowan, 2001). Hence, we will take as our working assumption (a conjecture that is required for the design of the piece) that the maximum number of motifs that can be the focus of attention at any one time will be nearer to Miller's original magical seven (1956) than somewhat lower more recent estimates (Cowan).

It may also be the case that individual memories of motifs, and the expectations arising from them, are not stored and processed in isolation, but interact with another. Hence

$$
P\left(\mathrm{E}_{\mathrm{c}}\right)_{\mathrm{n}}=f\left(1-\left(1-P\left(\mathrm{E}_{\mathrm{c}}\right)_{1}\right)^{\mathrm{n}}\right)
$$

where $f$ is the function of interaction. This may have the effect of increasing or decreasing $P\left(\mathrm{E}_{\mathrm{c}}\right)$ relative to $1-\left(1-P\left(\mathrm{E}_{\mathrm{c}}\right)_{1}\right)^{\mathrm{n}}$ or a combination of the two.

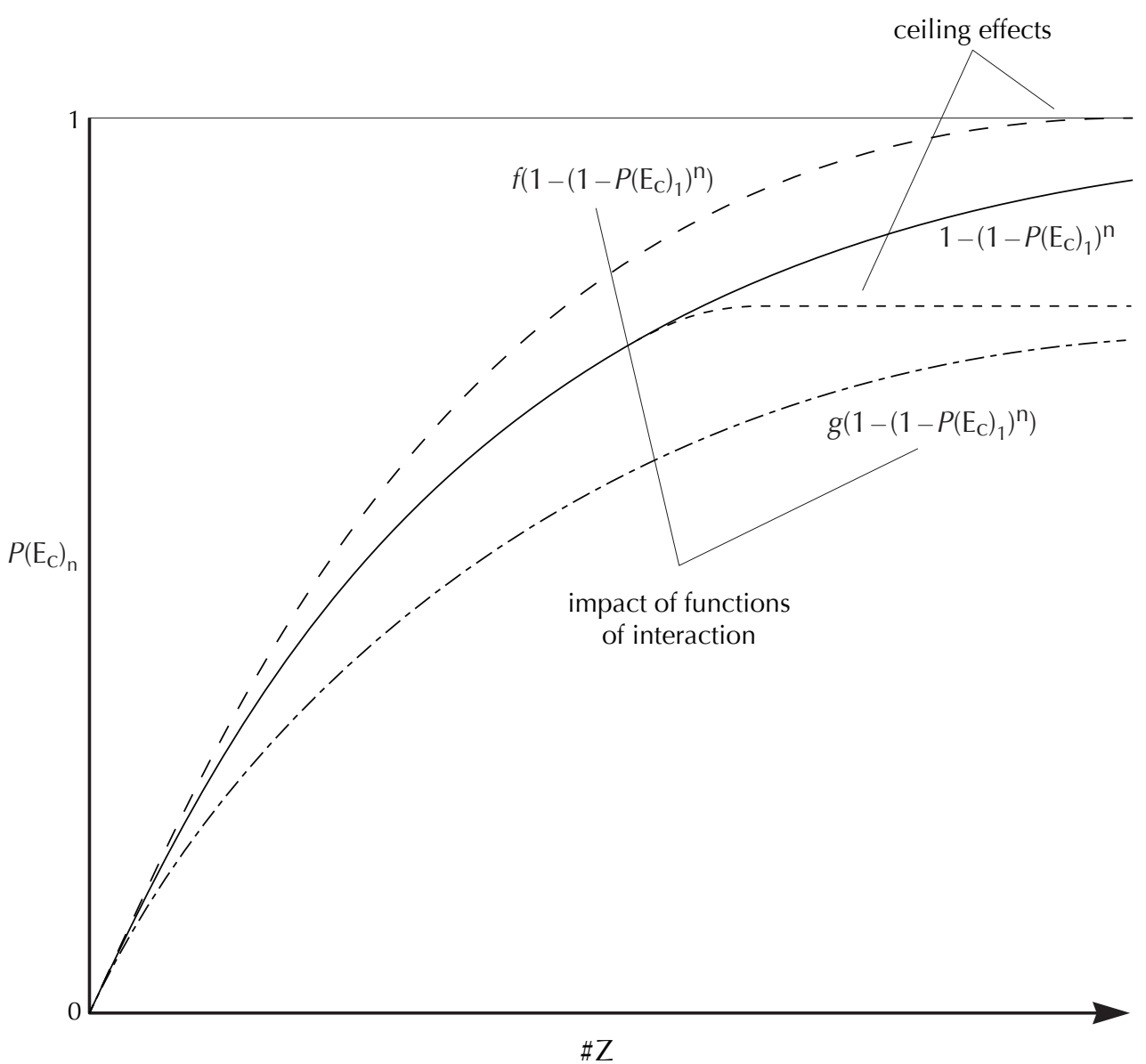

Fig. 8. Potential correlations between the number of implicative relationships pointing to an event and the probability of that event being anticipated correctly.

In order to gather a sufficient range of empirical data to be able to undertake purposeful analysis, the difference between $P\left(\mathrm{E}_{\mathrm{c}}\right)_{1}$ and $P\left(\mathrm{E}_{\mathrm{c}}\right)_{7}$ (or a similar value of $\# \mathrm{Z}$ ) needs to be as great as possible. For example, if $P\left(\mathrm{E}_{\mathrm{c}}\right)_{1}=0.5$ (such that Derek successfully processed half of all implicative relationships), then $P\left(\mathrm{E}_{\mathrm{c}}\right)_{\mathrm{n}}$ would approach 1 relatively quickly:

$P\left(\mathrm{E}_{\mathrm{c}}\right)_{2}=0.75$
$P\left(\mathrm{E}_{\mathrm{c}}\right)_{3}=0.88$
$P\left(\mathrm{E}_{\mathrm{c}}\right)_{4}=0.94$
$P\left(\mathrm{E}_{\mathrm{c}}\right)_{5}=0.97$ 
$P\left(\mathrm{E}_{\mathrm{c}}\right)_{6}=0.98$

$P\left(\mathrm{E}_{\mathrm{c}}\right)_{7}=0.99$

and differences between $P\left(\mathrm{E}_{\mathrm{c}}\right)_{5}, P\left(\mathrm{E}_{\mathrm{c}}\right)_{6}$ and $P\left(\mathrm{E}_{\mathrm{c}}\right)_{7}$ would be very small. Conversely, if $P\left(\mathrm{E}_{\mathrm{c}}\right)_{1}=0.05$ (say), whereby 1 in 20 relationships were detected and acted upon, then $P\left(\mathrm{E}_{\mathrm{c}}\right)_{\mathrm{n}}$ would approach 1 slowly, and, again, successive values would only be differentiated weakly:

$$
\begin{aligned}
& P\left(\mathrm{E}_{\mathrm{c}}\right)_{2}=0.10 \\
& P\left(\mathrm{E}_{\mathrm{c}}\right)_{3}=0.14 \\
& P\left(\mathrm{E}_{\mathrm{c}}\right)_{4}=0.19 \\
& P\left(\mathrm{E}_{\mathrm{c}}\right)_{5}=0.23 \\
& P\left(\mathrm{E}_{\mathrm{c}}\right)_{6}=0.27 \\
& P\left(\mathrm{E}_{\mathrm{c}}\right)_{7}=0.30
\end{aligned}
$$

The range from $P\left(\mathrm{E}_{\mathrm{c}}\right)_{2}$ to $P\left(\mathrm{E}_{\mathrm{c}}\right)_{7}$ is at a maximum when $P\left(\mathrm{E}_{\mathrm{c}}\right)_{1} \approx 0.2$, as the graph in Figure 9 shows. That is to say, the stimulus will be most effective in assessing Derek's grasp of between-group implication when its design means that he realises around 1 in 5 of the events implied from single structural source correctly. As we have seen, to achieve this requires due consideration be given to the length of the groups of notes concerned and their complexity; the ways in which they are related, the time between them, and the nature of any intervening material (which may reinforce or interfere with the recognition of structural implications). With so many variables pertaining to a hitherto untried experimental design, the construction of the stimulus necessarily had to rely on the authors' judgement having a good knowledge of Derek's musical capabilities.

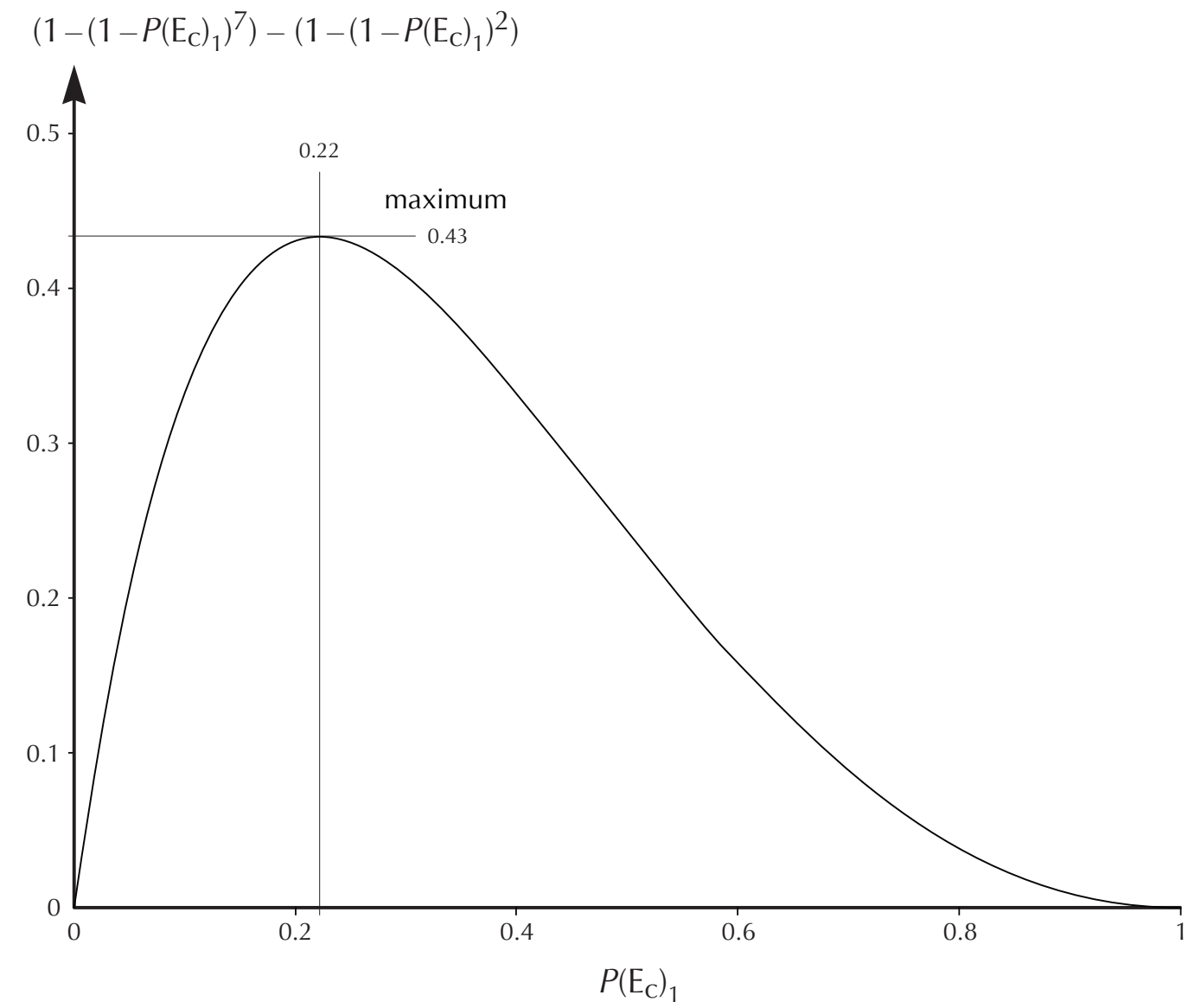

Fig. 9. Maximal value of $\left(1-\left(1-P\left(\mathrm{E}_{\mathrm{c}}\right)_{1}\right)^{7}\right)-\left(1-\left(1-P\left(\mathrm{E}_{\mathrm{c}}\right)_{1}\right)^{2}\right)$ 
Clearly, since the measure is a probabilistic one, involving a range of uncontrollable variables, such as Derek's potentially fluctuating levels of attention, which incur what is effectively random error, the greater the number of responses that are evaluated, the more robust the result is likely to be. However, there are limits to the length of the stimulus since the task is so demanding in terms of the concentration that is required. Hence constraints on the power of $P\left(\mathrm{E}_{\mathrm{c}}\right)_{\mathrm{n}}$ are inevitable.

There is another important methodological issue in the analysis of the results - namely, what counts as "correct"? It has been known for many years that human musical performance is characterised by wide variations in timing, both between successive notes (judged from an imaginary regular tactus), and in relation to clusters of sounds with ostensibly simultaneous onset times, with asynchrony in chords commonly ranging from $30-50 \mathrm{~ms}$ (see, for example, Rasch, 1979; Palmer, 1996; Repp, 1999). Hence we would expect deviations of this order to occur between the stimulus and Derek's efforts to play along with it. However, we also know from experiments with Derek in which he was required to imitate chords on the piano (Ockelford, 2008a) that he responds very quickly typically in less than a second, though formal measurement of his reaction times have not previously been made. Hence there is a danger, in the current context, that, given Derek's speed of response, his echoic production could be confounded with anticipation.

That is to say, while responses that occur within a time interval starting a fraction of a second before the onset of the corresponding note in the stimulus, or that occur at the same time, or within an as-yet-to-be-determined short period afterwards, can be regarded unequivocally as having stemmed from anticipation of that event through structural implication (see Figure 10), responses occurring later than this interval could be generated echoically or structurally, with an increasing likelihood of immediate imitation of the stimulus pitch just heard.

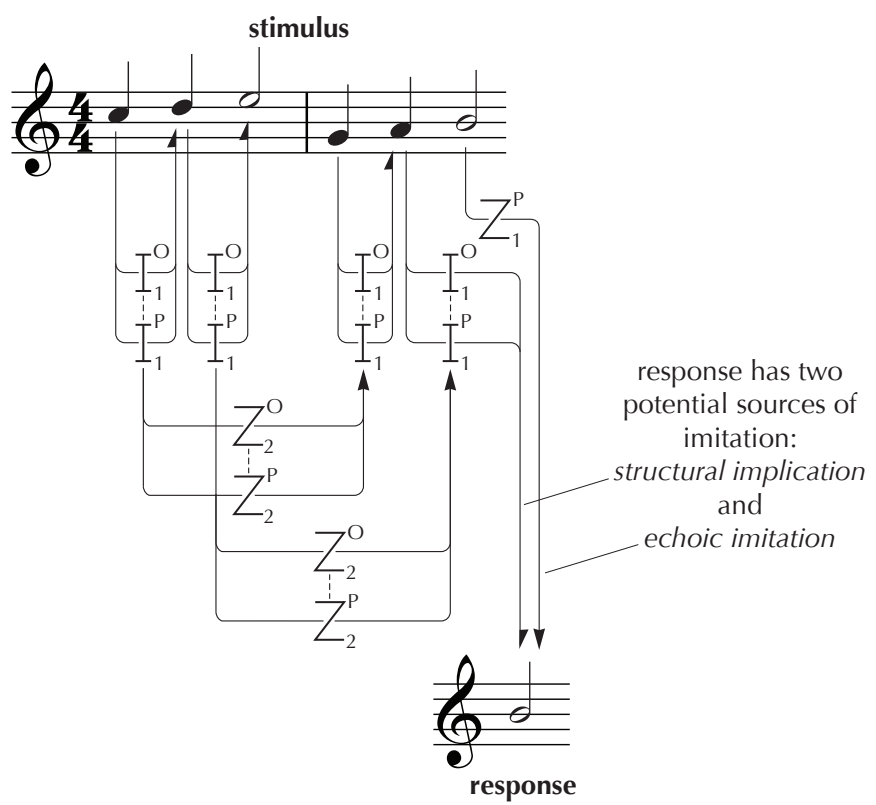

Fig. 10. (part i) Responses have two potential sources of imitation in the stimulus. 


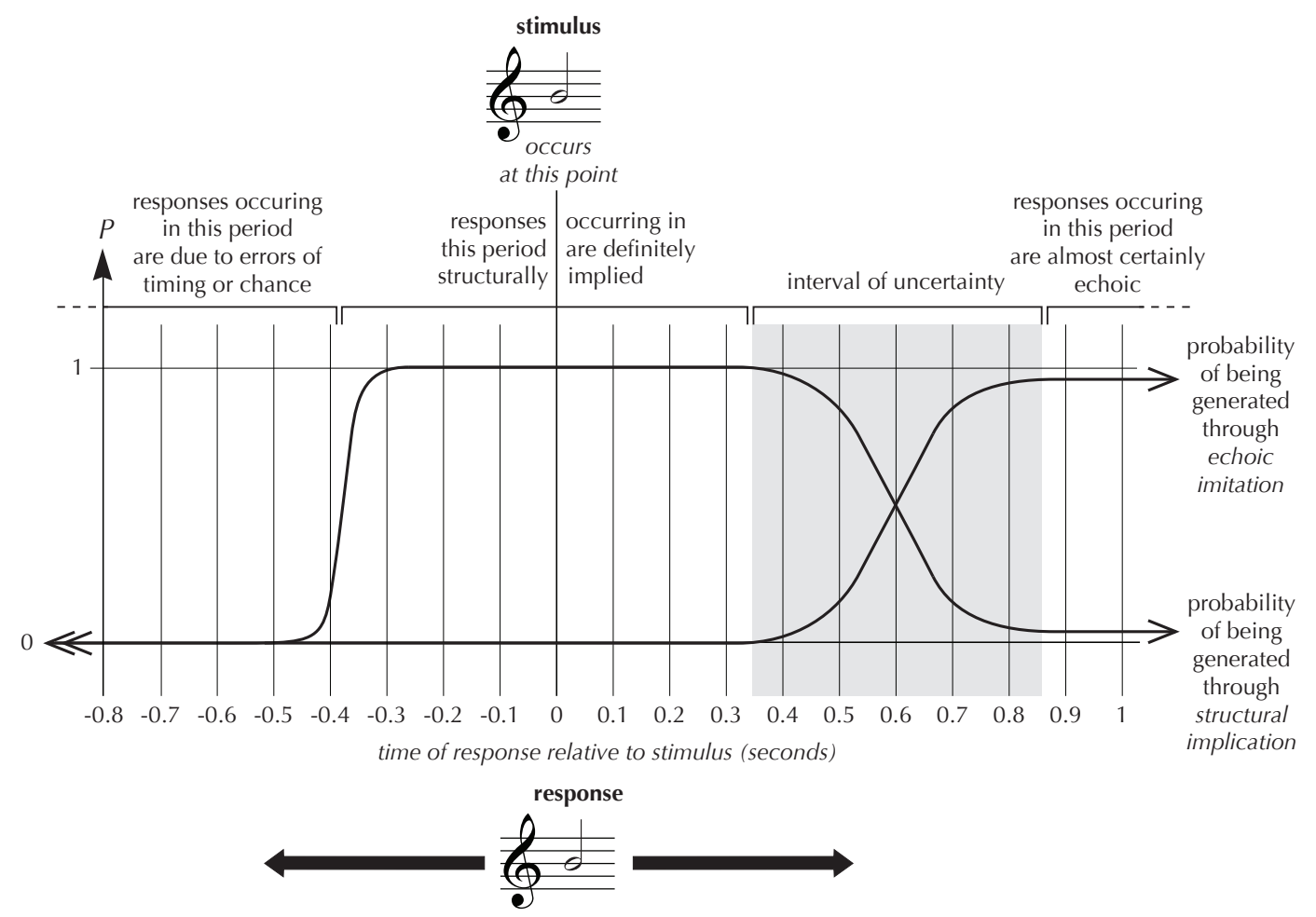

Fig. 10. (part ii) Responses have two potential sources of imitation in the stimulus.

It is the "interval of uncertainty" that is of particular interest, since therein lies the possibility of false positive and false negative results. That is, Derek's notes that were generated through structural anticipation could be misinterpreted as being echoic in nature, and vice versa. In the context of the research undertaken here, it is better to err on the side of caution: to have no false positives and risk some false negatives. Hence, responses falling within the interval of uncertainty should invariably be classified as echoic rather than structural. But what is the point at which we can be sure that Derek was not merely imitating the last note he heard? To ascertain this threshold, a preliminary experiment was undertaken as follows.

\section{PRELIMINARY EXPERIMENT TO DETERMINE THE SPEED OF DEREK'S ECHOIC RESPONSES: THE IMITATION THRESHOLD TASK}

\section{Materials}

Twenty-five different chords, ranging from two to six notes (five of each density), and five single pitches, were taken from the piece used as the stimulus in the main experiment (see below). They were selected in order to give as much variety as possible in terms of pitch-class combinations used and their spacing on the keyboard. These stimuli were recorded live using a Yamaha CP300 Stage Piano into the REAPER Digital Audio Workstation (version 4/x64) using a Toshiba Satellite R-830 laptop. All notes within a given chord were subsequently quantised to ensure synchronised onset times, but variations in duration (which ranged from 0.34 to 0.74 seconds) and velocity of notes were maintained to preserve ecological validity. The thirty stimuli were each repeated five times to create an extended sequence. The order of the resulting 150 chords and single notes was randomised using an output generated from random.org. Post-hoc validation was carried out on the resulting sequence to check for immediate repetitions of stimuli. Two such instances were identified and their order switched. The periods of silence between stimuli were also varied randomly, within the inter-onset range two to four seconds. The aim was to avoid any possibility of Derek anticipating what was going to occur next, and when, and therefore contaminate the results. 


\section{Procedure}

The experiment took place in a quiet room at the University of Roehampton, London. A Waveform Audio File format of the sequence was used in the experiment whereby the stimuli were made to sound like a grand piano, played via Edirol MA-10A speakers at a comfortable listening level. The MIDI version was played in precise synchrony but was muted, as the corresponding digital data were necessary in the analysis stage. Derek produced his responses on a Korg SP-200 88 note touch-sensitive hammer action keyboard, set to "Grand Piano 1" sound and amplified using a Roland 4-Channel Mixing Keyboard Amplifier. Derek's playing was recorded in MIDI format using REAPER on the Toshiba laptop.

A "listen and play" paradigm was used, whereby Derek was told that he would hear a sequence of notes and chords, and was asked to play each of them on the keyboard as soon as he could after hearing them. Derek began by spreading the chords (playing the notes successively from the bottom up), and, after about a minute, when it was evident he was going to continue in this vein, he was asked to play his responses "straight", a request to which he largely conformed. After the task, he was congratulated and thanked.

\section{Results and analysis}

Latencies were only considered for those pitches in relation to which Derek produced a "correct" response. In total he omitted 5\% of notes, which were invariably present at a different octave, and added 11\%, which always conformed to the broad harmonic style of the chords that were presented, including higher, chromatic discords; findings that accord with Derek's earlier attempts at chordal reproduction (see, for example, Ockelford, $2012 \mathrm{~b}$, pp. 206-207).

Omitting the first 30 chords (which were spread), the mean latency of the 120 remaining was 0.70 s, SD = 0.07 , range $0.49-1.38$. Four responses were less then $0.5 \mathrm{~s}$, one pertaining to a four-note chord, two to a single twonote chord, and one to a five-note chord. Surprisingly, the two responses that were $>1 \mathrm{~s}$ both pertained to solitary notes. In fact, in relation to the data as a whole, there is a significant inverse relationship between the size of a chord and the inter-onset interval between the stimulus and the first (or only) note that Derek played: $F(5,114)=3.88, p=$ .003 , within which the differences between responses to the one-note stimuli and those with four, five and six notes are all significant at the $p<.01$ level (Figure 11). There is, however, no correlation between the spacing of chords or their relative position on the keyboard and Derek's speed of response. Taken together, these findings suggest that Derek was performing well within his capacity in terms of response time and that, in the course of a piece of music, where successive events are often adjacent in pitch, or nearly so, and conform to a regular beat, there may well be occasions when individual responses could conceivably be less than $0.49 \mathrm{~s}$. Hence, given the undesirability of having any false positives, it was decided to set the threshold at $0.4 \mathrm{~s}$. 


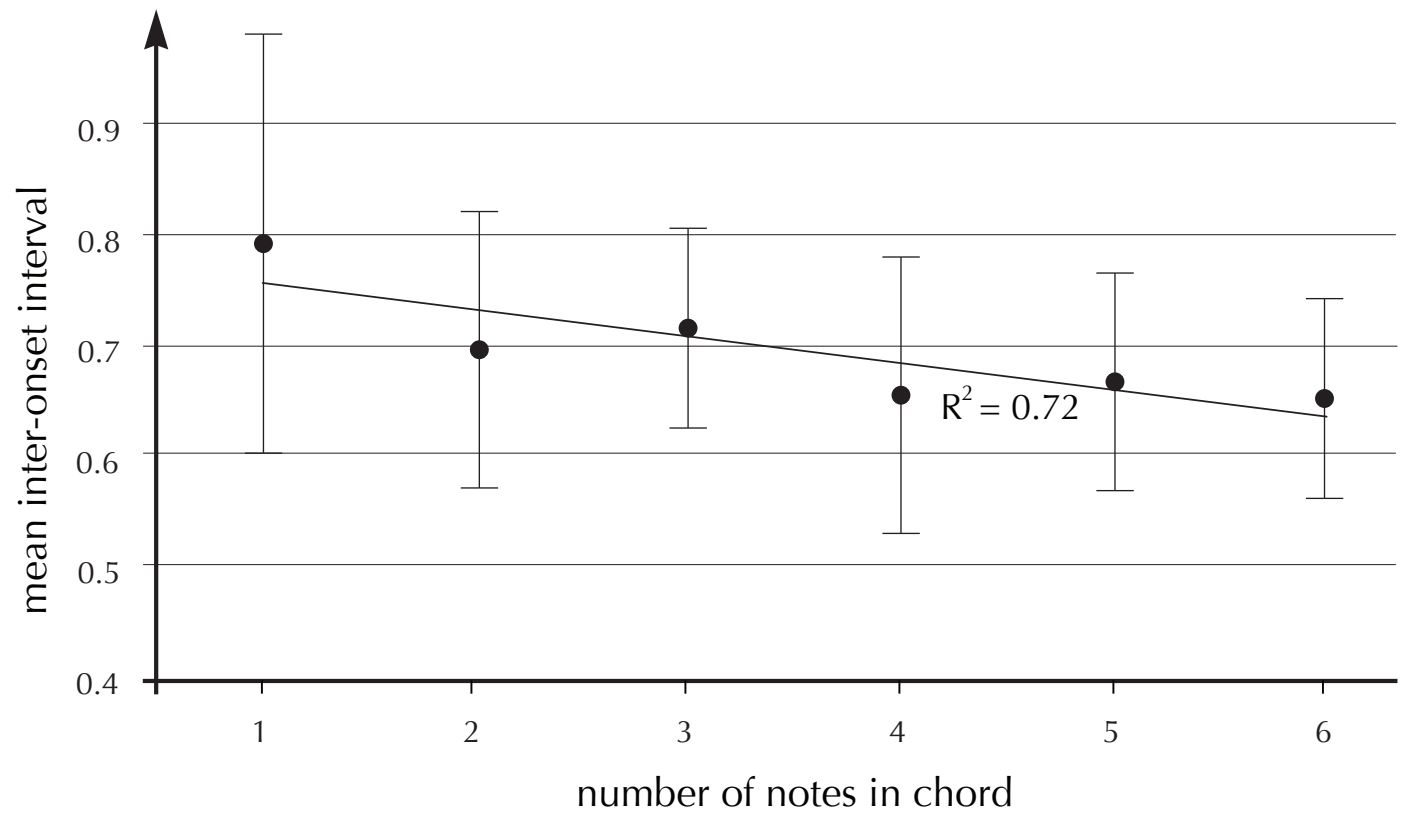

Fig. 11. Latency is inversely related to stimulus chord size in Derek's responses.

\section{SUMMARY OF HYPOTHESES}

The thinking up to this point can be summarised as follows.

It is hypothesised that, at a probabilistic level, the number of errors Derek will make in the initial "play along" task can be taken as an inverse proxy measure of the strength of implication, as characterised by the number of implicative relationships that point to a particular continuation. More specifically, it is postulated that

1. there will be a systematic decrease in the number of errors as the structure "strengthens" (with more implicative relationships);

2. there should be no "correct" anticipations of notes in the absence of structural implications

(a) within the bounds of chance, and

(b) given that there may be other types of implication (for example, "within groups") present; and

3. there may be "correct" anticipations (according to the theory) that do not reflect what actually happens in the piece, where this departs from the theory of between-group relationships set out above (or Derek at least should not play, beyond the bounds of chance, what actually occurs in the piece where this conflicts with theoretical projections).

\section{STIMULUS DESIGN}

The design of the stimulus was critical, since it had to enable data to be gathered that would permit our research question to be addressed. In general terms, it was evident that the piece should be:

1. original (since it is impossible to say what material Derek does or does not know until he has tried to play it - and even then he can pick up new musical ideas so quickly, that the issue can quickly become muddied); and

2. technically undemanding in Derek's terms (since we would not want his responses to be trammelled by problems with fingering, for example).

More specifically, it should comprise:

1. series of motifs, variously repeated and transformed, of which Derek should be able to process around $20 \%$ correctly, and that would: 
a. generate different combinations of between-group implications, and

b. as far as possible, avoid the immediate repetition of pitch, since this could have meant that, on some occasions, it might have been difficult to ascertain which event (in the stimulus) corresponded to which (in the response); and that would

2. use textures in which the schematic implications

a. in the domain of pitch - in particular, those associated with a given tonal centre - would be minimised (since these could potentially interfere with the short-term and veridical betweengroup expectations that may be evoked), and

b. in the domain of perceived time would be maximised (so that the when of expectation would not interfere with the what).

With regard to pitch, previous work (Ockelford, 2011) had demonstrated that in the absence (or virtual absence) of tonality, Derek would become confused: indeed, he would impose tonal schemata on atonal material by changing pitches to accord with conventional Western intervallic frameworks. Specifically, the opening of Arnold Schoenberg's Klavierstück, Op. 11, No. 1, became transformed over time in Derek's mind, so that when he attempted to recall it after 12 months, the result was akin to the harmonic world of Richard Wagner. To this end, it was decided to create the new piece broadly speaking in the harmonic style of Wagner's Tristan und Isolde, and the composition, called the Romantic Rollercoaster[4], actually derives its opening pitches from the famously harmonically ambiguous first phrase of the Tristan overture.

Rhythmically, however, something different was required, both to prevent specific expectations being aroused from Derek's possible knowledge of Tristan, and also since, as we have seen, Romantic Rollercoaster needed to be predictable in the perceived temporal domain. There are many established rhythmic frameworks that promote predictability (without being monotonous), and the "siciliano" was chosen, with a rhythmic fragment being adapted (through metrical change) from the opening of a work by Wagner's contemporary, Johannes Brahms: No. 7 of his Haydn Variations.

The result of this (music-historically unlikely) Wagner/Brahms merger (see Figure 12) is a motif, whose secure rhythmic framework is capable of supporting fluctuating arrays of harmonies, that lends itself readily to repetition, transposition and variation.

Wagner: Tristan und Isolde

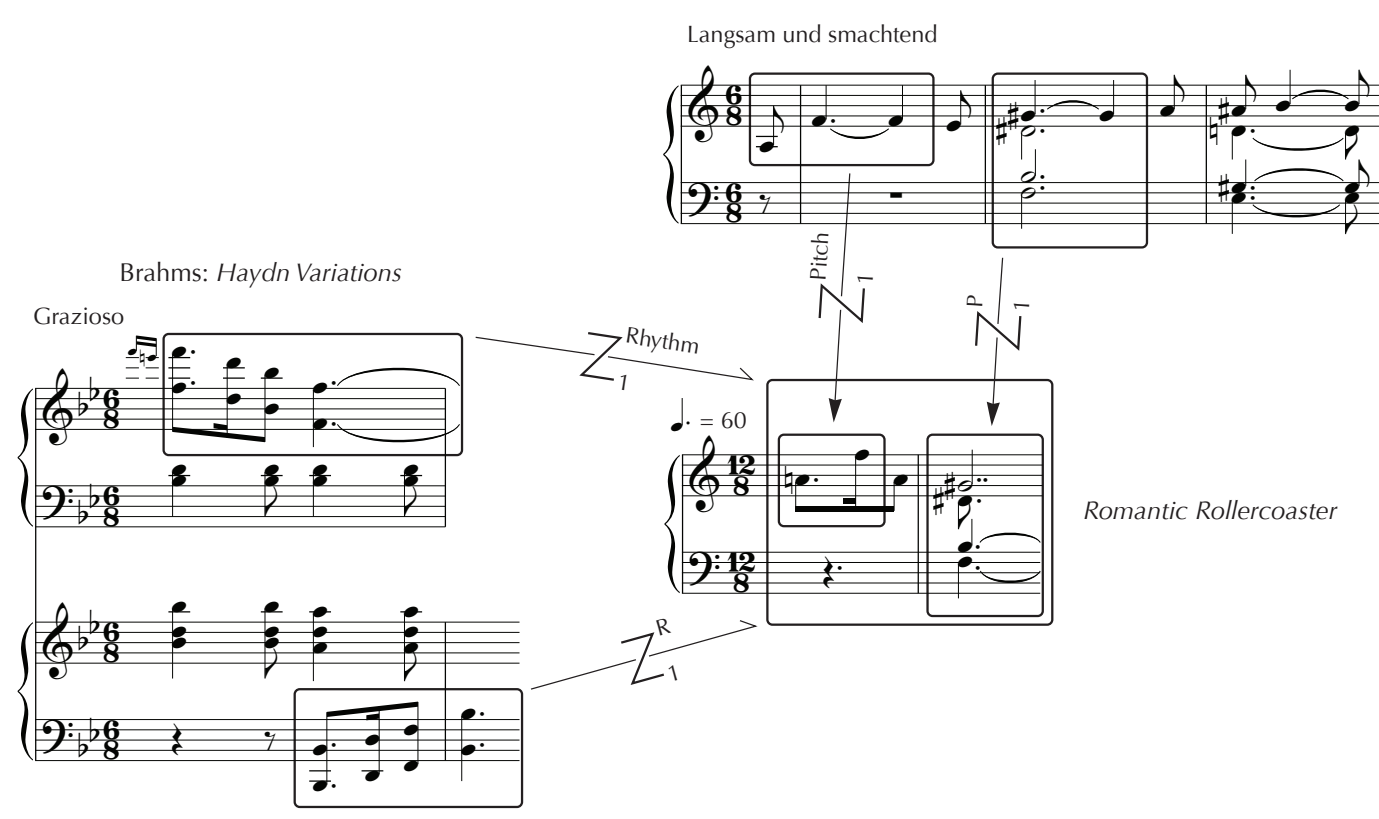

Fig. 12. The derivation of the opening of Romantic Rollercoaster from the introductory pitches in Wagner's Prelude to Tristan und Isolde and the rhythm in Brahms's Haydn Variations (No. 7). 
The manner in which the motif was used in global terms was determined by the need for Romantic Rollercoaster to be of the same structure as, and similar in length and complexity to, the other pieces used in the Fragment of Genius research project: Chromatic Blues (Ockelford \& Pring, 2005) and Classical Turn (Mazzeschi, 2014) - see Table 1.

Table 1. Structure of Chromatic Blues, Classical Turn and Romantic Rollercoaster.

\begin{tabular}{|l|l|l|l|l|l|}
\hline Segment & $\mathrm{A}_{1.1}$ & $\mathrm{~B}_{1.1}$ & $\mathrm{~A}_{2.1}$ & $\mathrm{~B}_{2.2}$ & $\mathrm{C}$ \\
\hline Function & $\begin{array}{l}\text { Theme A } \\
\text { exposition }\end{array}$ & $\begin{array}{l}\text { Theme B } \\
\text { exposition }\end{array}$ & $\begin{array}{l}\text { Theme A } \\
\text { reprise }\end{array}$ & $\begin{array}{l}\text { Theme A } \\
\text { transposed, } \\
\text { extended }\end{array}$ & Coda \\
\hline
\end{tabular}

Given these constraints, Romantic Rollercoaster is as follows (Figure 13). The colour coding of notes and the annotations are explained below. 

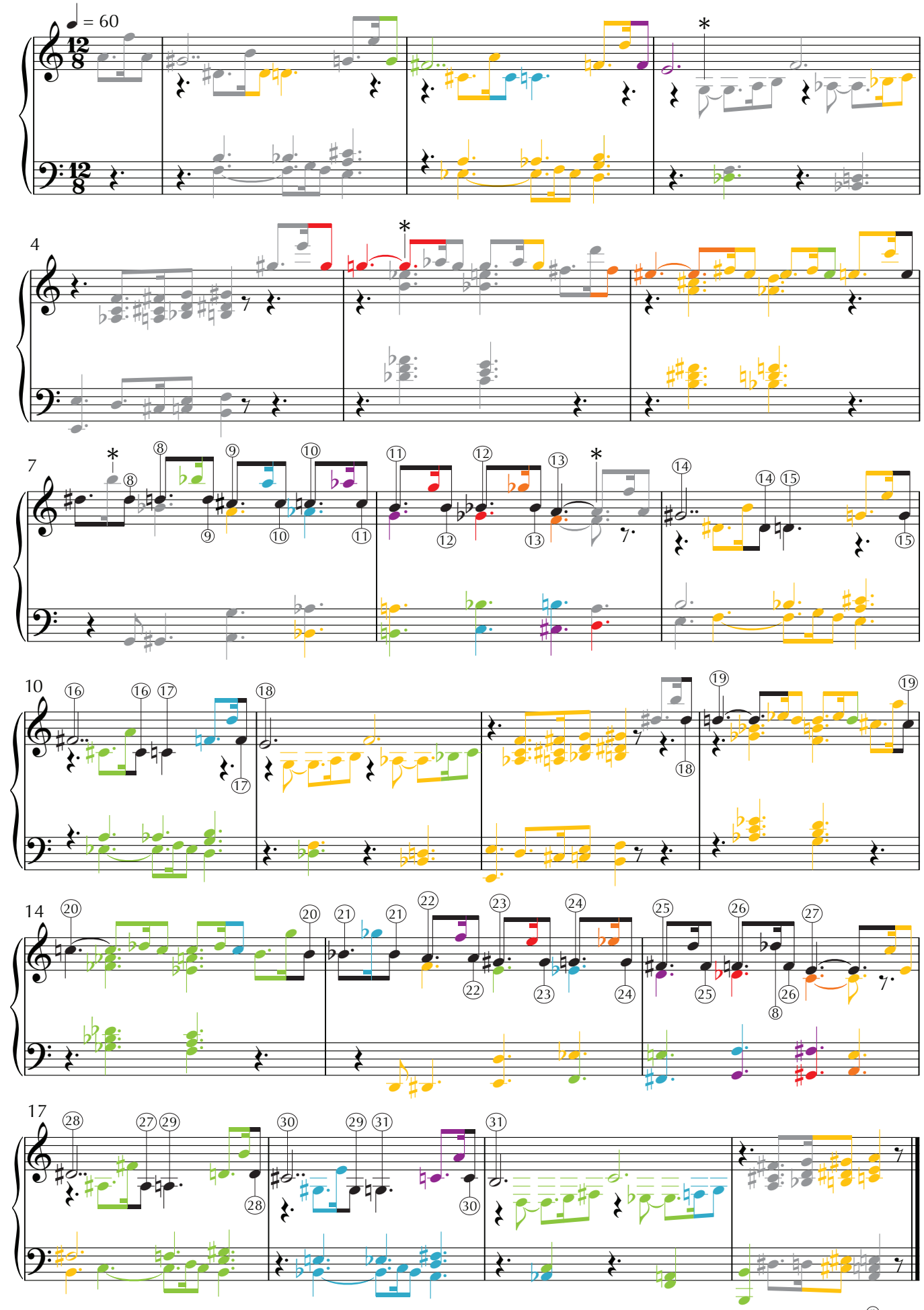

not predictable predictable from predictable from predictable from predictable from predictable from predictable from $\mid$ predictable from $\mid$ predictable from one pattern two patterns $\mid$ three patterns four patterns five patterns $\mid$ six patterns $\mid$ seven patterns $n$ patterns

$*$

Fig. 13. Romantic Rollercoaster 


\section{Modelling implication in the stimulus}

The expectations pertaining to each note were calculated as follows.

As the first musical event is heard, only within-group expectations will be available to the first-time listener, representing a range of likely pitches and onset times, circumscribed by stylistic convention, whereby it would be unusual for the opening interval of a piece to exceed an octave, and to occur more than a second or so after the first (Thorpe, Ockelford \& Aksentijevic, 2012, p. 447). While a general sense of what will probably occur next may be useful in priming the auditory perceptual system from the point of view of a someone responding purely reactively to the music (cf. Bharucha, 1987; Bregman, 1990, p. 130), it is of little value to the pianist trying to play along with the piece, who needs to be able to predict precisely what will occur next and when. As a point of comparison, consider that Thorpe et al. (op. cit., p. 457) found that the vocal predictions from an initial D4 (with octave correction for men) ranged from G3 to D5, with nine distinct pitches being anticipated by the 40 different subjects. Hence, to return to the current experiment, guesswork would Derek's only option available at this early stage in proceedings.

A similar situation applies in respect of Events 2, 3, 4 and 5 (see Figure 14). 


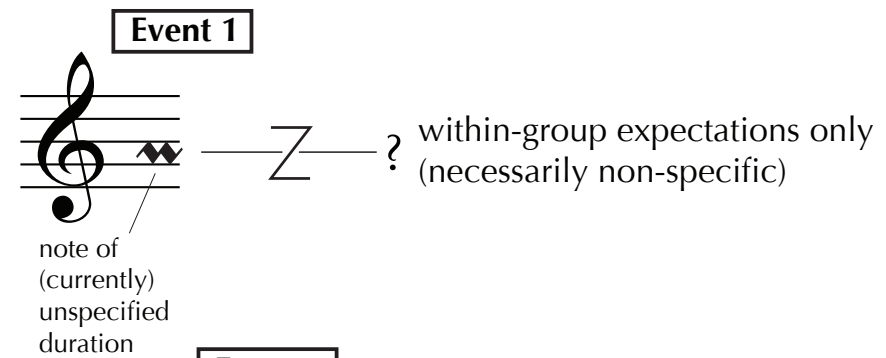

Event 2
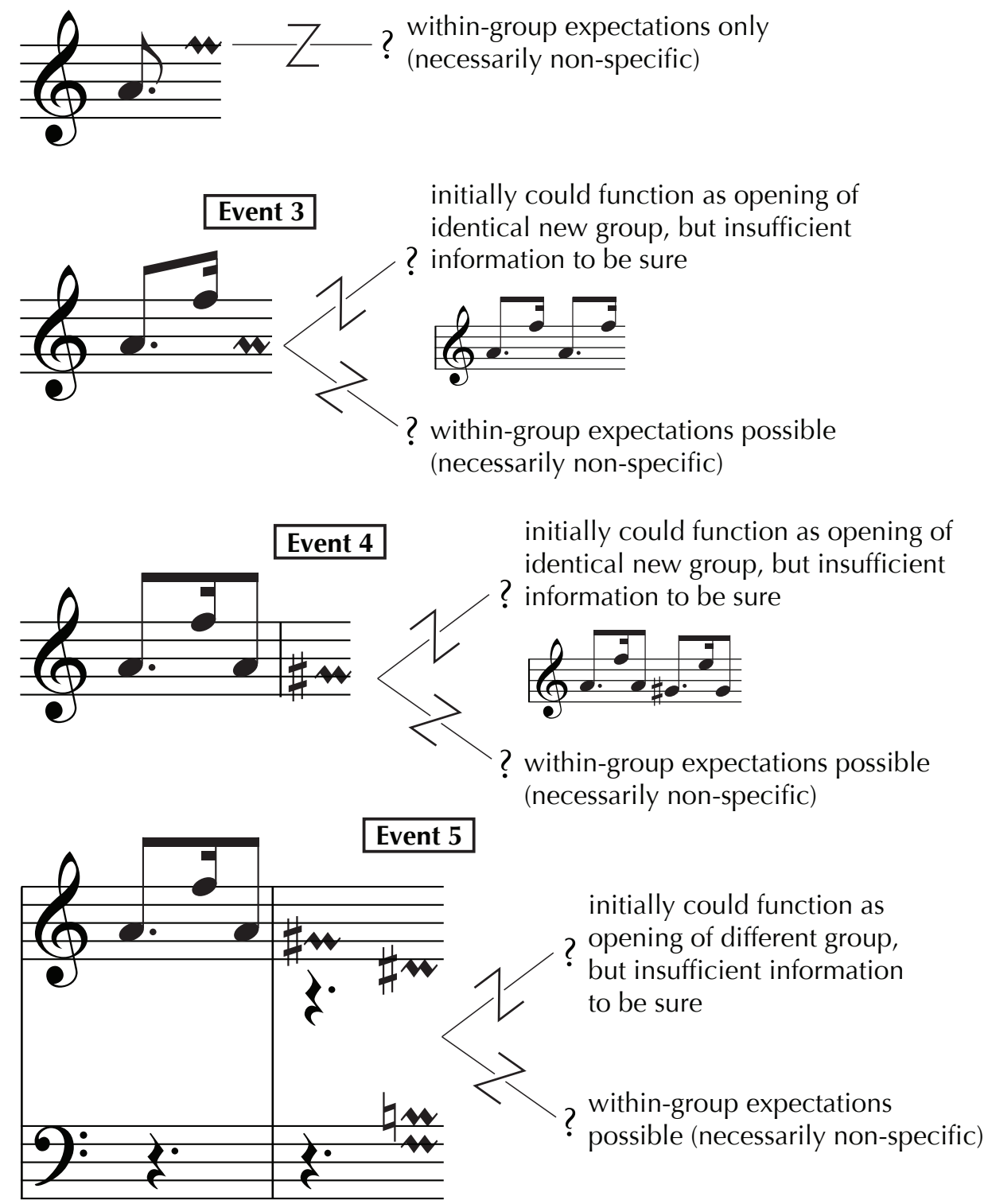

Fig. 14. The expectations pertaining to successive notes in the opening of Romantic Rollercoaster.

Observe that, since Derek has AP, the precise representation of pitch (including chords broken down into their constituent notes) in Figure 14 and those that follow is thought to be a reasonable reflection of what Derek hears. (In subjects without AP, this would not, of course, be the case, since, we can assume that their mental processing would comprise a far more complex network of relativities plugged in at various points to the absolute 
values of the piano keyboard. In fact, one can surmise that the complexity of the task would prove overwhelming in most cases, resulting in a "floor" effect.)

With Event 6, everything changes. Here, for the first time, we have two consecutive events that share the same melodic and inter-onset interval heard at the outset of the piece, which together imply the likely what (pitch) and the when (onset and duration) of the note that follows, and signal that here we have a transposed version of the opening motif (Figure 15).

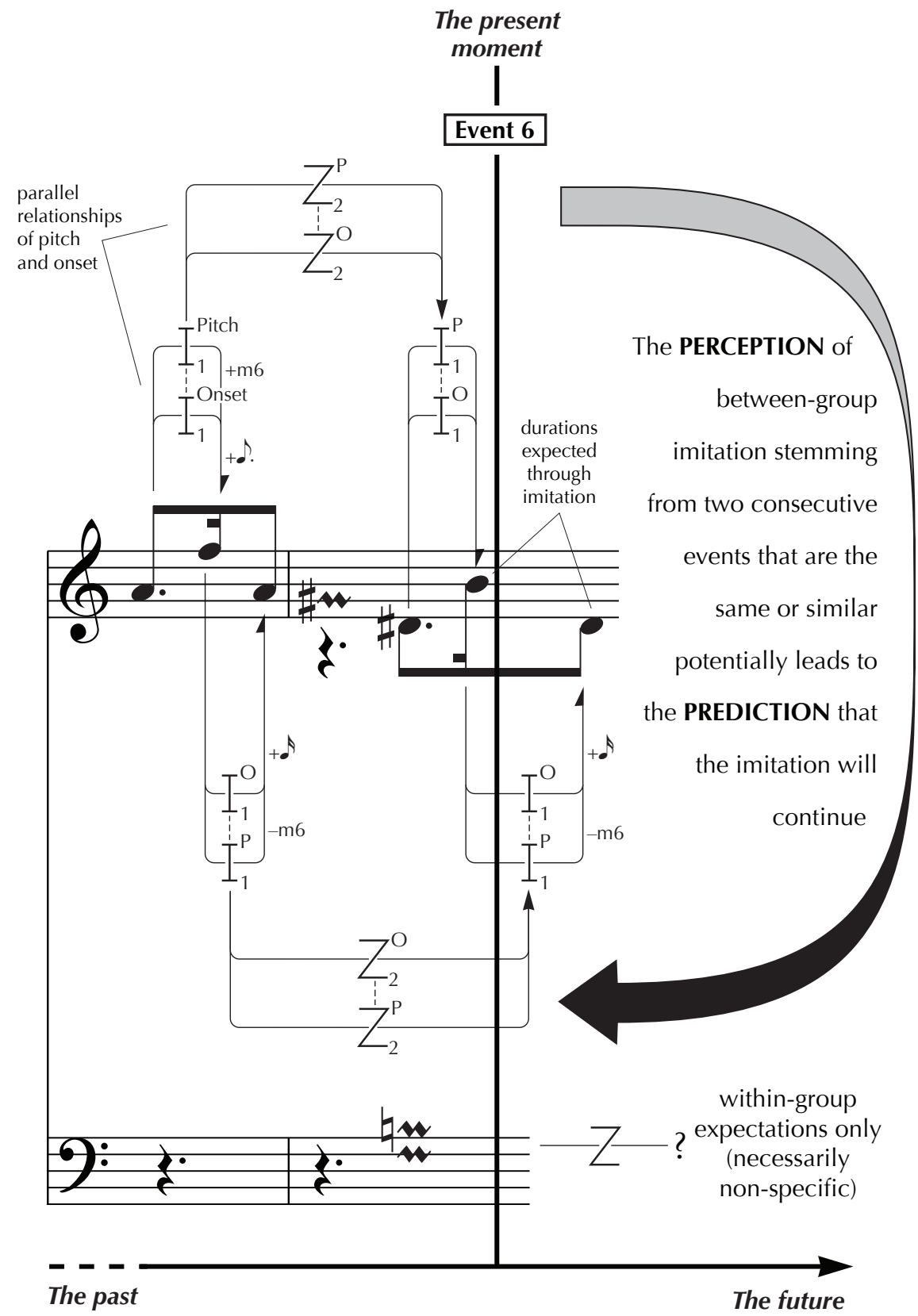

Fig. 15. The expectations pertaining to successive notes in the opening of Romantic Rollercoaster.

Event 7 realises these implications, and the onset and pitch of a further note is suggested (whose duration is as yet unknown) - see Figure 16 . 


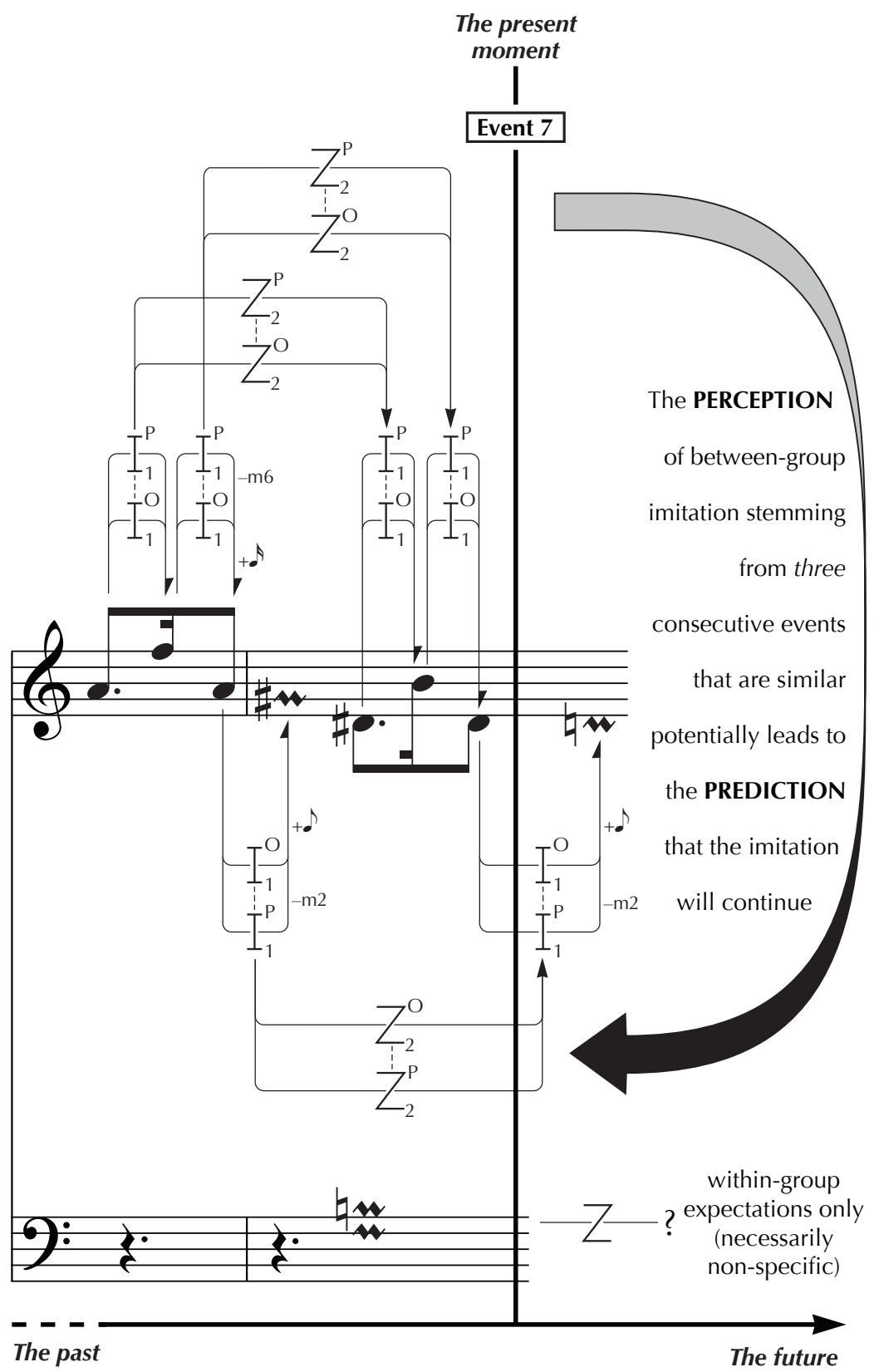

Fig. 16. The expectations pertaining to successive notes in the opening of Romantic Rollercoaster.

With Events 8, 9, 10 and 11, there are no between-group implications, and so (it is anticipated) expectations could only be non-specific. See Figure 17. 


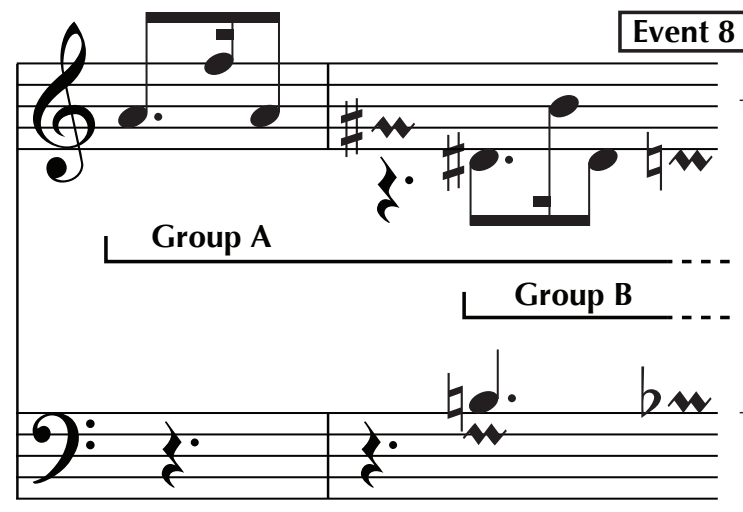

Z ?

it is unclear what betweengroup expectations could follow, since Group A (which overlaps with Group B) is in stasis at this point

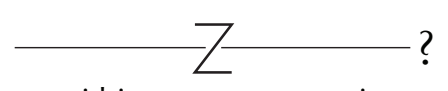

within-group expectations only (necessarily non-specific)
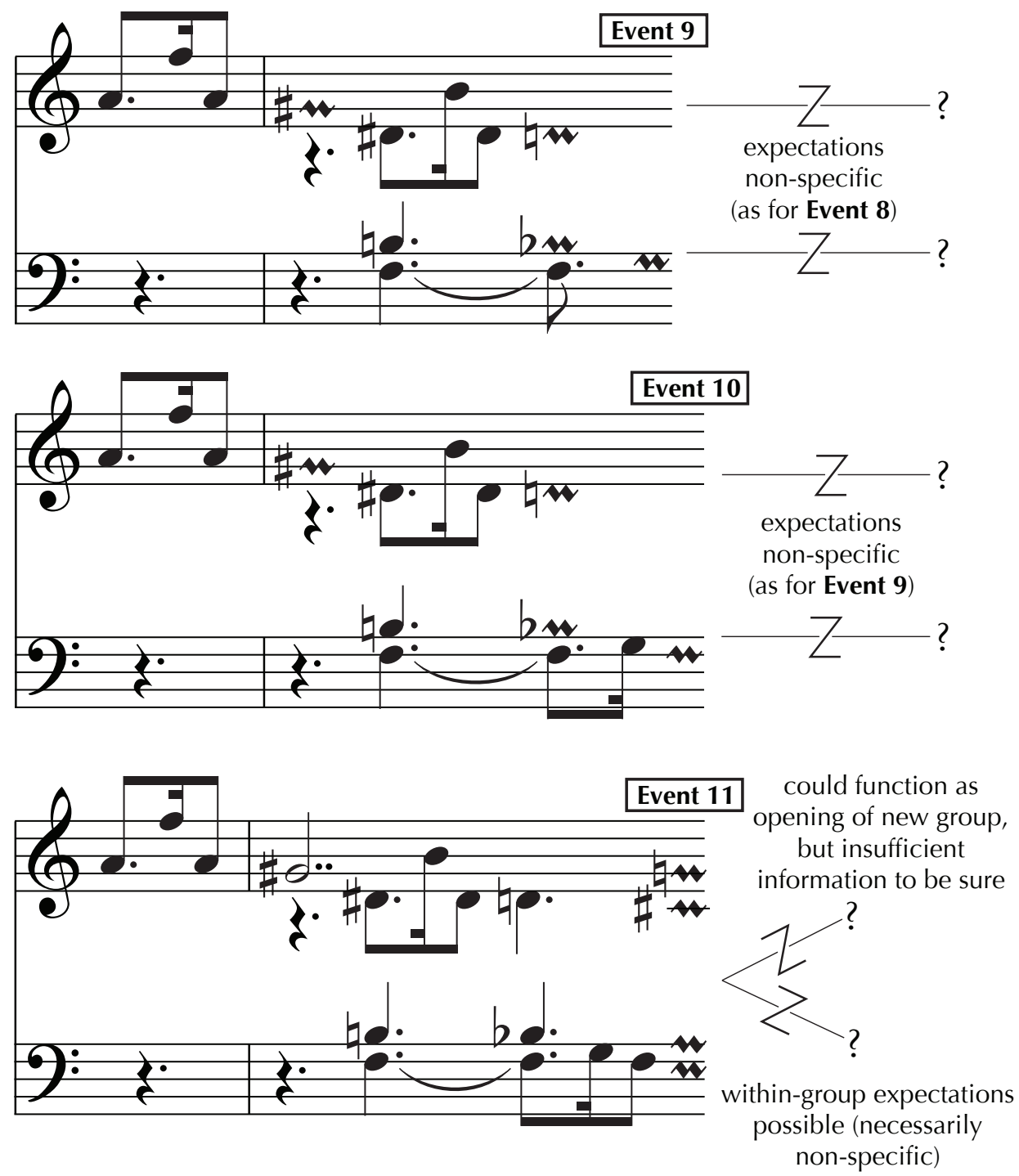

Fig. 17. The expectations pertaining to successive notes in the opening of Romantic Rollercoaster. 
Event 12 forms pitch and inter-onset intervals with Event 11 that are implied in two sources: the opening motif and a transposed version that immediately follows. Here it is hypothesised (as shown in Figure 6) that the strength of perceived expectation will reflect this dual implication (Figure 18).

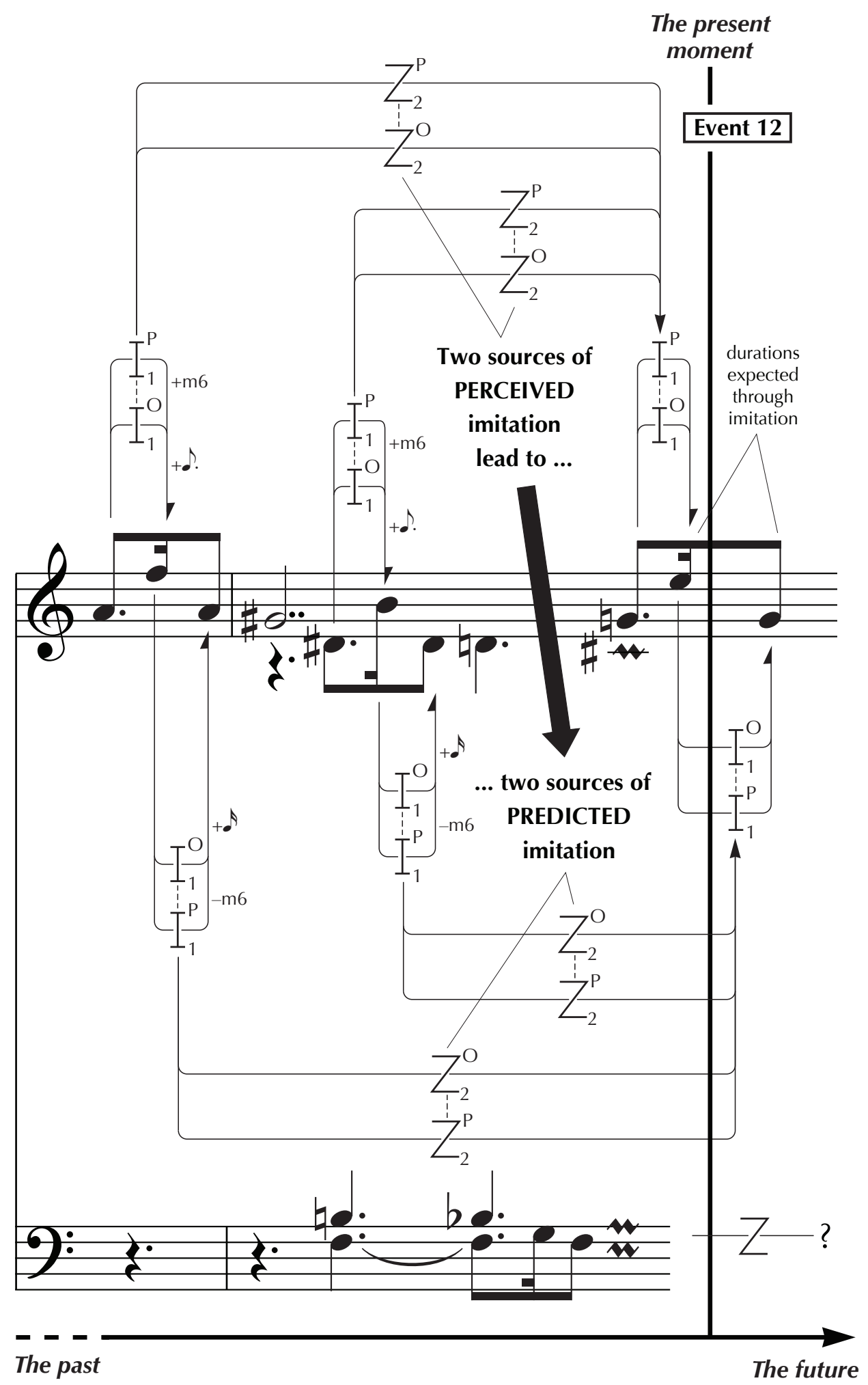

Fig. 18. The expectations pertaining to successive notes in the opening of Romantic Rollercoaster. 
This pattern continues with Event 13 (see Figure 19).

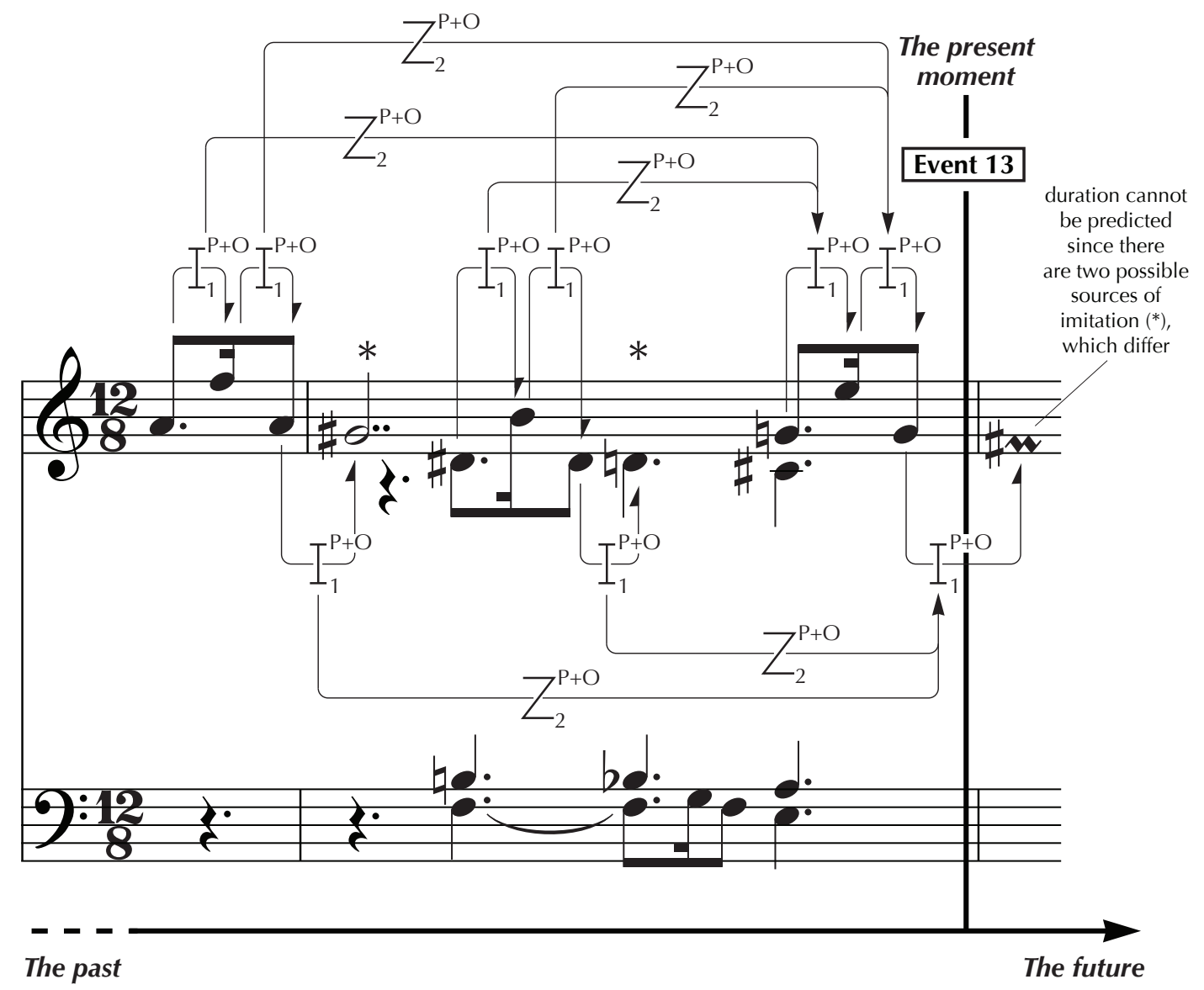

Fig. 19. The expectations pertaining to Event 13 of Romantic Rollercoaster.

Event 14 triggers the first of a new wave of implications based on concatenations of motifs, which function as compound groups. In this case, it is the relationship between Events 4 and 5 that implies a comparable connection between Events 14 and 15, involving the transition from a single melody note to a three-part chord (Figure 16). 


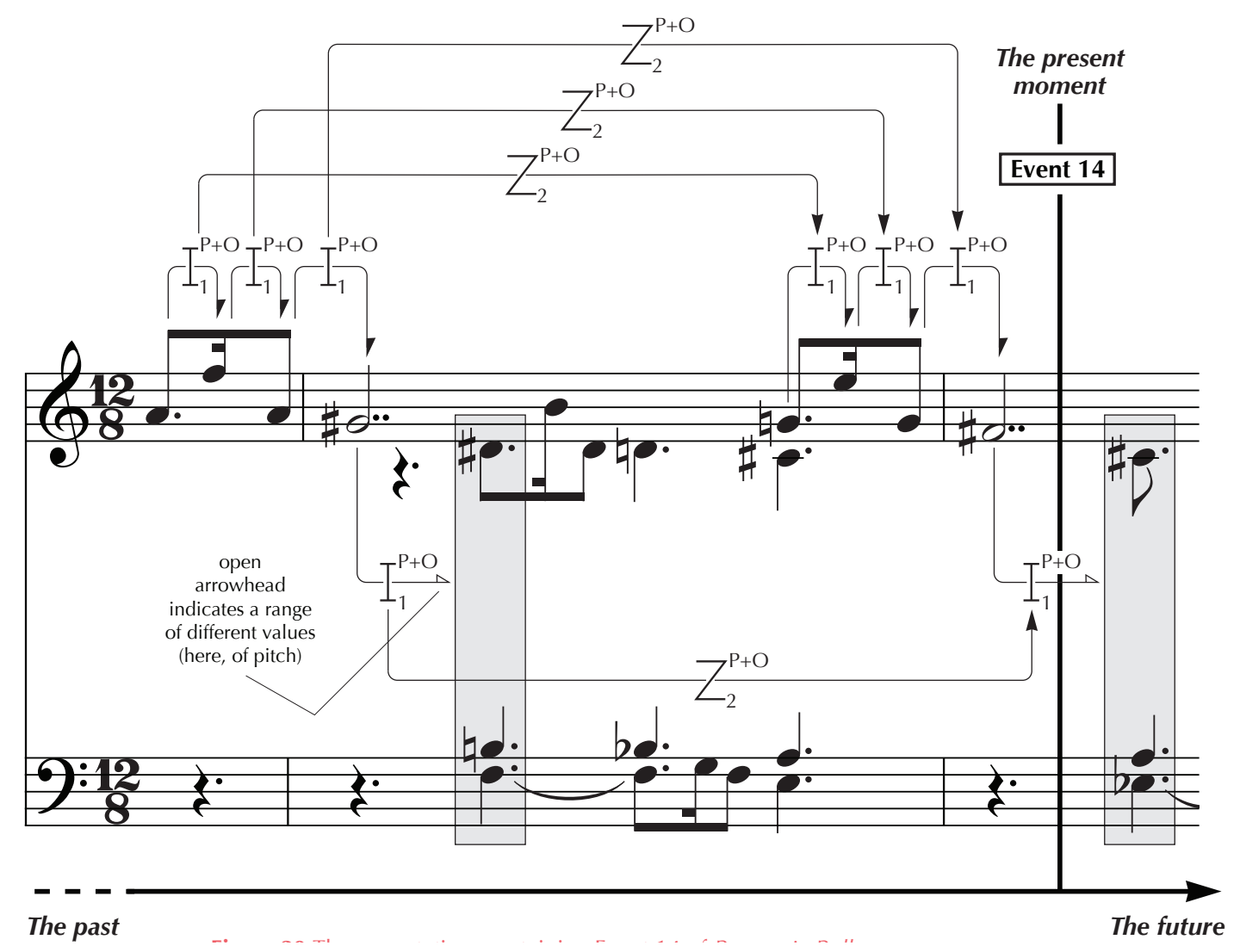

Fig. 20. The expectations pertaining to Event 14 of Romantic Rollercoaster.

At Event 16, three sources of perceived imitation, arising from individual motifs and chains thereof give rise to three sources of implication (see Figure 21). 


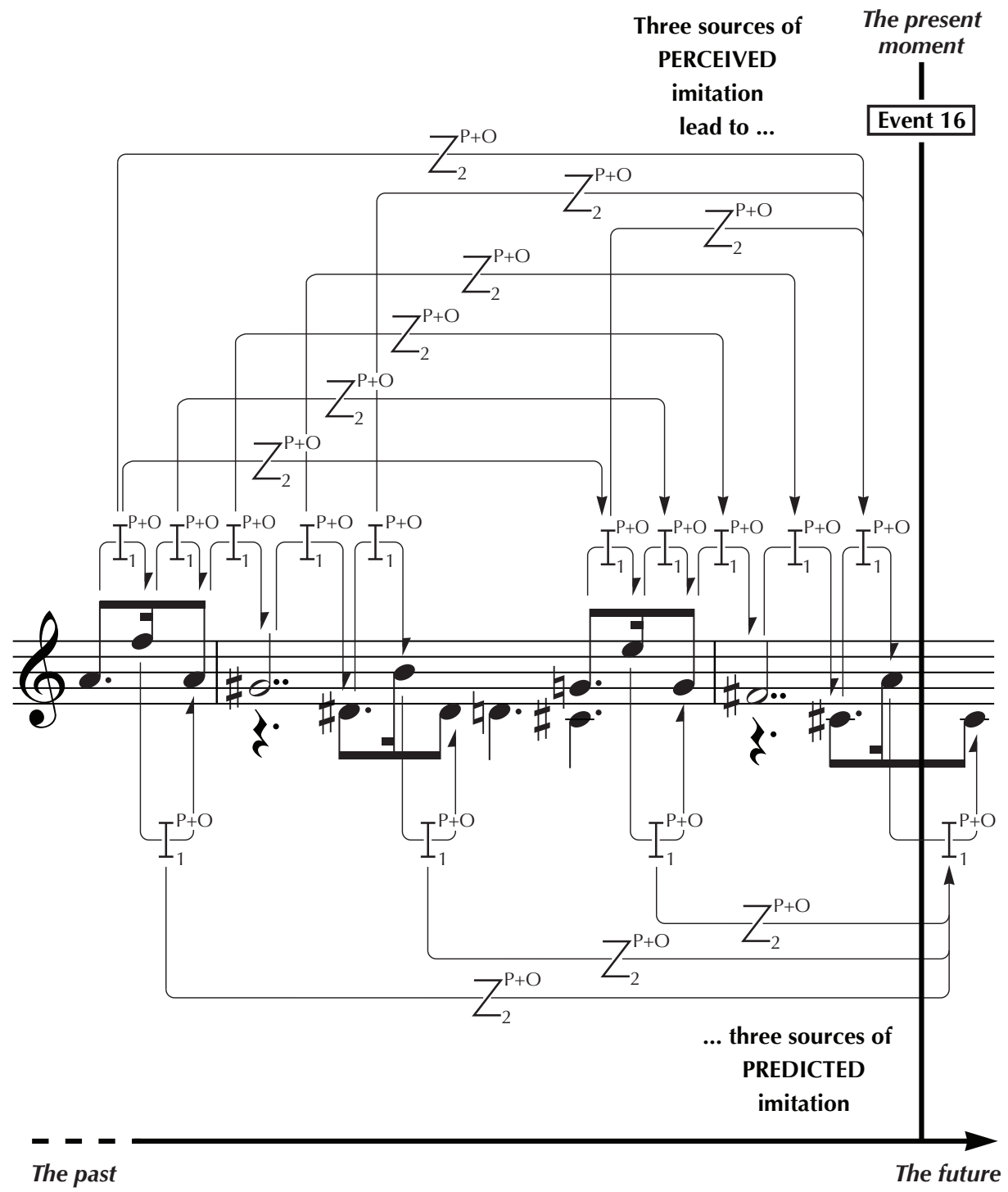

Fig. 21. The complex network of expectations thought to pertain to Event 16 of Romantic Rollercoaster.

And so the pattern of implications continues; the numbers of between-group zygonic relationships (theoretically) pertaining to each note are shown Figure 13. Note that there are two passages (in bars 8-9 and 16-17) where prediction occurs via inversion (Figure 22). 


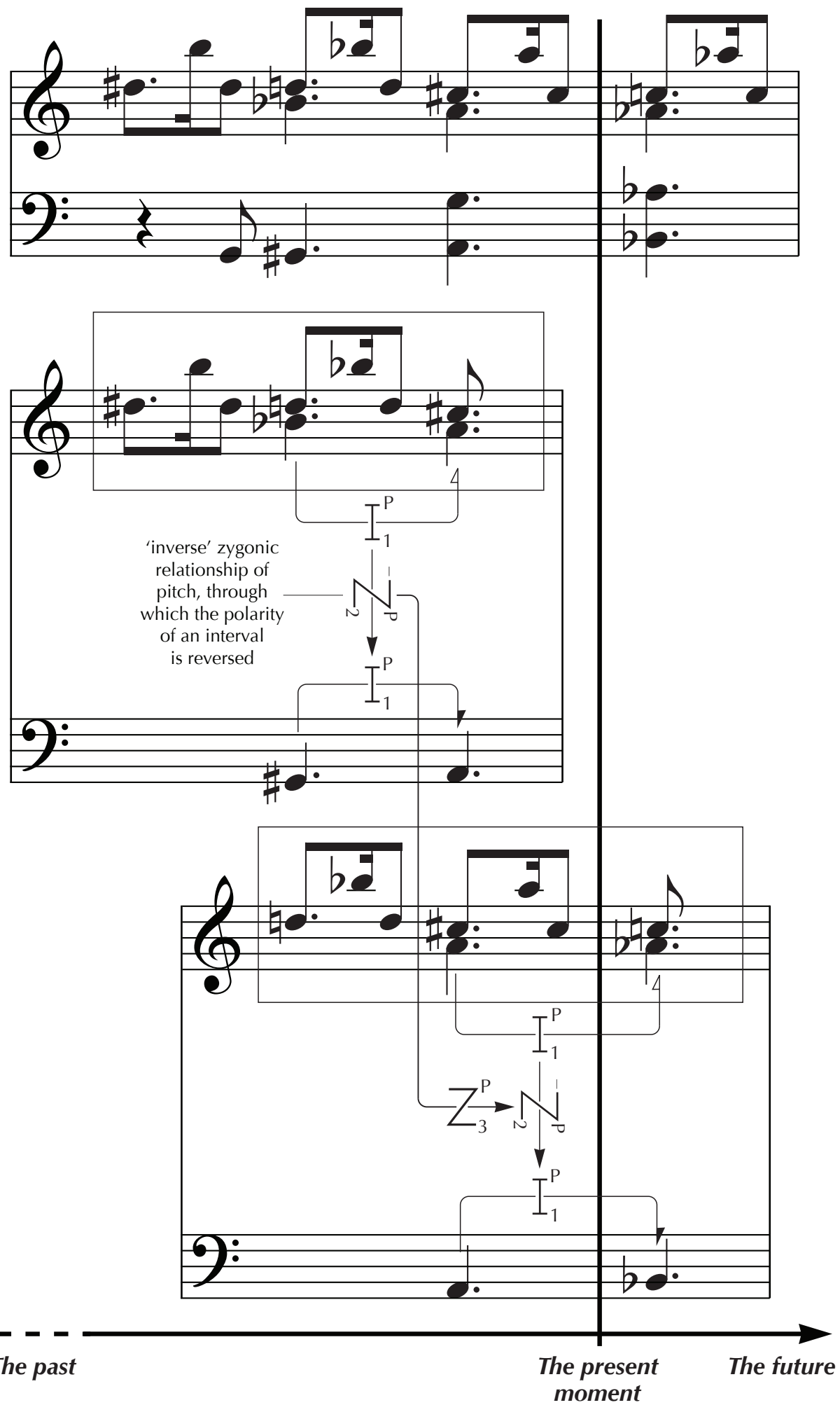

Fig. 22. Expectation via inversion in bar 8 of Romantic Rollercoaster. 
On four occasions, the within-group model of zygonic implication predicts continuations that do not actually occur. These are marked with asterisks in Figure 13. A detailed example is provided in Figure 23.

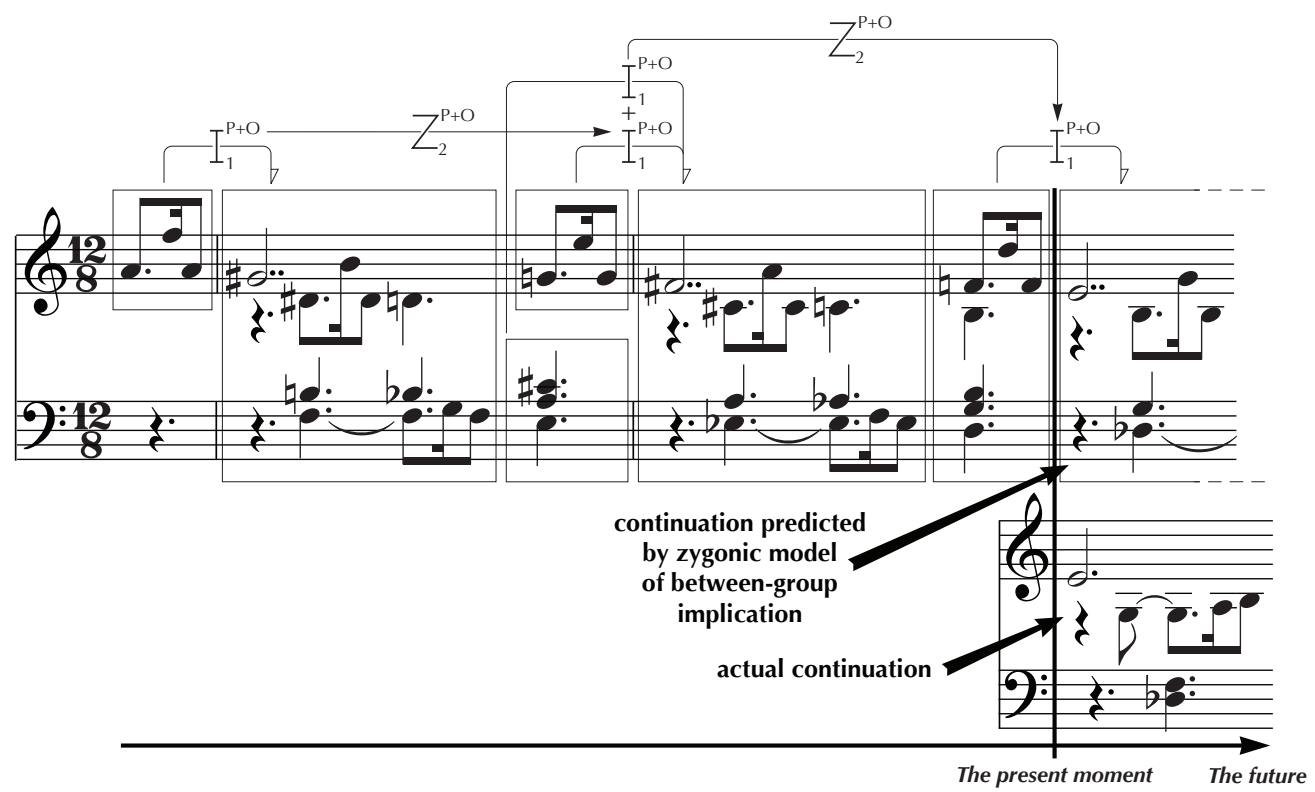

Fig. 23. An example of the zygonic model implying a continuation not found in Romantic Rollercoaster.

Finally, although one of the objectives in writing Romantic Rollercoaster was to minimise (if not eliminate) within-group and schematic implication (see Figure 1), to avoid potential contamination of expectations generated between groups, there are occasions when the more fundamental aim of having the music "make sense" on an intuitive level caused these experimentally (though not musically) anomalous patterns to occur. The most powerful examples occur in bars 8-9 and 16-17, which utilise simultaneous chromatic ascent and descent (see Figure 24). As we have seen, these regular patterns of change can also be heard as stemming from between-group implications (Figure 22), and it may be that the within-group structures reinforce the sense of expectation derived between groups, thereby skewing the probabilities with which Derek was able to anticipate what was going to occur next. 

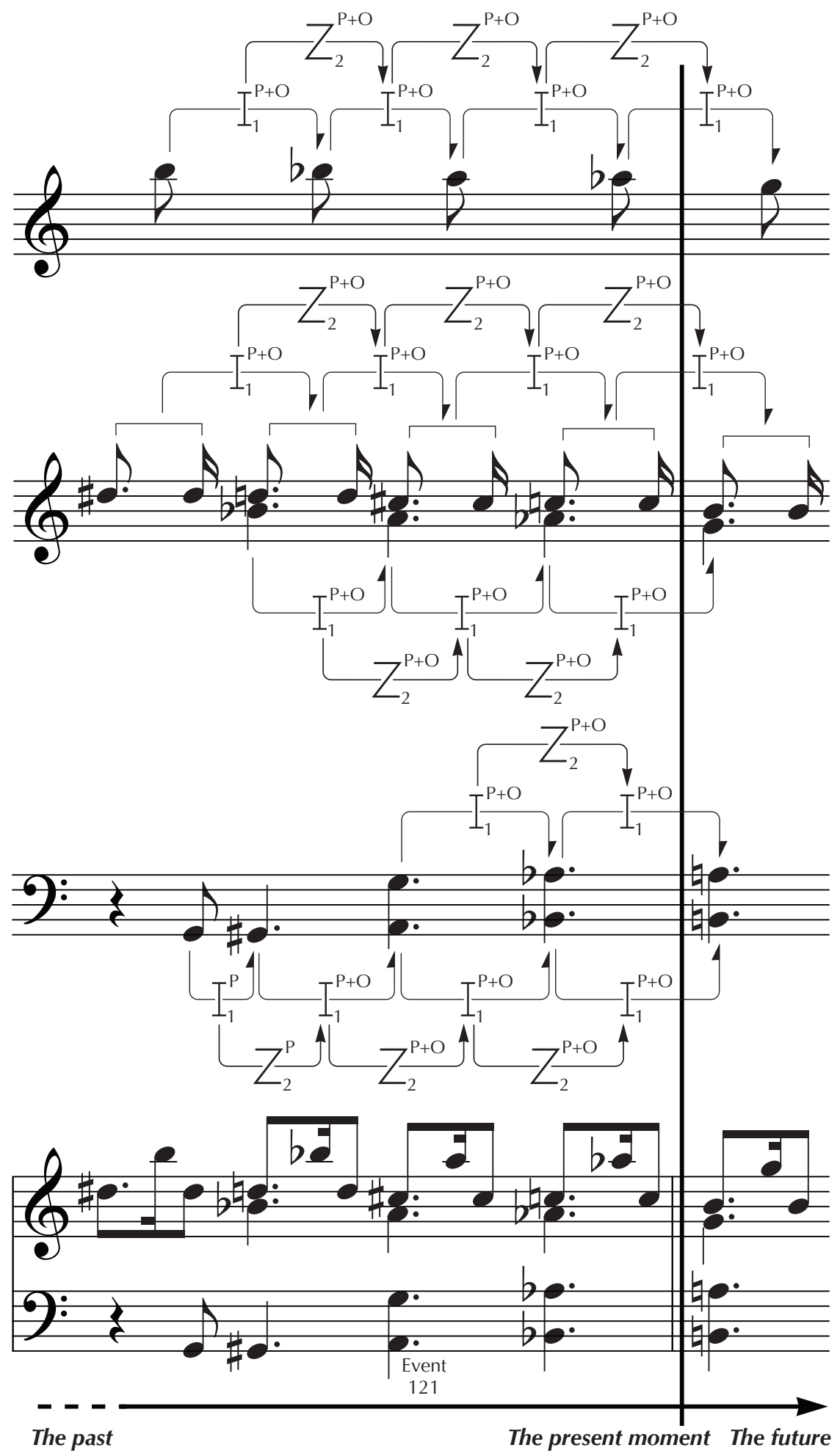

Fig. 24. Within-group implications that were incidental to the design of Romantic Rollercoaster.

On other occasions, within-group patterning exists in the absence of between-group organisation, as in bar 5, where chromatic scales again feature. These, we can assume, may lead to false positive results. Similarly, in bar 8 , the chord on the second beat (comprising, from the bottom up, G\#, $\mathrm{B}^{\mathrm{b}}$ and $\mathrm{D}$ ) could be heard schematically as an 
Italian 6th chord in D minor, whereby the G\# would have a perceived tendency to rise to an A, and the $\mathrm{B}^{\mathrm{b}}$ and $\mathrm{D}$ to fall to $\mathrm{A}$ and $\mathrm{CA}$. If Derek detected these propensities to descend, they would reinforce the between-group implications present in the right hand parts, while in the left hand, the rise from G\# to A would indicate a movement not implied between groups. Clearly, an awareness of these potentially contaminating factors was felt to be important in the evaluation of the results, and will be discussed in the analysis that follows.

\section{DEREK'S FIRST ATTEMPT AT PLAYING ALONG WITH ROMANTIC ROLLERCOASTER}

\section{Preparation of stimulus and equipment used}

Prior to the Derek's first session, Romantic Rollercoaster was performed on the same Yamaha CP300 Stage Piano as the chords used for the preliminary experiment had been, and recorded in audio and MIDI format using the same hardware and software. From the point of view of ecological validity, it was important that the stimulus was created in this way, to sound as musically natural as possible, and featuring the complex patterns of rubato and dynamics that characterise live performance, even though this meant that measuring the inter-onset intervals between what Derek heard and what he produced was a more complex task than might otherwise have been the case.

Again, Derek's responses were captured on a Korg SP-200 88 note touch-sensitive hammer action keyboard in the same way as before. Additionally, a video recording of Derek's hands on the keyboard was made using a Vivitar DVR 985HD camcorder. The data gathered in MIDI format by REAPER were converted into CSV (CommaSeparated Values) format and analysed using Microsoft Excel (2010) and IBM SPSS Statistics, Version 19.

\section{Procedure}

The session took place in a quiet room at the University of Roehampton. Derek was invited to orient himself in relation to the keyboard, and was informed that he would hear a new piece of music that he should play along with as best he could. Afterwards, he was thanked but no comment was made as to how well he had performed the task (though the researchers' initial impression was that he had done remarkably well). Derek's playing was recorded with a temporal granularity of $0.0005 \mathrm{~s}$. For the purposes of analysis, the data were subsequently rounded to the nearest $0.01 \mathrm{~s}$.

\section{Results, analysis and discussion}

Two representative excerpts from the full set of data are shown in Figures 25, 26 and 28. Excerpt 1 extends from the beginning of Romantic Rollercoaster to the first note of bar 3. Excerpt 2 comprises bars 7 and 8 and the first beat of bar 9. In Table 2, events in the stimulus are numbered in column 1 according to their onset time, gauged from the start of the first note, which is deemed to occur at 0 seconds. For reference, note names appear in column 3 , and their onset and offset times, rounded to the nearest $100^{\text {th }}$ of a second, in columns 5 and 6 . The expectancy rating of each, which represents the number of inter-group zygonic relationships through which a pitch can be considered to be derived (see Figure 13), is shown in column 4. 
Table 2. The pitch, onset and offset data from two excerpts of Romantic Rollercoaster and Derek's response to it.

Excerpt 1

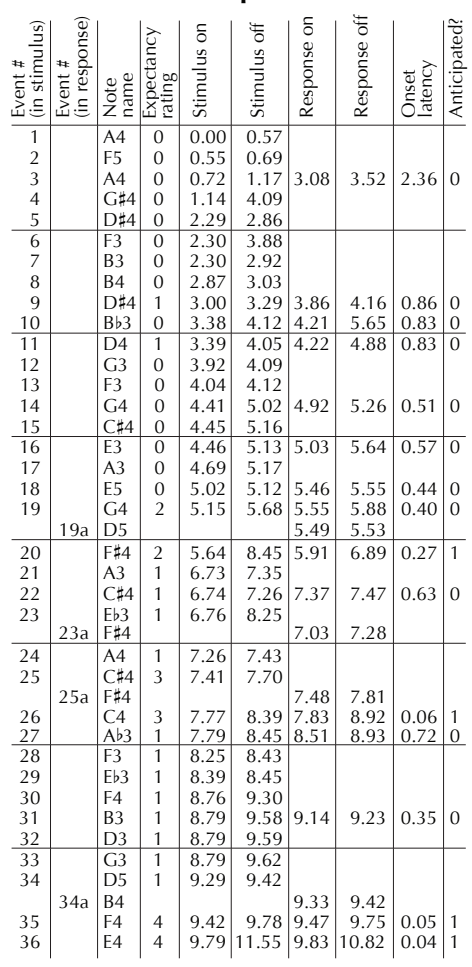

Excerpt 2

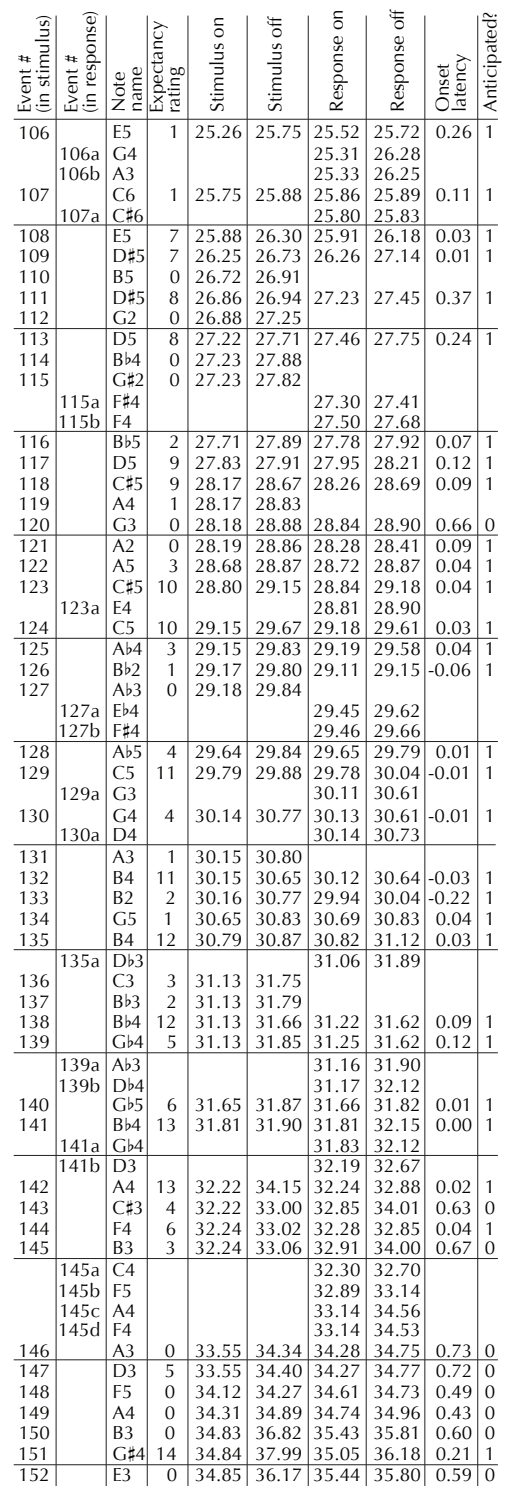

Where Derek's responses can be matched to notes occurring in the stimulus, their onsets and offsets are recorded in columns 7 and 8 respectively. The criterion for matching is that a given response can reasonably be thought to be derived from an identical pitch in the stimulus. Beyond this, the chief determinant of derivation is onset latency. Generally speaking, only responses whose onsets occur $\pm 1 \mathrm{~s}$ from the commencement of the same pitch in the stimulus are regarded as corresponding (although an exception is made for the first note of Derek's response, which occurs $2.36 \mathrm{~s}$ after its equivalent in the stimulus). Where duplication occurs, only the temporally most adjacent response is taken into consideration. 
Matched notes are scored according to the assumed nature of their genesis. Those occurring $\pm 0.4 \mathrm{~s}$ from the stimulus onset (see Figure 10) are regarded as likely to have been generated through structural anticipation, and score 1 (column 9). Responses that occur outside this timeframe are either considered to have been derived echoically (in the case of those that appear $>0.4 \mathrm{~s}$ after the corresponding note in the stimulus) or by chance (those that were played $<-0.4 \mathrm{~s}$ before their potential source of derivation) and score 0 . On two occasions, pitches occur in the wrong octave, one of which (event 31) is within the $0.4 \mathrm{~s}$ threshold, though this is also deemed to score 0 .

There are four instances in Excerpt 1, and 19 in Excerpt 2, of Derek playing notes that have no direct correlates in the stimulus (their potential raisons d'être are considered below), and these are intercalated between entries of stimulus events listed in the tables according to their onset times (see column 2).

Figures 25 and 28 represent an attempt illustrate the musical effect of these numerical data using enhanced stave notation. In each case, the stimulus and Derek's response are shown on different systems. The stimulus is notated as it was in the score used for performance (Figure 13), but, additionally, the temporal attributes of notes are shown precisely in the horizontal dimension, using red lines to indicate points of onset and offset, and (therefore) duration. The onset times are each reinforced with the left edge of the note-head concerned. Vertical lines mark out intervals of $0.4 \mathrm{~s}$ for reference, aligned between systems. In the case of Derek's response, the representation of rhythm was sometimes problematic since, particularly in Excerpt 1, conventional indications of duration were unable to capture consistently the complexity of the micro-timings that occurred, and so symbols were chosen that intuitively offered the best fit on a case-by-case basis. This notation should, anyway, be treated only as a guide, since precise temporal data are shown using the procedure of horizontal red lines. Presumed echoic imitation is displayed in green in both stimulus and response; anticipatory notes and the relationships between them are shown in purple. All others are black. The overall result is a hybrid of conventional and graphic notation, annotated with zygonic analysis, which is intended to offer a sense of the unfolding musical narrative.

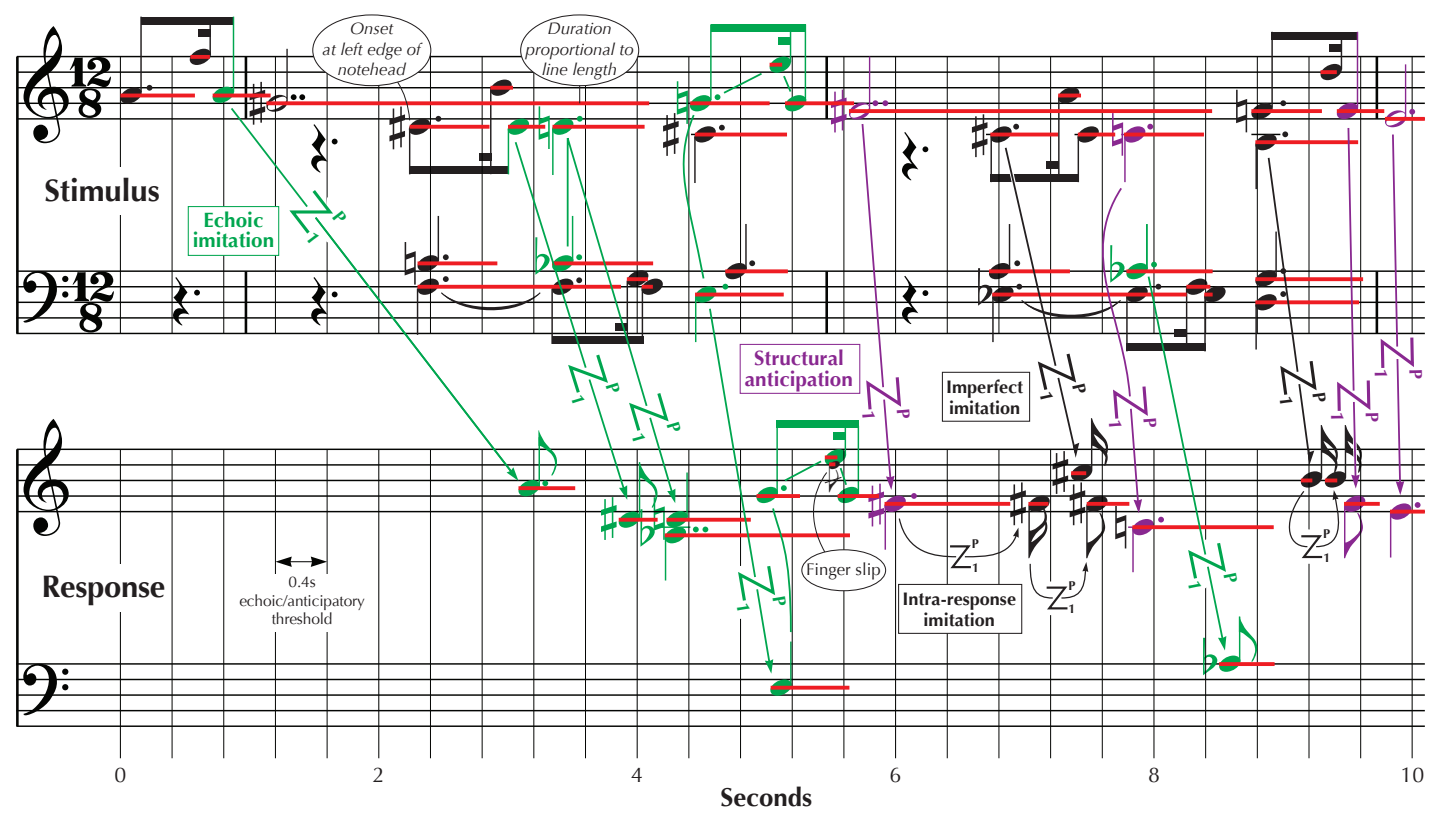

Fig. 25. Excerpt 1, stimulus and response with analysis of echoic/anticipatory imitation.

While the whole task was of playing along with Romantic Rollercoaster while listening to it for the first time was difficult (and far beyond the capacity of most pianists), the beginning was particularly challenging, as Derek had no idea of what he was about to hear, and so had no knowledge yet of an emerging tonal structure, or a sense of tessitura, or of a metrical framework, or even an awareness of tempo - general constraints operating in the dimensions of pitch and time that would subsequently facilitate prognostication of a more specific type made possible by between-group repetition and transformation (see Figure 1).

As the analysis in Figure 15 shows, none of the opening eight notes was predictable. Hence the best Derek could have done was to have imitated these echoically. However, the rate at which certain notes followed one another, such as the leap from F5 to A4 in the opening anacrustic group, which occurs in $0.17 \mathrm{~s}$, faster than Derek's reaction time (see Figure 11), meant that some overlap between notes in the stimulus and response that were 
sequentially out of kilter was inevitable. That is, in order to succeed in echoic imitation, Derek would have to register, store and retrieve two separate strands of music in working memory, that would be more or less similar (according to Derek's accuracy of reproduction), but that would in any case be operating in different time-frames and with likely interference in the domain of pitch too. Moreover, at the point where structural anticipation became possible, we surmised that there would either be a hiatus in the response, in which Derek "caught up" with the stimulus suddenly (perhaps by omitting material), or a temporal "shifting up a gear", whereby inter-onset intervals and durations were shortened. Conversely, there would need to be a pause in proceedings at the points where structural anticipation was no longer possible, and Derek had to rely once more on the immediate imitation of what he had heard.

How such musically counterintuitive dual processing would function cognitively was not clear, although, as well shall see, insights could subsequently be gleaned from the patterns of systematic and apparently random errors that Derek made. It is of interest to note that some theorists working in the domain of simultaneous interpretation have suggested that this, in some ways comparable, task may be managed dichotically, involving the rapid switching of attention between the two (input and output) streams (see, for example, Monsell, 1987; Lambert, 1989), whereas others (see Setton, 1999, p. 15) have proposed a sharing of resources, following the mental models theory of Johnson-Laird (1983), following the thinking of Craik (1943). As we shall see, Derek's efforts to play along with Romantic Rollercoaster seem to indicate the presence both shared and discrete cognitive processing pertaining to the stimulus and response.

In fact, the first, striking feature of Derek's response is the delay between the onset of the stimulus and the first note that he plays (around three seconds). Even if we assume imitation from the second A4 (rather than the first - see Figure 25), this still represents a latency of $2.36 \mathrm{~s}$, which is around three times slower than Derek's typical reaction time in reproducing individual chords (see Figure 11), and can likely be attributed to the interference effect of the sequence of five sounds (three temporal events) in the stimulus that occur before he responds.

Derek's second note (D\#4) occurs $0.78 \mathrm{~s}$ after the first, whose model in the stimulus appears at the same time as his initial A4. Here, then, is an early example of Derek's ability to process stimulus and response simultaneously yet discretely within a shared pitch framework. The interval between the D\#4 in Romantic Rollercoaster and Derek's imitation of it is $0.86 \mathrm{~s}$, a reduction of $1.5 \mathrm{~s}$ on delay between the A4s, something which he achieves by omitting five notes from the stimulus.

The $\mathrm{D \# 4}$ is the first note that could have been predicted, though, as we have seen, Derek does not anticipate it, presumably because the task at this point was overwhelming. Instead, his echoic approach continues with virtually the same latency $(0.83 \mathrm{~s})$ in respect of the following D4 (which was also theoretically predictable) and the $\mathrm{B}^{\mathrm{b}_{3}}$ that occurs at the same time (which was not). Derek's immediate imitation of the stimulus becomes more assured over the next three events, which he manages with only chordal omissions of the inner parts (A3 and C\#4), and with a more or less consistent reduction in the time lag between stimulus and response through a shortening of inter-onset intervals. In fact, Events 18 (E5 - not predictable) and 19 (G4 - predictable), are on the borderline of what Derek could manage echoically, and, with Event 20 (F\#4 - predictable), the latency drops to 0.27, and he achieves his first structural anticipation. The trend of decreasing latency is to all intents and purposes linear from Event 9 (see Figure 26), hinting at the co-existence of two discrete temporal frameworks in Derek's working memory: the relatively constant beat of the stimulus, and his accelerating response. 


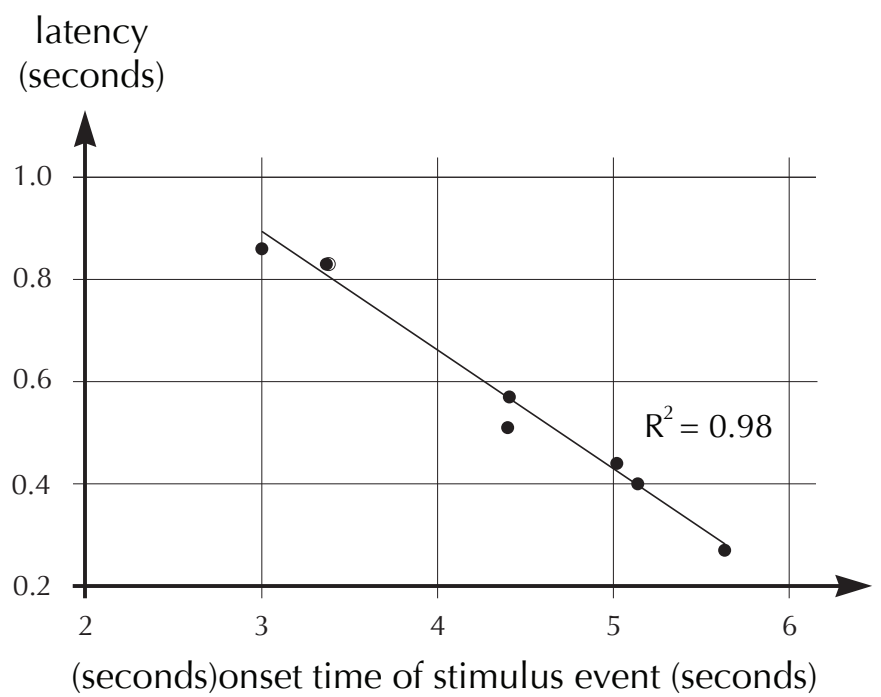

Fig. 26. Decreasing latency leading to Derek's first structural anticipation.

Although Events 20-24 are theoretically predictable (each on the basis of one zygonic relationship), Derek apparently fails to discern the inter-group pitch structure concerned, and none is anticipated. The . Do rhythm, now in its fourth appearance, is, however, predicted, although the first note is late, shown in stimulus inter-onset intervals of $0.67,0.15$ and $0.36 \mathrm{~s}$, and response intervals of $0.34,0.11$ and $0.35 \mathrm{~s}$. This rhythmic motif is populated with the pitches F\#4, C\#5 and F\#4, echoed from the stimulus (though the $\mathrm{C \#}$ is displaced by an octave), thus maintaining the melodic contour of the original. It may be this preservation of contour that prevents Derek from anticipating Event $25(\mathrm{CH})$, which is predictable from three sources. The same expectancy rating pertains to Event 26, which Derek does anticipate, with the most precise timing yet (a lag of just 0.06s). Event 27 (Ab3), which occurs at the same time as Event 26, in the middle of the texture, is less strongly structurally indicated (stemming from only one source), and is echoed markedly later (with a latency of $0.72 \mathrm{~s}$ ). This suggests that Derek disaggregates the chord's elements differentially according to their predictability.

The difference between Derek's success in anticipating events that are more strongly (as opposed to weakly) predicted manifests itself with even greater clarity in relation to the following eight notes: Events 28 to 34 , with expectancy ratings of 1, are neither echoed nor anticipated, while Events 35 and 36 (rated 4) are both executed with some precision in relation to the stimulus (with latencies of only $0.05 \mathrm{~s}$ and $0.04 \mathrm{~s}$ respectively).

In summary, the stimulus Excerpt 1 comprises 36 events, of which Derek omits 21 (58\%), anticipates four $(11 \%)$ and echoes $11(31 \%)$. He adds a further four notes $(11 \%)$ - see Figure 27. 

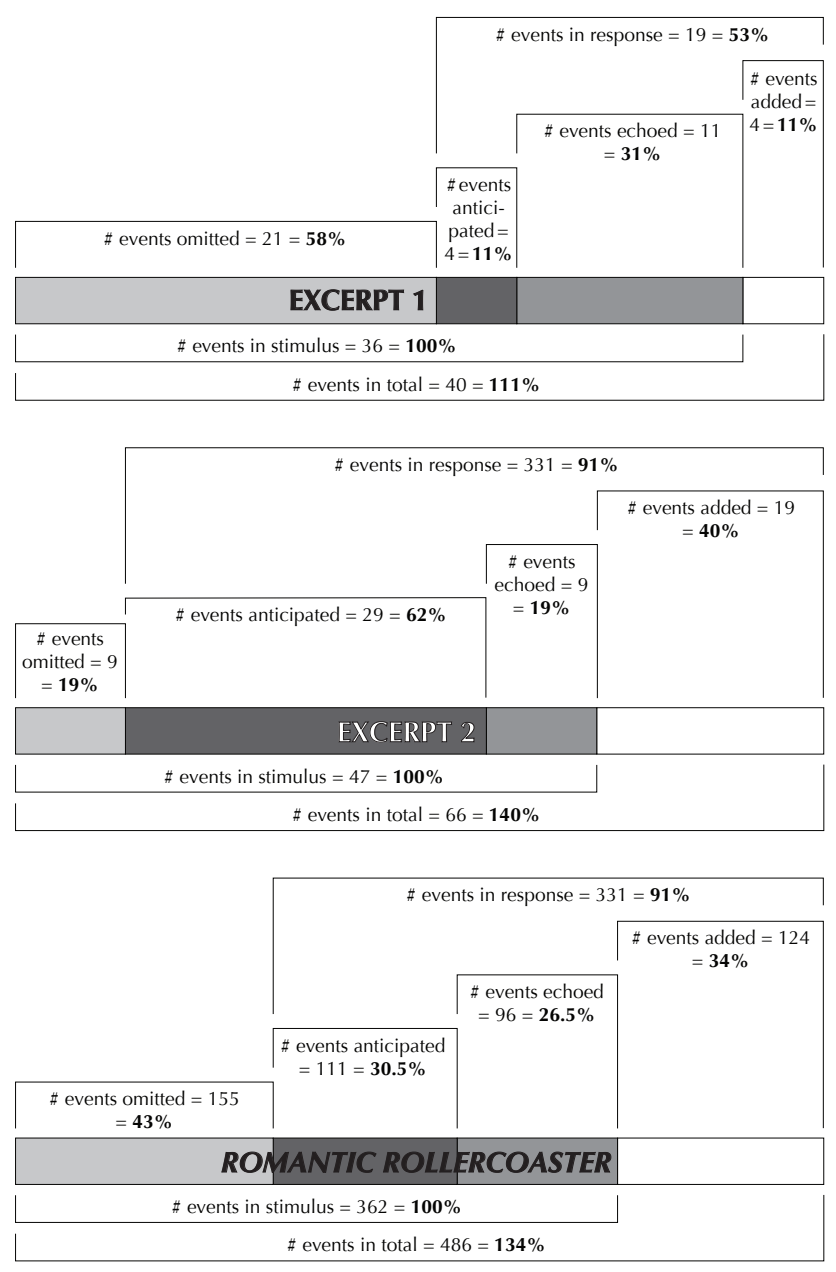

Fig. 27. General statistics pertaining to Derek's response to Romantic Rollercoaster.

Excerpt 2 occurs four bars (15 seconds) later - see Figure 28. Here, Derek is much more successful in anticipating events, managing 29 out of the 49 that are present $(62 \%)$. He omits only nine notes (19\%), and echoes the same number. He makes considerably more additions, however: 19, amounting to $40 \%$ (see Figure 27 ). How do we account for these changes?

This passage is, on the whole, very much more predictable than Excerpt 1, particularly the melody line, comprising 22 notes, with a mean expectancy rating of 7.4. Moreover, the succession of three-note groups 5 are locked into a pattern of regular semitonal descent (see Figure 24). Two events - the B5 that is second in the series, and the tied A4 near the end - are of particular interest, since they run counter to the inter-group expectations that are set up, and in both cases Derek anticipates what is structurally implied (but does not occur). In the first case, he sustains the D\#4 (and omits the B5), following the pattern of bars 5 and 6 . In the second, he continues with the - D. figure, substituting it for the sustained A4 that actually features in Romantic Rollercoaster in bar 8.3. All the other melody notes that are predicted (and occur), Derek anticipates correctly.

The majority of notes that are added are in the inner parts, filling out the chords through realizing the harmonic implications of the melody (as Derek heard them). These additions form a sequence in their own right, taking on a musical logic of their own that was not present in the stimulus. In the left hand, changes are made that reflect this new harmonic environment: the $\mathrm{A} 3$ at the beginning of 8 is replaced with a $\mathrm{G}$, for example, and the $\mathrm{C} 3$ on the following beat becomes a $\mathrm{D} b$. It is of particular interest to note that Derek anticipates the A2 in the bass line at bar 7.3 despite the lack of inter-group implication (see Figure 13). His success in predicting this note may instead be attributable to the schematically-induced expectations arising from the harmony on the previous (second) beat of 
the bar, which gives the sense of an Italian $6^{\text {th }}$ in D minor - that is, a chord of Bb major with G\# in the bass, constituting a chromatic inflection that would typically rise to the dominant (A).

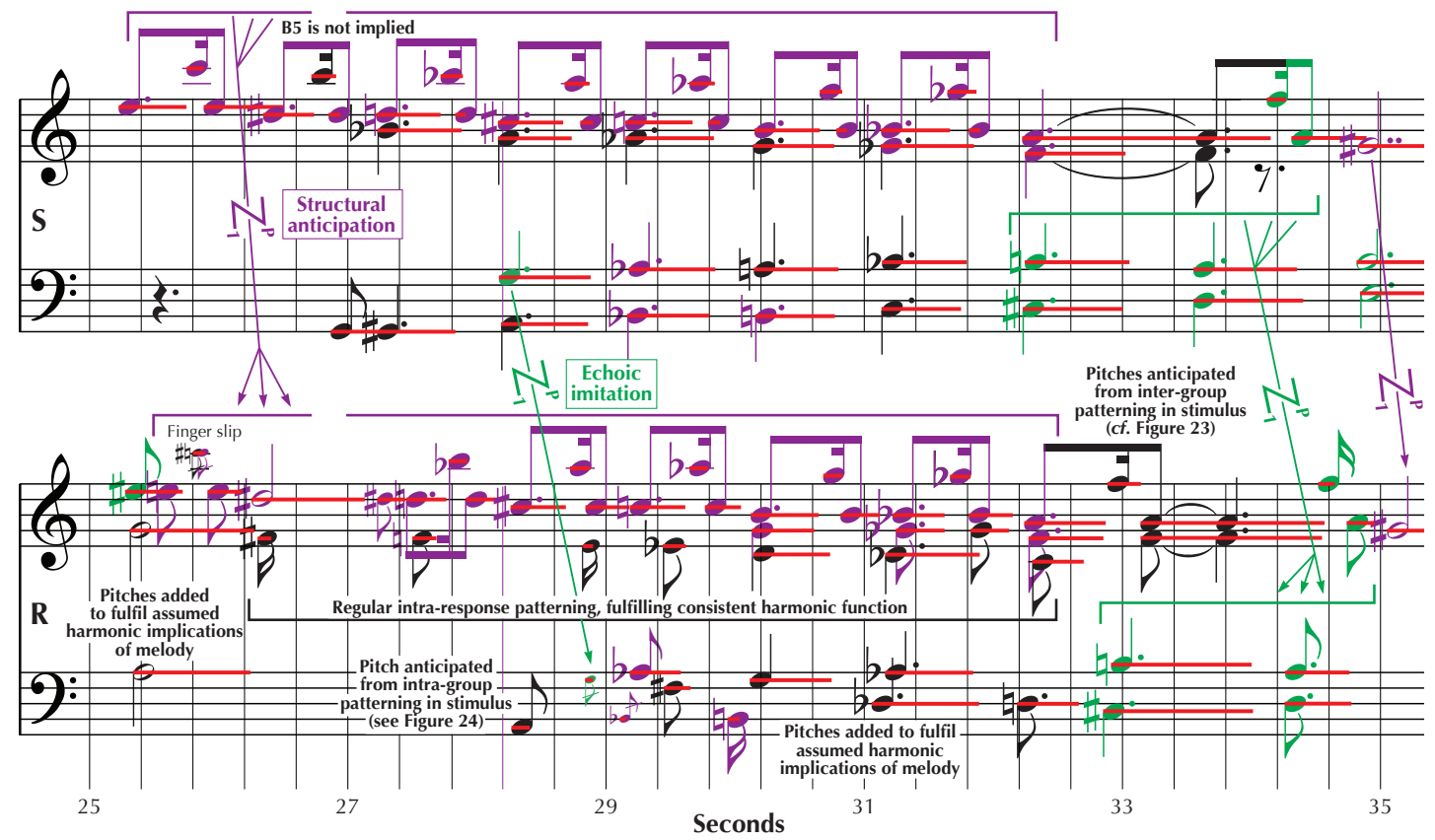

Fig. 28. Excerpt 2, stimulus and response with analysis of echoic/anticipatory imitation.

These accounts give some idea of the complex cognitive processing that Derek's musical shadowing entails. We now move on to consider his response to Romantic Rollercoaster as a whole. Table 3 shows the full data set, which is summarized graphically in Figure 27. Of the 362 events in the stimulus, Derek omits 155 (43\%), and adds 124 (34\%). He echoes 96 notes (26.5\%) and anticipates $111(30.5 \%)$, which represents $41 \%$ of those that, according to the zygonic model, are predictable (271). The data enable us to test the Hypothesis 1 set out above - that there will be a systematic decrease in the number of errors as the structure "strengthens" (with more implicative relationships), in accordance with the equation

$$
P\left(\mathrm{E}_{\mathrm{c}}\right)_{\mathrm{n}}=1-\left(1-P\left(\mathrm{E}_{\mathrm{c}}\right)_{1}\right)^{\mathrm{n}}
$$

where $P\left(\mathrm{E}_{\mathrm{c}}\right)_{\mathrm{n}}$ is the probability of an event being anticipated correctly, given that the number of inter-group zygonic relationships through which it can be predicted is " $n$ ". A comparison of hypothesized and actual values of $P\left(\mathrm{E}_{\mathrm{c}}\right)_{\mathrm{n}}$ (for reference, up to $n=14$; twice Miller's 7) is shown in Table 4, where \#Z is the number of predictive zygonic relationships, and $P\left(\mathrm{E}_{\mathrm{c}}\right)_{1}=0.18$ (the proportion of notes predictable through one zygonic relationship that Derek anticipated correctly). This ratio accords with the desirability of $P\left(\mathrm{E}_{\mathrm{c}}\right)_{1} \approx 0.2$ (see Figure 9). The data are represented graphically in Figure 29. 
Table 3. Data pertaining to Derek's response to Romantic Rollercoaster.

\begin{tabular}{|c|c|c|c|c|c|c|}
\hline 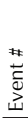 & 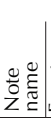 & 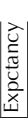 & 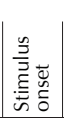 & 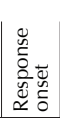 & 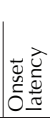 & \\
\hline 1 & A4 & 0 & \begin{tabular}{|l|}
0.00 \\
\end{tabular} & & & \\
\hline 2 & F5 & 0 & 0.55 & & & \\
\hline 3 & A4 & 0 & 0.72 & 3.08 & 2.36 & 0 \\
\hline 4 & $G \# 4$ & 0 & 1.14 & & & \\
\hline 5 & $\mathrm{D} \sharp 4$ & 0 & 2.29 & & & \\
\hline 6 & F3 & \begin{tabular}{|l|} 
\\
\end{tabular} & 2.30 & & & \\
\hline 7 & B3 & 0 & 2.30 & & & \\
\hline 8 & B4 & 0 & 2.87 & & & \\
\hline 9 & $\mathrm{D} \sharp 4$ & 1 & 3.00 & 3.86 & 0.86 & 0 \\
\hline 10 & $\mathrm{Bb} 3$ & 0 & 3.38 & 4.21 & 0.83 & 0 \\
\hline 11 & D4 & 1 & 3.39 & 4.22 & 0.83 & 0 \\
\hline 12 & G3 & 0 & 3.92 & & & \\
\hline 13 & F3 & 0 & 4.04 & & & \\
\hline 14 & G4 & 0 & 4.41 & 4.92 & 0.51 & 0 \\
\hline 15 & $C \sharp 4$ & 0 & 4.45 & & & \\
\hline 16 & E3 & 0 & 4.46 & 5.03 & 0.57 & 0 \\
\hline 17 & A3 & 0 & 4.69 & & & \\
\hline 18 & E5 & 0 & 5.02 & 5.46 & 0.44 & 0 \\
\hline 19 & G4 & 2 & 5.15 & 5.55 & 0.40 & 0 \\
\hline 20 & $\mathrm{~F} \# 4$ & 2 & 5.64 & 5.91 & 0.27 & 1 \\
\hline 21 & A3 & 1 & 6.73 & & & \\
\hline 22 & $C \sharp 4$ & 1 & 6.74 & 7.37 & 0.63 & 0 \\
\hline 23 & $\mathrm{~Eb} 3$ & 1 & 6.76 & & & \\
\hline 24 & A4 & 1 & 7.26 & & & \\
\hline 25 & $C \sharp 4$ & 3 & 7.41 & & & \\
\hline 26 & C4 & 3 & 7.77 & 7.83 & 0.06 & 11 \\
\hline 27 & $A b 3$ & 1 & 7.79 & 8.51 & 0.72 & 0 \\
\hline 28 & F3 & 1 & 8.25 & & & \\
\hline 29 & $\mathrm{~Eb} 3$ & 1 & 8.39 & & & \\
\hline 30 & F4 & 1 & 8.76 & & & \\
\hline 31 & B3 & $\begin{array}{ll}1 \\
\end{array}$ & 8.79 & 9.14 & 0.35 & 0 \\
\hline 32 & D3 & 1 & 8.79 & & & \\
\hline 33 & G3 & 1 & 8.79 & & & \\
\hline 34 & D5 & 1 & 9.29 & & & \\
\hline 35 & F4 & 4 & 9.42 & 9.47 & 0.05 & 1 \\
\hline 36 & E4 & 4 & 9.79 & 9.83 & 0.04 & 1 \\
\hline 37 & G3 & 0 & 10.47 & & & \\
\hline 38 & F3 & 0 & 10.84 & & & \\
\hline 39 & $\mathrm{Db} 3$ & 2 & 10.84 & & & \\
\hline 40 & A3 & 0 & 11.36 & & & \\
\hline 41 & B3 & 0 & 11.50 & & & \\
\hline 42 & F4 & 0 & 11.85 & 12.33 & 0.48 & 0 \\
\hline 43 & $A b 3$ & 0 & 12.47 & & & \\
\hline 44 & D3 & 0 & 12.84 & & & \\
\hline 45 & $\mathrm{Bb} 2$ & 0 & 12.84 & & & \\
\hline 46 & $\mathrm{Bb} 3$ & 1 & 13.34 & & & \\
\hline 47 & C4 & 1 & 13.48 & & & \\
\hline 48 & E2 & 0 & 13.82 & & & \\
\hline 49 & E3 & 0 & 13.82 & & & \\
\hline 50 & F4 & 0 & 14.78 & 15.32 & 0.54 & 0 \\
\hline $5 \overline{1}$ & $\mathrm{~A} b 3$ & 0 & 14.78 & 15.18 & 0.40 & 0 \\
\hline 52 & $\mathrm{C} 4$ & 0 & 14.78 & 15.23 & 0.45 & 0 \\
\hline 53 & D3 & 0 & 14.79 & & & \\
\hline 54 & $\mathrm{~F} \# 4$ & 0 & 15.22 & 15.73 & 0.51 & 0 \\
\hline 55 & $C \# 3$ & 0 & 15.23 & 15.74 & 0.51 & 0 \\
\hline 56 & $\mathrm{C} \# 4$ & 0 & 15.23 & & & \\
\hline 57 & A3 & 0 & 15.23 & 15.75 & 0.52 & 0 \\
\hline 58 & G4 & 0 & 15.36 & 15.86 & 0.50 & 0 \\
\hline 59 & $\mathrm{~B} b 3$ & 0 & 15.36 & 15.89 & 0.53 & 0 \\
\hline 60 & E3 & 0 & 15.37 & & & \\
\hline 61 & C3 & 0 & 15.37 & & & \\
\hline 62 & D4 & 0 & 15.38 & 15.86 & 0.48 & 0 \\
\hline 63 & $G \# 4$ & 0 & 15.70 & 16.06 & 0.36 & 1 \\
\hline 64 & $\mathrm{D} \sharp 4$ & 0 & 15.71 & 16.09 & 0.38 & 1 \\
\hline 65 & B2 & 0 & 15.71 & & & \\
\hline 66 & B3 & 0 & 15.71 & 16.11 & 0.40 & 1 \\
\hline 67 & F3 & 0 & 15.72 & 16.12 & 0.41 & 0 \\
\hline 68 & $G \# 5$ & 0 & 17.12 & 17.62 & 0.50 & 0 \\
\hline 69 & E6 & 0 & 17.60 & 18.08 & 0.48 & 0 \\
\hline 70 & $G \# 5$ & 5 & 17.76 & 18.25 & 0.49 & 0 \\
\hline 71 & G5 & 5 & 18.16 & 18.50 & 0.34 & 1 \\
\hline 72 & Eb5 & 0 & 19.22 & 19.85 & 0.63 & 0 \\
\hline 73 & B4 & 0 & 19.24 & 19.65 & 0.41 & 0 \\
\hline 74 & F4 & 0 & 19.24 & 19.97 & 0.73 & 0 \\
\hline 75 & $\mathrm{Db} 4$ & 0 & 19.25 & 19.67 & 0.42 & 0 \\
\hline 76 & $\mathrm{~A} b 4$ & 0 & 19.27 & & & \\
\hline 77 & $A b 5$ & 0 & 19.75 & & & \\
\hline 78 & G5 & 0 & 19.90 & & & \\
\hline 79 & G4 & 0 & 20.25 & & & \\
\hline 80 & G5 & 0 & 20.25 & 20.61 & 0.36 & 1 \\
\hline 81 & $\mathrm{Bb} 4$ & 0 & 20.25 & 20.62 & \begin{tabular}{|l|}
0.37 \\
\end{tabular} & \\
\hline 82 & C4 & 0 & 20.25 & 20.65 & 0.40 & 1 \\
\hline 83 & E4 & 0 & 20.25 & & & \\
\hline 84 & E5 & 0 & 20.26 & 20.63 & 0.37 & 1 \\
\hline 85 & $A b 5$ & 0 & 20.77 & & & \\
\hline 86 & G5 & 1 & 20.93 & & & \\
\hline 87 & $F \# 5$ & 0 & 21.30 & 21.32 & 0.02 & \\
\hline 88 & D6 & 0 & 21.79 & & & \\
\hline 89 & $F=5$ & & 2193 & 2197 & 0,04 & \\
\hline 90 & $E=5$ & 6 & 2.93 & $\begin{array}{l}2 \\
22.93\end{array}$ & 0 & \\
\hline & & & & & & \\
\hline
\end{tabular}


Table 4 Comparison with the zygonic model of the ratio $\frac{\# \text { anticipated events }}{\# \text { events }}(\alpha)$ per expectancy rating.

\begin{tabular}{|c|c|c|c|c|}
\hline $\begin{array}{l}\# Z \text { (predictive } \\
\text { zygonic } \\
\text { relationships) }\end{array}$ & $\begin{array}{l}\text { \# events in Romantic } \\
\text { Rollercoaster }\end{array}$ & $\begin{array}{l}\# \text { events } \\
\text { anticipated } \\
\text { by Derek }\end{array}$ & $\begin{array}{l}\# \text { anticipated events } \\
\# \text { events } \\
=\alpha\end{array}$ & $\begin{array}{l}\text { predicted } \\
\alpha\end{array}$ \\
\hline 0 & 87 & 9 & 0.10 & 0.00 \\
\hline 1 & 110 & 20 & 0.18 & 0.18 \\
\hline 2 & 61 & 14 & 0.23 & 0.33 \\
\hline 3 & 26 & 6 & 0.23 & 0.45 \\
\hline 4 & 11 & 7 & 0.64 & 0.55 \\
\hline 5 & 6 & 4 & 0.67 & 0.63 \\
\hline 6 & 7 & 5 & 0.71 & 0.70 \\
\hline 7 & 3 & 3 & 1.00 & 0.75 \\
\hline 8 & 2 & 2 & 1.00 & 0.80 \\
\hline 9 & 3 & 3 & 1.00 & 0.84 \\
\hline 10 & 2 & 2 & 1.00 & 0.87 \\
\hline 11 & 2 & 2 & 1.00 & 0.89 \\
\hline 12 & 2 & 2 & 1.00 & 0.91 \\
\hline 13 & 2 & 2 & 1.00 & 0.93 \\
\hline
\end{tabular}

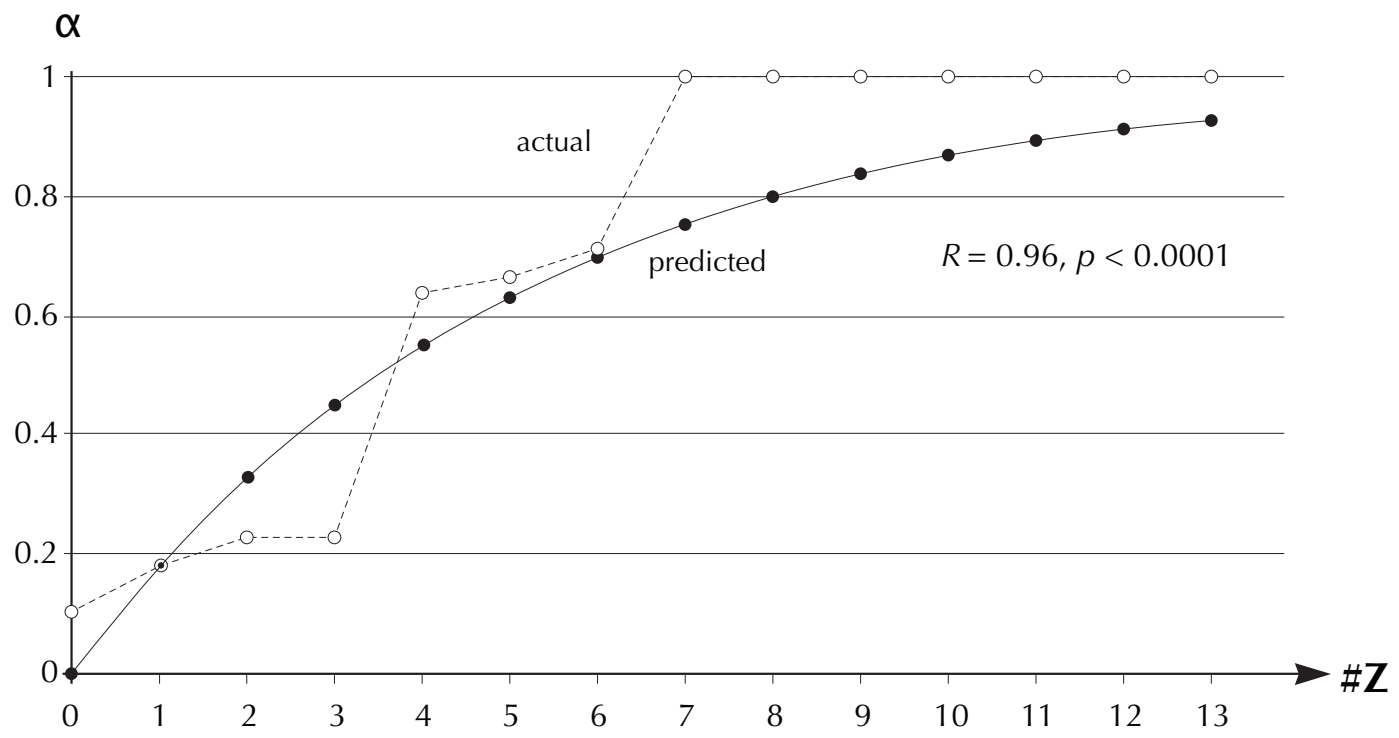

Fig. 29. Comparison of $\alpha$ (predicted) and $\alpha$ (actual).

Derek's responses and the model are highly correlated $\left(R^{2}=0.91\right)$, with only around $9 \%$ of the total variance unaccounted for. Note that there is a ceiling effect where $\# Z \geq 7$, which happens to be the point at which 
the limitations of working memory are assumed to kick in. That is to say, seven sources of prediction are (at least in the case of Derek's response Romantic Rollercoaster) sufficient to ensure successful anticipation of musical events, and, in terms of accurate prognostication, values of $\# Z>7$ are likely to be redundant in terms of the cognition of structure, since it is probable that the capacity of working memory will in any case be exceeded.

The data can be analysed in a number of other ways too, potentially offering a range of different insights into how Derek's musical mind works. Here the confines of space mean that it is possible only to mention one other finding, which relates to his differential treatment of pitches according to their relative position in the stimulus (and response) - in particular whether they are at the top of the texture, or the bottom, or somewhere between (comprising an inner part). By way of context, recall that, as part of the Fragments of Genius project, Mazzeschi (2014) investigated the chordal disaggregation abilities of six musical savants and 17 neurotypical advanced music students with AP, all of whom were fluent pianists. The research participants had to reproduce on a MIDI keyboard, as quickly and as accurately as they could, clusters of between four and nine notes that they heard played on the piano. Hence there is a certain similarity between this and the echoic aspect of the present investigation. Mazzeschi found that all the savants, and the six highest-scoring students, who together made up the 12 most successful subjects in the study, tended to reproduce the lowest notes of chords most consistently and the highest least reliably. Derek's results were, in this respect, typical (although he was by some margin the most successful of the 23 musicians overall). He omitted 0 notes from the bottom $(n=120,100 \%$ correct $), 17$ inner pitches $(n=440,96 \%$ correct) and 12 notes from the top ( $n=120,90 \%$ correct).

To calculate comparable scores for Derek's echoic responses in the Romantic Rollercoaster trial, it is necessary to weight pitches according to their structurally-determined probability of occurrence, since this has an impact on the likelihood of Derek imitating them - see Table 5. It is evident from the data presented that Derek's tendency not to echo (or anticipate) a pitch $(\varepsilon)$ is inversely related to its expectancy rating (\#Z), a trend that is highly correlated to his anticipation of events pitch $(\alpha)$ (to facilitate comparison, the values of $\varepsilon$ are inverted and normalised); see Figure 30.

Table 5 Derek's tendency not to echo a pitch $(\varepsilon)$ is inversely related to its expectancy rating (\#Z) and $\alpha$.

\begin{tabular}{|l|l|l|l|l|l|}
\hline $\begin{array}{l}\text { expectancy } \\
\text { rating }\end{array}$ & \# events & $\begin{array}{l}\text { \# events not } \\
\text { echoed } \\
\text { (or anticipated) } \\
=\text { \# ECH }\end{array}$ & $\begin{array}{l}\text { \# ECH } \\
\text { \# events }\end{array}$ & $\begin{array}{l}\mathbf{0 . 5 5}-\boldsymbol{\varepsilon} \\
\mathbf{0 . 5 5} \\
\text { (inversion and } \\
\text { normalisation) }\end{array}$ & \multirow{2}{*}{} \\
\hline 0 & 87 & 40 & 0.46 & 0.16 & 0.10 \\
\hline 1 & 110 & 58 & 0.53 & 0.04 & 0.18 \\
\hline 2 & 61 & 35 & 0.57 & -0.04 & 0.23 \\
\hline 3 & 26 & 14 & 0.54 & 0.02 & 0.23 \\
\hline 4 & 11 & 1 & 0.09 & 0.83 & 0.64 \\
\hline 5 & 7 & 1 & 0.14 & 0.74 & 0.57 \\
\hline 6 & 6 & 0 & 0 & 1 & 0.83 \\
\hline 7 & 3 & 0 & 0 & 1 & 1 \\
\hline 8 & 2 & 0 & 0 & 1 & 1 \\
\hline 9 & 3 & 0 & 0 & 1 & 1 \\
\hline 10 & 2 & 0 & 0 & 1 & 1 \\
\hline 11 & 2 & 0 & 0 & 1 & 1 \\
\hline 12 & 2 & 0 & 0 & 1 & 1 \\
\hline 13 & 2 & 0 & 0 & 1 & 1 \\
\hline
\end{tabular}




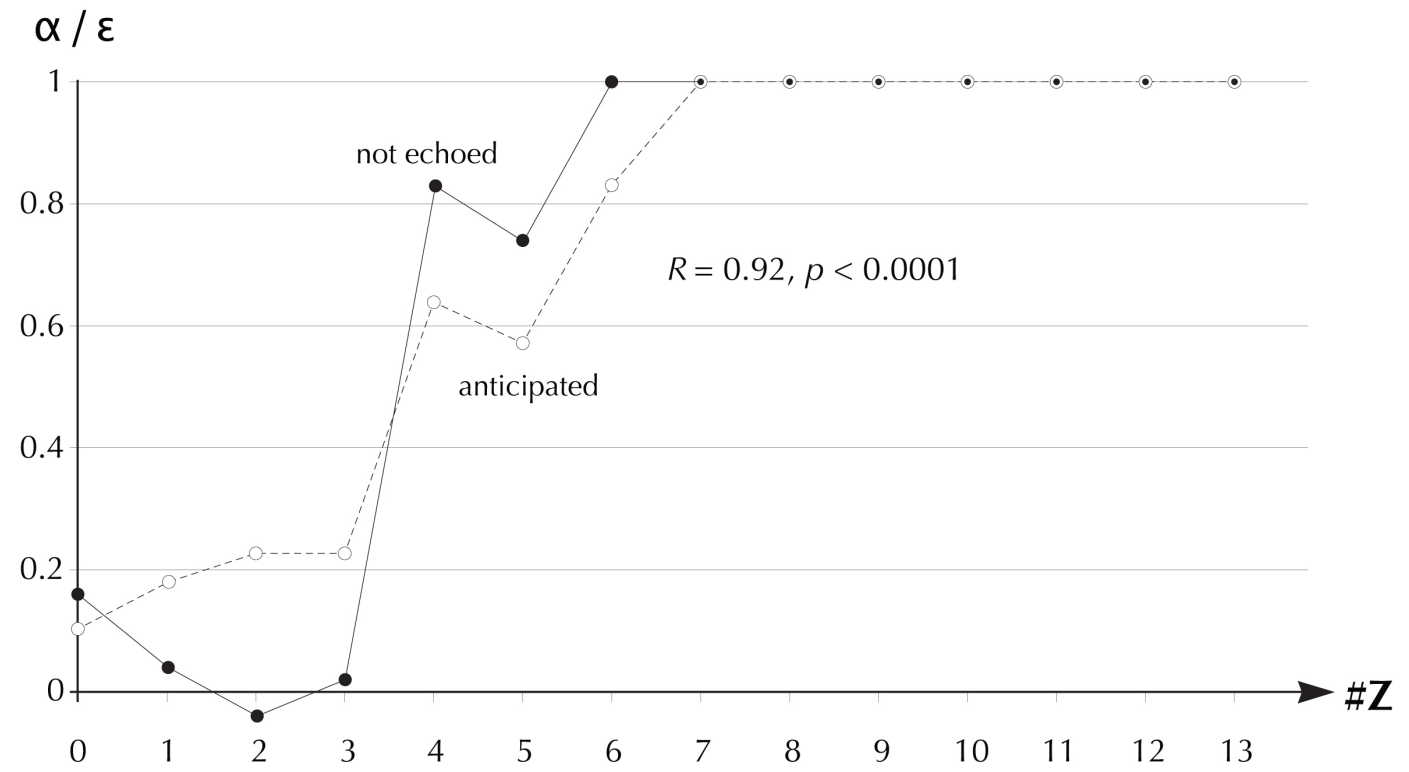

Fig. 30. Comparison of $\alpha$ and $\varepsilon$

Weighting was achieved by taking the mean expectancy rating of the events in each of the top, inner and bottom parts. The number events that were echoed were then calculated as a percentage of the total in each textural strand, and the results divided by the ratios obtained through weighting. The results are shown in Table 6 and Figure 31. The tendency of Derek to echo pitches more successfully "from the bottom up" replicates the finding of Mazzeschi.

Table 6 Weighted scores for anticipated and echoed responses.

\begin{tabular}{|c|c|c|c|c|}
\hline line number & characteristic & top note & $\begin{array}{l}\text { middle } \\
\text { parts }\end{array}$ & $\begin{array}{l}\text { bottom } \\
\text { note }\end{array}$ \\
\hline 1 & \# events & 129 & 162 & 71 \\
\hline 2 & mean expectancy rating per event & 7.16 & 2.31 & 1.42 \\
\hline 3 & \# predictable events & 104 & 115 & 52 \\
\hline 4 & \# predictable events that Derek anticipates & 80 & 23 & 8 \\
\hline 5 & $\begin{array}{l}\% \text { predictable events that Derek } \\
\text { anticipates } \\
\left(=\frac{\text { line } 4}{\text { line } 3} \%\right)\end{array}$ & 76.92 & 20.00 & 15.38 \\
\hline 6 & \# events that Derek echoes & 25 & 52 & 17 \\
\hline 7 & $\%$ events that Derek echoes $\left(=\frac{\text { line } 6}{\text { line } 1} \%\right)$ & 19.38 & 32.10 & 23.94 \\
\hline 8 & $\begin{array}{l}\text { Derek's weighted anticipation score } \\
\left(=\frac{\text { line } 4}{\text { line } 2}\right)\end{array}$ & 11.17 & 9.94 & 5.62 \\
\hline 9 & Derek's weighted anticipation $\%\left(=\frac{\text { line } 5}{\operatorname{line} 2}\right)$ & 10.74 & 8.64 & 10.81 \\
\hline 10 & Derek's weighted echoic score $\left(=\frac{\operatorname{line} 6}{\operatorname{line} 2}\right)$ & 3.49 & 22.46 & 11.95 \\
\hline 11 & Derek's weighted echoic $\%\left(=\frac{\text { line } 7}{\text { line } 2}\right)$ & 2.71 & 13.87 & 16.83 \\
\hline
\end{tabular}




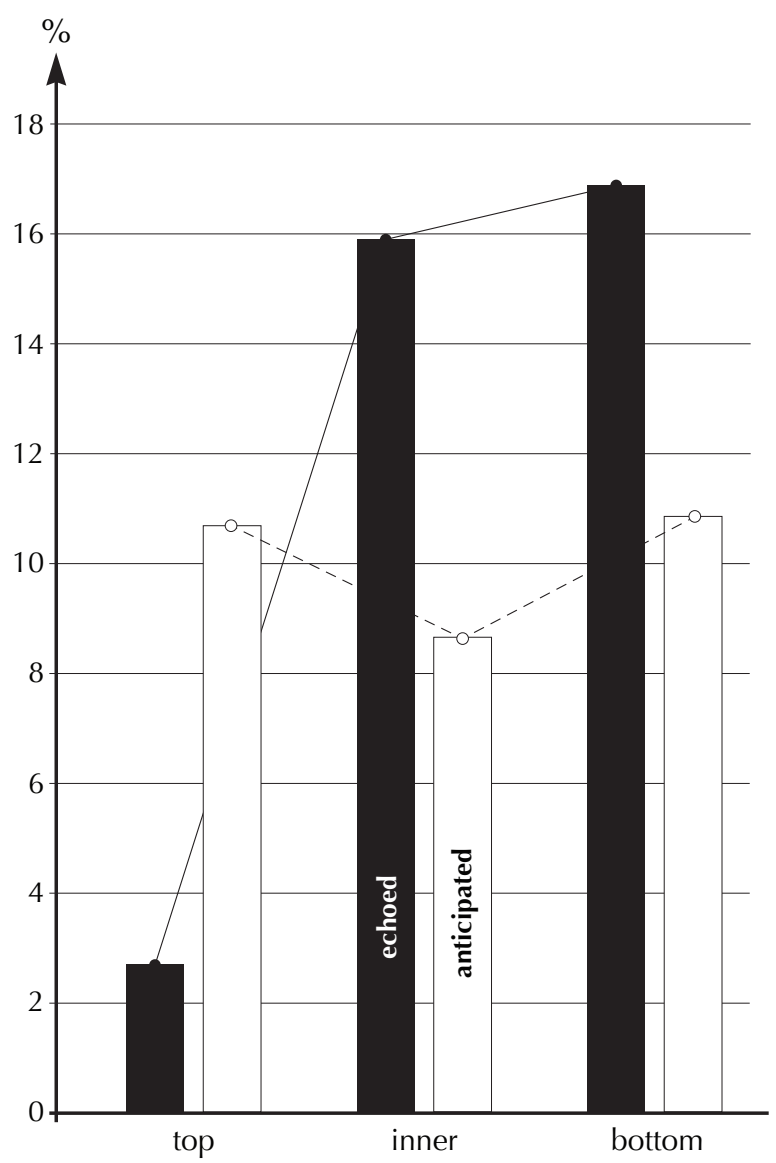

Fig. 31. Top, inner and bottom parts, anticipated and echoed.

This is not the whole story, however. In a further phase of the Fragments of Genius project, which involved long-term memory, Derek learnt a novel piece, Chromatic Blues, through repeated hearings and attempts at reproduction over a four-year period (Ockelford, 2012b, p. 284). Chromatic Blues comprised 134 musical events, consisting of between one and seven simultaneous notes (with an average density of 3.85). Over 26 trials, which took place over four years, Derek achieved scores of $72 \%$ accuracy for the bottom notes, $56 \%$ for the inner parts and $70 \%$ for the highest pitches - suggesting a subtly different pattern of auditory processing from that used in the chordal disaggregation task. Clearly, structural anticipation (of various types) was playing a part here, and it is of interest to note that Derek's capacity to anticipate pitches in Romantic Rollercoaster followed the same pattern (see Table 6 and Figure 31). That is to say, differential processing appears to be present here, whereby Derek's initial perception and reaction to simultaneities appears to favour pitches more the lower they are in chords, whereas his structural anticipation is more equitably spread across textures. To put it another way: the asymmetricality of Derek's preliminary processing of complex musical events (presumably driven by the need to prevent potential auditory overload) is subsequently corrected in cognition.

We will now turn to Hypothesis 2: that there should be no "correct" anticipations of notes in the absence of structural implications, given that chance may play a part, and that there may be other types of implication (for instance, within groups) present. First: the matter of chance. Derek anticipates nine events out of $87(10 \%)$ in the absence of intra-opus, between-group zygonic relationships. If, for the sake of argument, we take the pitch range of Romantic Rollercoaster (B1 to E5) to be the universe of possible responses, then the probability of playing any one note correctly by chance is 1 in 54, or 0.0185 . This means that the probability of getting at least one pitch right out of the 87 hypothetically non-predictable events is given by the equation:

$$
P(\text { at least one event correct })=1-(1-0.0185)^{87}=0.8
$$


That is to say, there is only a $20 \%$ chance that, were Derek to play random pitches, he would fail to produce any correct responses [5]. However, analysis shows that each of Derek's nine accurate predictions can in any case be accounted for through musical logic. The first three (Events 63, 64 and 66) occur as a chord (see Figure 32). Although these could not have been anticipated purely on the basis of between-group imitation, Derek's response does represent a coherent continuation of the preceding chromatic scale (ascending semitones), cast in the by-thenestablished -0 rhythmic mould.

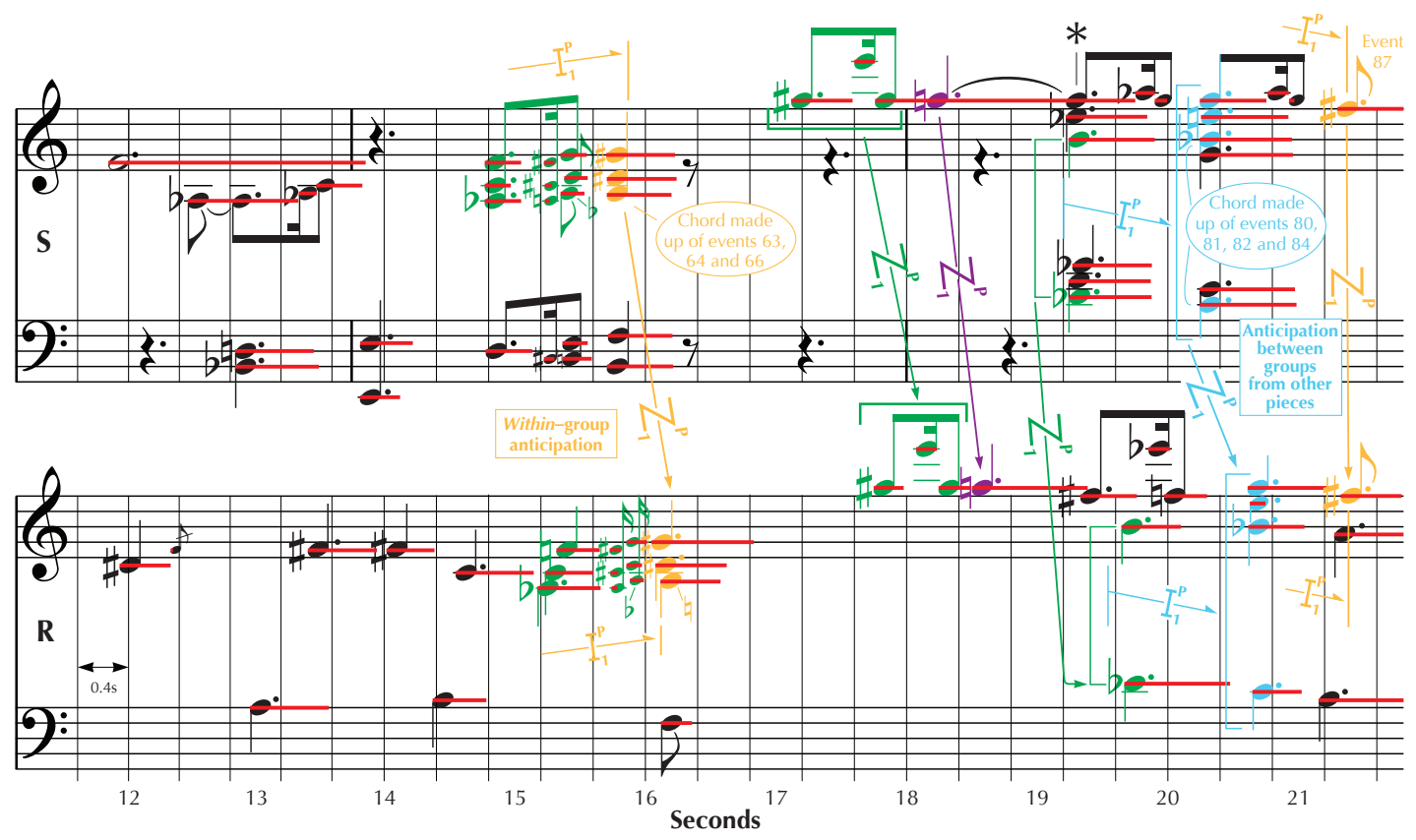

Fig. 32. Anticipation hypothesised to occur through within-group structures, and particularly salient between-group transitions found in other pieces.

Derek's next unanticipated success is correct prediction of the $\mathrm{C}^{7}$ chord formed by Events $80,81,82,84$, which could not have been foreseen from the materials presented in Romantic Rollercoaster up to that point. However, the somewhat unusual (and therefore stylistically salient) progression of a ninth chord with a raised fourth resolving onto a seventh chord whose root is a semitone lower is one that the second author frequently uses in jazz improvisation with Derek, while a very similar progression (in which the seventh chord has an added thirteenth) is used in the first bar of Chromatic Blues (the piece that was used in the first of the longitudinal memory experiments undertaken with him; see Ockelford \& Pring, 2005; Ockelford, 2012a). Hence, Derek's anticipation of the seventh chord would appear to be a case of veridical prognostication (between groups) occurring between pieces (Figure 1); again, see Figure 32.

The remaining instances of anticipation that were not predicted by the model pertain to Events $87(\mathrm{~F} \# 5)$ and 121 (A2). Both can be accounted for through the prolongation of within-group structures (chromatic scales) - see Figures 32 and 24 respectively.

Finally, we address Hypothesis 3: that Derek may make "correct" anticipations (according to the theory of between-group implication) that do not reflect what actually happens in the piece. The first of the four occasions occurs in bar 3 (see Figure 23). As the model predicts, Derek fails to anticipate the note that is not structurally indicated. However, he also fails to forehear the notes that were suggested by the model (see Figure 33). A similar thing occurs in bar 5, in that the chord that occurs beneath the G5 tie is not predicted by the model, which suggests instead a D, B b, E combination, in line with the progression in bar 1 (see Figure 35). However, Derek does not detect this possibility, instead producing, once more, a semitonal descent (to F\#). The third occasion upon which the design of Romantic Rollercoaster departs from the zygonic between-groups model is in bar 7, where the second event (B5) is contrary to what would be expected and, indeed, Derek does not play it (Figure 28). This omission is 
all the more striking since it is unique in the extended 0 sequence. The fourth and final instance of the stimulus departing from the model is at the end of the same sequence - the third beat of bar 8 - where, in Romantic Rollercoaster, an unforeseeable moment of stasis occurs (rather than a continuation of the between-groups pattern). Derek perseveres with the pattern, in line with the zygonic projections. So, in summary, on none of the four occasions when Romantic Rollercoaster diverged from the model did Derek anticipate what actually occurred in the stimulus. Twice he used the between-group forecasts suggested by the model, and twice he resorted to within-group patterning (semitonal descent).

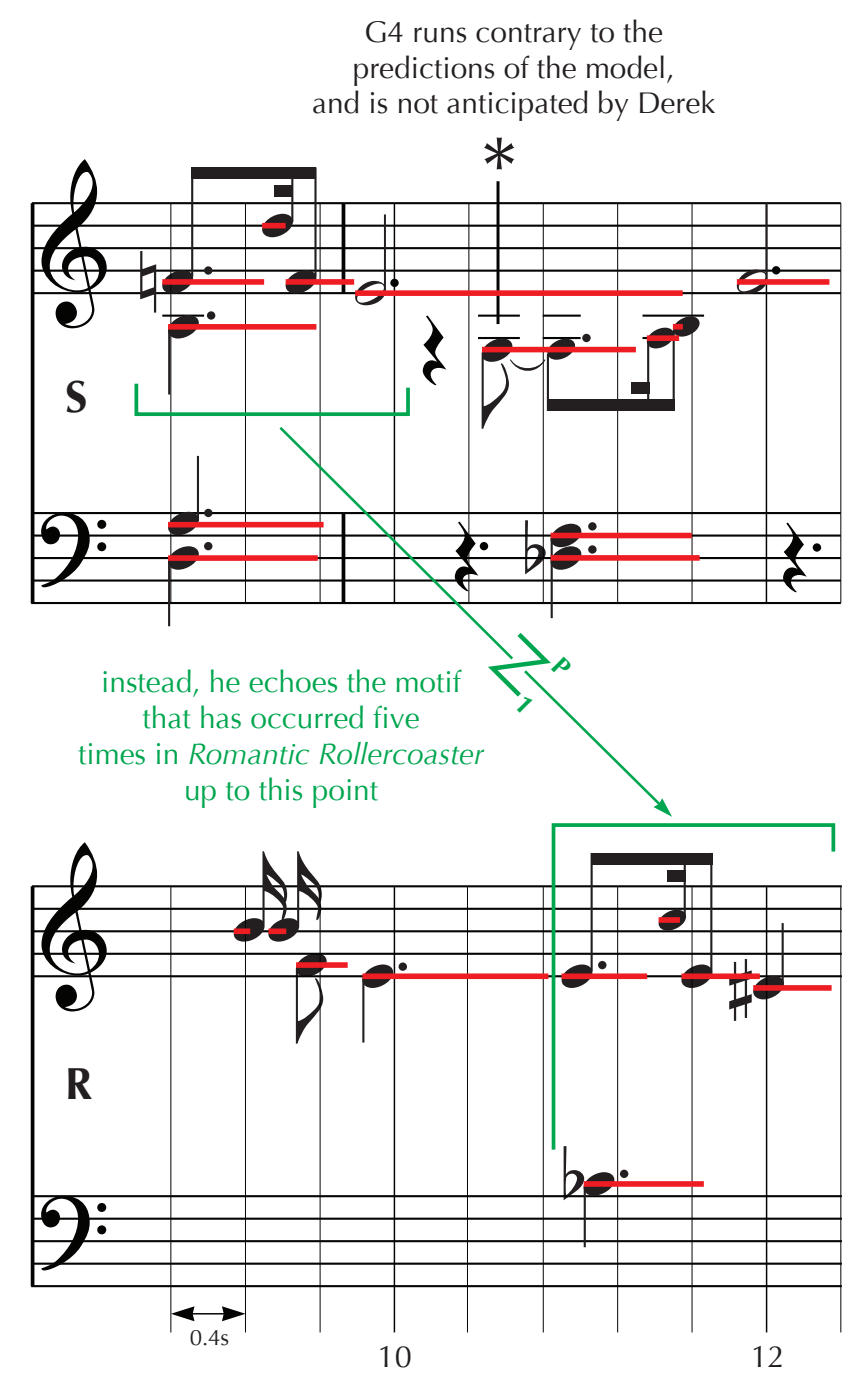

Seconds

Fig. 33. As the model predicts, Derek fails to anticipate a note in Romantic Rollercoaster that is not structurally indicated; neither does he anticipate the notes that were suggested by the model, however.

\section{CONCLUSION}

The study reported here examined one aspect of the zygonic model of implication and expectation in music: in general terms, how between-group expectations interact on the first hearing of a piece, and, more specifically, what impact repeated appearances of the same motif have on what a listener anticipates. To this end, a novel stimulus, Romantic Rollercoaster, was constructed and played to a prodigious musical savant (Derek Paravicini), who attempted to reproduce the piece on the piano at the same time as hearing it. The results support the theory that, the 
more often a motif appears, the stronger the expectations are that future material will be patterned in the same way. That is, it seems to be the case that implications from groups of notes, whose representations are stored in working memory, function cumulatively, up to a maximum of about seven or eight chunks, in accordance with George Miller's famous dictum.

Clearly, the experiment that was undertaken was limited in many respects - Romantic Rollercoaster was designed to enable between-group predictions to be made with relative ease, and avoided, as far as possible, tonal implications and those arising from within-group patterning. And, importantly, it could be argued that data acquired from a savant such as Derek are of limited value in understanding human musicality in a general sense, since he is, by definition, atypical (Ockelford, 2011, p. 282). However, researchers have in the past used savant data to consider the nature of neurotypical abilities: to test issues of modularity in intelligence, for example (see Smith \& Tsimpli, 1995), and memory (Sloboda, Hermelin, \& O’Connor, 1985). Moreover, as we have seen, Mazzeschi's doctoral studies (2014) suggest that musical savants and advanced music students use the same strategies to disaggregate chords. It is at least conceivable, then, that Derek functions like most other people as a listener (a "super listener", perhaps, given his AP abilities) in that his musical understanding is implicit rather than explicit, and perceptual rather than conceptual. Where he differs from the vast majority is in his capacity to reproduce immediately what he hears on the keyboard: complex musical textures that are far more substantial than the short vocal fragments or unpitched rhythms that are all that most people can manage to replicate (Ockelford, 2011, p. 283). In summary, then, Derek's unusual capacity for being able to produce the music that he can hear, remember or predict offers us a rare glimpse into the workings of the musical mind in general - in this case, in the processing of between-group musical structures held in working memory.

\section{ACKNOWLEDGEMENTS}

We offer our sincere thanks to Derek Paravicini, for his cheerful participation in the study, to Evangelos Himonides, for his music-technological expertise, and to Linda Pring for her support with the statistical analysis.

\section{NOTES}

[1] Correspondence concerning this article can be addressed to: ruth.grundy@,hotmail.com

[2] A problem that was recognised at least as far back as Thomas Love Peacock's Headlong Hall of 1815, in relation to the aesthetics of landscape gardening (p. 24):

"Allow me," said Mr Gall. "I distinguish the picturesque and the beautiful, and I add to them, in the laying out of grounds, a third and distinct character, which I call unexpectedness."

"Pray, sir," said Mr Milestone, "by what name do you distinguish this character, when a person walks round the grounds for the second time?"

[3] See www.derekparavicini.net

[4] The title given to the piece had to be memorable, since Derek's capacity for remembering labels such as this is considerably weaker than his ability to recall the music to which they refer, but the design of the experiment means that he nonetheless needs a verbal prompt.

[5] The probability of all nine events occurring by chance is, of course, vanishingly small, a characteristic shared by Derek's responses to events with other expectancy ratings (see Table 4). Hence, the potential impact of random error can be considered to be negligible in the results of the experiment as a whole.

\section{REFERENCES}

Aarden, B. (2003). Dynamic melodic expectancy. Unpublished doctoral dissertation, Ohio State University, USA.

Al-Khanji, R., El-Shiyab, S. \& Hussein, R. (2000). On the use of compensatory strategies in simultaneous interpretation. Meta: Journal des Traducteurs, 45(3), 548-557.

Aslin, R. \& Newport, E. (2012). Statistical learning: From acquiring specific items to forming general rules. Current Directions Psychological Science, 21(3), 170-176. 
Bailly, G. (2003). Close shadowing natural versus synthetic speech. International Journal of Speech Technology, 6, $11-19$.

Bharucha, J. (1987). Music cognition and perceptual facilitation: A connectionist framework. Music Perception, $5(1), 1-30$.

Bishop, D., North, T. \& Donlan, C. (1996). Nonword repetition as a behavioural marker for inherited language impairment: Evidence from a twin study. Journal of Child Psychology and Psychiatry, 37(4), 391-403.

Bregman A. (1990). Auditory scene analysis: The perceptual organization of sound. Cambridge, MA: MIT Press.

Carlsen, J., Divenyi, P. \& Taylor, J. (1970). A preliminary study of perceptual expectancy in melodic configurations. Council for Research in Music Education Bulletin, 22(1), 4-12.

Cowan, N. (2001). The magical number 4 in short-term memory: A reconsideration of mental storage capacity. Behavioral and Brain Sciences, 24(1), 87-114.

Craik, K. (1943). The nature of explanation. Cambridge: Cambridge University Press.

Cross, I. (1998). Music analysis and music perception. Music Analysis, 17(1), 3-20.

Dowling, W. \& Harwood, D. (1986). Music cognition. London: Academic Press.

Fauconnier, G. (1994). Mental spaces: Aspects of meaning construction in natural language (2nd ed.). Cambridge: Cambridge University Press.

Fay, W. (1973). On the echolalia of the blind and of the autistic child. Journal of Speech and Hearing Disorders, $38(4), 478-489$.

Fielder, A. \& Reynolds, J. (2001). Retinopathy of prematurity: Clinical aspects. Seminars in Neonatology, 6(6), $461-475$.

Gile, D. (1995). Basic concepts and models for interpreter and translator training. Amsterdam: John Benjamins Publishing Company.

Gjerdingen, R. (1999). An experimental music theory? In N. Cook and M. Everist (Eds), Rethinking music (pp. 16170). Oxford: Oxford University Press.

Himonides, E. (2011). Mapping a beautiful voice: The continuous response measurement apparatus (CReMA). Journal of Music, Technology and Education, 4(1), 5-25.

Huron, D. (2006). Sweet anticipation: Music and the psychology of expectation. Cambridge, MA: MIT Press.

Jackendoff, R. (1991). Musical parsing and musical affect. Music Perception, 9(2), 199-230.

Johnson-Laird, P. (1983). Mental models: Towards a cognitive science of language, inference and consciousness. Cambridge: Cambridge University Press.

Krumhansl, C. \& Shepard, R. (1979). Quantification of the hierarchy of tonal functions within a diatonic context. Journal of Experimental Psychology: Human Perception and Performance, 5(4), 579-594.

Kuhl, P. \& Meltzoff, A. (1996). Infant vocalizations in response to speech: Vocal imitation and developmental change. Journal of the Acoustical Society of America, 100(4), 2425-2438.

Lakoff, G. (1987). Women, fire, and dangerous things: What categories reveal about the mind. Chicago: University of Chicago Press. 
Lambert, S. (1989). One ear may be better than two. The Interpreter's Newsletter, 4, 15-24.

Lambert, S. (1992). Shadowing. Meta: Journal des Traducteurs, 37(2), 263-273.

Margulis, E. (2003). Melodic expectation: A discussion and model. Unpublished doctoral dissertation, Columbia University, USA.

Margulis, E. (2005). A model of melodic expectation. Music Perception, 22(4), 663-713.

Marslen-Wilson, W. (1973). Linguistic structure and speech shadowing at very short latencies. Nature, 244(5417), 522-523.

Marslen-Wilson, W. (1985). Speech shadowing and speech comprehension. Speech Communication, 4(1-3), 55-73.

Mazzeschi, A. (2014). Musical savants: Perception and cognition. Unpublished doctoral dissertation, University of London, UK.

Mazzeschi, A., Ockelford, A., Welch, G., Bordin, A., Taddei, S. \& Sirgatti, S. (2011). Musical savants: A new study in the capacity to disaggregate pitches presented simultaneously. Proceedings of The Neurosciences and Music IV: Learning and Memory, Edinburgh: Edinburgh University.

Meyer, L. (1956). Emotion and meaning in music. Chicago: University of Chicago Press.

Meyer, L. (1967). Music, the arts, and ideas. Chicago: University of Chicago Press.

Meyer, L. (1973). Explaining music. Chicago: University of Chicago Press.

Meyer, L. (2001). Music and emotion: distinctions and uncertainties. In P. Juslin and J. Sloboda (Eds.) Music and emotion: Theory and research (pp. 341-60). Oxford: Oxford University Press.

Miller, G. (1956). The magical number seven, plus or minus two: Some limits on our capacity for processing information. Psychological Review, 63, 81-97.

Miller, L. (1989). Musical savants: Exceptional skill in the mentally retarded. Hillsdale, New Jersey: Lawrence Erlbaum.

Miller, O. \& Ockelford, A. (2005). Visual needs. London and New York: Continuum.

Monsell, S. (1987). On the relation between lexical input and output pathways for speech. In A. Allport, D. Mackay, W. Prinz \& E. Scheerer (Eds.), Language perception and production: Relationships between listening, speaking, reading and writing (pp. 273-312). London: Academic Press.

Narmour, E. (1977). Beyond Schenkerism: The need for alternatives in music analysis. Chicago: University of Chicago Press.

Narmour, E. (1990). The analysis and cognition of basic melodic structures. Chicago: University of Chicago Press.

Narmour, E. (1992). The analysis and cognition of melodic complexity. Chicago: University of Chicago Press.

Narmour, E. (1996). Analyzing form and measuring perceptual content in Mozart's Sonata K. 282: A new theory of parametric analogues. Music Perception, 13(3), 265-318.

Ockelford, A. (1991). The role of repetition in perceived musical structures. In P. Howell, R. West and I. Cross (Eds.), Representing Musical Structure (pp. 129-60). London: Academic Press. 
Ockelford, A. (2005). Repetition in music: Theoretical and metatheoretical perspectives. London: Ashgate.

Ockelford, A. (2006). Implication and expectation in music: A zygonic model. Psychology of Music, 34(1), 81-142.

Ockelford, A. (2007). In the key of genius: The extraordinary life of Derek Paravicini. London: Hutchinson.

Ockelford, A. (2008a). Music for children and young people with complex needs. Oxford: Oxford University Press.

Ockelford, A. (2008b). Review article: D. Huron's Sweet Anticipation: Music and the Psychology of Expectation. Psychology of Music, 36(3), 367-382.

Ockelford, A. (2009). Zygonic theory: Introduction, scope, prospects. Zeitschrift der Gesellschaft für Musiktheorie, $6(1), 91-172$.

Ockelford, A. (2011). Another exceptional musical memory: Evidence from a savant of how atonal music is processed in cognition. In I. Deliege and J. Davidson (Eds.), Music and the mind: Essays in honour of John Sloboda (pp. 237-288). Oxford: Oxford University Press,.

Ockelford, A. (2012a). Imagination feeds memory: Exploring evidence from a musical savant using zygonic theory. In D. Hargreaves, D. Miell and R. MacDonald (Eds.), Musical imaginations: Multidisciplinary perspectives on creativity, performance and perception (pp. 31-61). Oxford: Oxford University Press.

Ockelford, A. (2012b). Applied musicology: Using zygonic theory to inform music education, therapy, and psychology research. New York: Oxford University Press.

Ockelford, A. (2013). Music, language and autism: Exceptional strategies for exceptional minds. London: Jessica Kingsley.

Ockelford, A. \& Pring, L. (2005). Learning and creativity in a prodigious musical savant. International Congress Series, 1282, 903-907.

Ockelford, A. \& Sergeant, D. (2013). Musical expectancy in atonal contexts: Musicians' perception of "antistructure", Psychology of Music, 41(2), 139-174.

Palmer, C. (1996). Anatomy of a performance: Sources of musical expression. Music Perception, 13(3), 433-453.

Parkinson, S. (1972). Short-term memory while shadowing: Multiple-term recall of visually and aurally presented letters. Journal of Experimental Psychology, 92(2), 256-265.

Peacock, T. (1815). Headlong Hall. London: T. Hookham, Jun. and Co.

Peschke, C., Ziegler, W., Kappes, J. \& Baumgärtner, A. (2009). Auditory-motor integration during fast repetition: The neuronal correlates of shadowing. Neuroimage, 47(1), 392-402.

Peters, A. (1993). The interdependence of social, cognitive and linguistic development: Evidence from a visually impaired child. In H. Tager-Flusberg (Ed.), Constraints on language acquisition: Studies of atypical children (pp. 195-219). Hillsdale: Lawrence Erlbaum Associates.

Pring, L., Woolf, K. \& Tadic, V. (2008). Melody and pitch processing in five musical savants with congenital blindness. Perception, 37(2), 290-307.

Rasch, R. (1979). Synchronization in performed ensemble music. Acustica, 43(2), 121-131.

Repp, B. (1999). Control of expressive and metronomic timing in pianists. Journal of Motor Behavior, 31(2), 145164. 
Roberts, J. (1989). Echolalia and comprehension in autistic children. Journal of Autism and Developmental Disorders, 19(2), 271-281.

Saffran, J. (2003). Statistical language learning: mechanisms and constraints. Current Directions in Psychological Science, 12(4), 110-114.

Schellenberg, E. (1996). Expectancy in melody: Tests of the implication-realization model. Cognition, 58(1), 75125 .

Schellenberg, E. (1997). Simplifying the implication-realization model of melodic expectancy. Music Perception, 14(3), 295-318.

Schmuckler, M. (1989). Expectation in music: investigation of melodic and harmonic processes. Music Perception, $7(2), 109-50$.

Setton, R. (1999). Simultaneous interpretation: A cognitive-pragmatic analysis. Amsterdam: John Benjamins Publishing Company.

Shibazaki, K., Ockelford, A., \& Marshall, N.A. (2013). Extending zygonic theory to analyse patterns of musical influence in children's group composition. Musicae Scientiae, 17(4), 429-471.

Sloboda, J., Hermelin, H. \& O'Connor, N. (1985). An exceptional musical memory. Music Perception, 3(2), 15170 .

Smith, N. \& Tsimpli, I. (1995). The mind of a savant: Language, learning and modularity. Oxford: Blackwell.

Spence, C. \& Read, L. (2003). Speech shadowing while driving: On the difficulty of splitting attention between eye and ear. Psychological Science, 14(3), 251-256.

Takeuchi, A. \& Hulse, S. (1993). Absolute pitch. Psychological Bulletin, 113(2), 345-361.

Thompson, W. \& Stainton, M. (1996). Expectancy in Bohemian folk song melodies: Evaluation of implicative principles for implicative and closural intervals. Music Perception, 15(3), 231-252.

Thorpe, M., Ockelford, A. \& Aksentijevic, A. (2012). An empirical exploration of the zygonic model of expectation in music. Psychology of Music, 40(4), 429-470.

Treffert, D. (1989). Extraordinary people: Understanding savant syndrome. New York: Harper and Row.

Treisman, A. (1965). The effects of redundancy and familiarity on translating and repeating back a foreign and a native language. British Journal of Psychology, 56(4), 369-379.

Trower, H. (2011). An investigation into the effect of tonality on memory for melodies. Unpublished Masters Dissertation, University of Roehampton, London.

Vogiatzoglou, A., Ockelford, A., Welch, G. \& Himonides, E. (2011). Sounds of Intent: Software to assess the musical development of children and young people with complex needs. Music and Medicine, 3(3), 189-195.

von Hippel, P. \& Huron, D. (2000). Why do skips preceded reversals? The effect of tessitura on melodic structure. Music Perception, 18(1), 59-85.

Waters, G., Komoda, M. \& Arbuckle, T. (1985). The effects of concurrent tasks on reading: implications for phonological recoding. Journal of Memory and Language, 24(1), $27-45$. 